\title{
Focus on change : influencing segments of housing associations to adopt energy conservation measures and innovations
}

Citation for published version (APA):

Egmond, C. C. (2006). Focus on change : influencing segments of housing associations to adopt energy conservation measures and innovations. [Doctoral Thesis, Maastricht University]. De Gouwzee. https://doi.org/10.26481/dis.20060324ce

Document status and date:

Published: 01/01/2006

DOI:

10.26481/dis.20060324ce

Document Version:

Publisher's PDF, also known as Version of record

Please check the document version of this publication:

- A submitted manuscript is the version of the article upon submission and before peer-review. There can be important differences between the submitted version and the official published version of record.

People interested in the research are advised to contact the author for the final version of the publication, or visit the DOI to the publisher's website.

- The final author version and the galley proof are versions of the publication after peer review.

- The final published version features the final layout of the paper including the volume, issue and page numbers.

Link to publication

\footnotetext{
General rights rights.

- You may freely distribute the URL identifying the publication in the public portal. please follow below link for the End User Agreement:

www.umlib.nl/taverne-license

Take down policy

If you believe that this document breaches copyright please contact us at:

repository@maastrichtuniversity.nl

providing details and we will investigate your claim.
}

Copyright and moral rights for the publications made accessible in the public portal are retained by the authors and/or other copyright owners and it is a condition of accessing publications that users recognise and abide by the legal requirements associated with these

- Users may download and print one copy of any publication from the public portal for the purpose of private study or research.

- You may not further distribute the material or use it for any profit-making activity or commercial gain

If the publication is distributed under the terms of Article $25 \mathrm{fa}$ of the Dutch Copyright Act, indicated by the "Taverne" license above, 


\section{Focus on change}

Influencing segments of housing associations to adopt energy conservation measures and innovations 
ISBN-10:90-9020418-0 ISBN-13:978-90-9020418-0 NUR: 770

Uitgeverij De Gouwzee OC.C. Egmond Omslagontwerp: Esther Kool Editing: Ed Hull Druk: Febodruk B.V. Enschede The study presented in this thesis was performed by SenterNovem within an intervention programme commisioned by the Dutch ministry of Housing, Spatial Planning and the Environment, the programme 'Compass', energy- awareness in living and working, $\mathrm{CO}_{2}$ reduction in the built environment 


\section{Focus on Change Influencing Segments of Housing Associations to Adopt Energy Conservation Measures and Innovations}

ter verkrijging van de graad van doctor aan de Universiteit Maastricht, op gezag van de rector magnificus, Prof. mr. G.P.M.F. Mols, volgens het besluit van het College van Decanen, in het openbaar te verdedigen op vrijdag 24 maart 2006 om 14.00 uur.

door

Cornelis Claes Egmond 
Promator: Prof. Dr. G.J. Kok

Copromotot: Dr. R. Jonkers, Haarlem

Beoordelingscommissie:

Prof. Dr. B. van den Borne (voorzitter)

Prof. Dr. J. Th. A. Bressers (Universiteit Twente)

Prof. Dr. P. Martens

Dr. R.M. Meertens

Dr. W.J.V. Vermeulen (Universiteit Utrecht) 


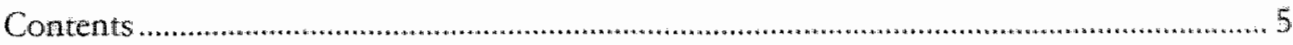

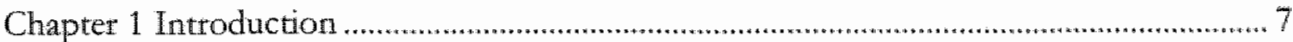

1.1 What's the matter?

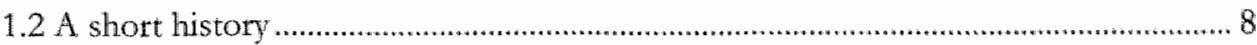

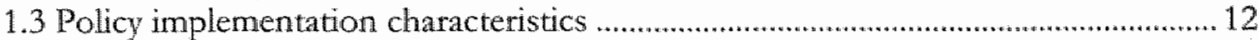

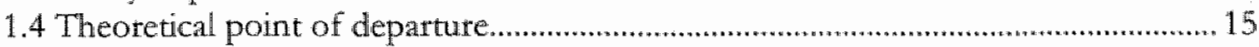

1.5 Central research questions and overview of the dissertation ........................................21

Chapter $2 \mathrm{~A}$ strategy to encourage housing associations to invest

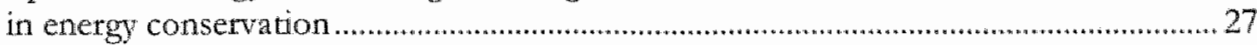

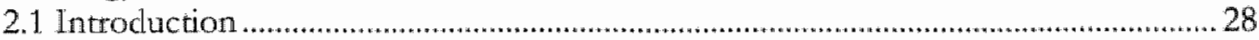

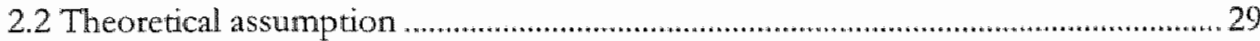

2.3 The Target Group Study ………….......................................................................32

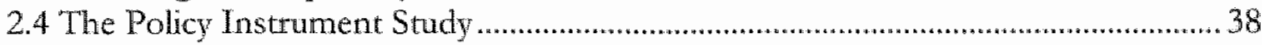

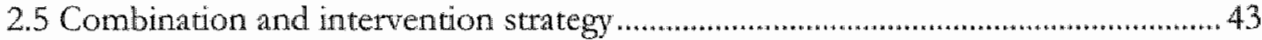

2.6 Discussion and conclusion................................................................................. 44

Chapter 3 Target group segmentation makes sense:

if one sheep leaps over the ditch all the rest will follow ....................................................49

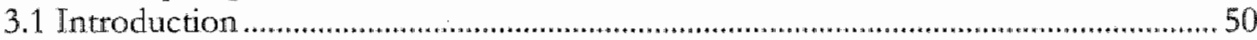

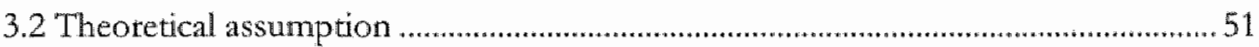

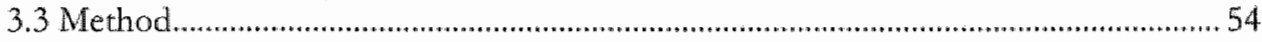

3.4 Results reviewing the target group study survey housing associations …..................57

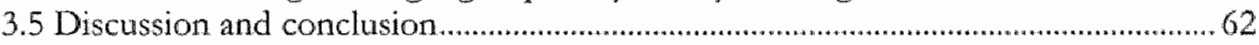

Chapter 4 One size fits all? Policy instruments should

fit the segments of target gtoups...............................................................................67

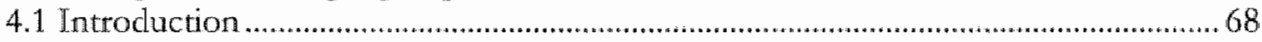

4.2 Process of change in early market actors and mainstream market actors .................69

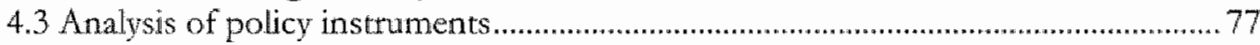

4.4 Early market and mainstream market instruments............................................... 80

4.5 Discussion and conclusion............................................................................... 81

Chapter 5 A strategy and protocol to increase diffusion of energy related innovations into the mainstream of housing associations ..................................................8. 87

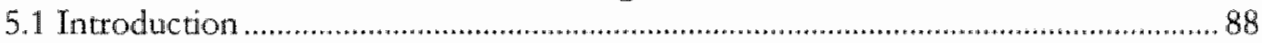

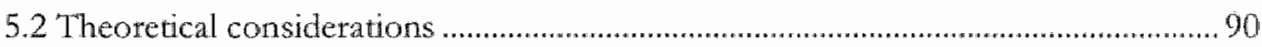

5.3 Identifying the niche in the mainstream of housing associations ................................94

5.4 Implications for practice: a protocol to cross the chasm.......................................... 99

5.5 Discussion and Conclusion............................................................................... 102

Chapter 6 Discussion and Conclusion.............................................................................. 105

References of the thesis ........................................................................................ 117

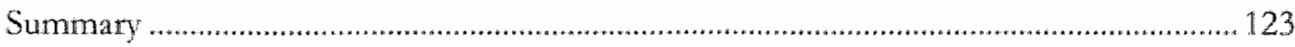

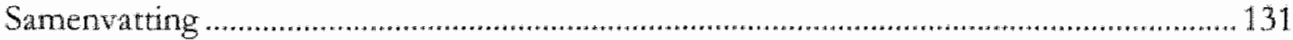

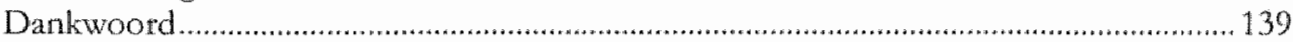

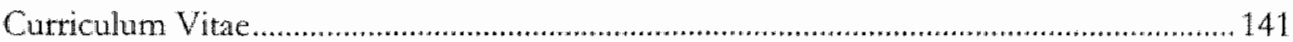




\section{Chapter 1 Introduction}

\subsection{What's the matter?}

The change of climate, a big environmental problem, confronts us all. Research thto the climate and the influence of human action on it, via the enhanced greenhouse eftect, has caused a great deal of concern throughout the world. The climate and the thean temperature at earth's surface depend on the balance between incoming solar energy and outgoing energy emitted from the earth's surface. Greenhouse gases trap some of the infrared radiation emitted by earth and keep the planet warmer than it wonld be otherwise. The mean global temperature, about $15^{\circ} \mathrm{C}$, would be far below zero without this natural greenhouse effect (Vellinga and Verseveld, 2000).

But things are on the move: climate changes are apparent. In the $20^{\text {th }}$ century, the mean temperature has risen between $0.6^{\circ} \mathrm{C}+/-0.2^{\circ} \mathrm{C}$, and a closer look reveals that the greatest increase, $0.2^{\circ} \mathrm{C}$ per decade, occurred during the last few decades (IPCC, 2001). Experts of the Intergovernmental Panel for Climate Change, the IPCC, expect the following climate. developments in the $21^{\text {st }}$ century:

- a 1 to $3.5^{\circ} \mathrm{C}$ increase in global mean temperature;

- a 5 to 20 percent increase in global mean precipitation;

- a 9 to 88 centimetre increase in the sea level.

Furthermore, the Royal Netherlands Meteorological Institute (KNMI), in its latest Climate Report (Verbeek, 2003), has set out a scenario for the Nethetlands at the end of the $21^{\text {s: }}$ century. This report, based on the IPCC conclusions, predicts:

- a 1 to $3.5^{\circ} \mathrm{C}$ increase in temperature,

- a shorter duration of severe winters;

- More intense rain in situations of sustained, severe winter precipitacion, with an increase of several percent per degree of warming:

- Heavier summer showers.

Even though a lot of uncertainty remains, present knowledge is sufficient reason for many governments to enter into international agreements that were instituted in the United Nations Framework Convention on Climate Change in 1992. Subsequent to the convention, in 1997, more than one hundred nations entered into binding agreements the Kyoto Protocol - in the Japanese city of Kyoto. The Kyoto Protocol seeks to reduce the emissions of greenhouse gases in the industrial nations. These countries have 
developed policies to reduce the emissions of greenhouse gases in 2010 by an average of $5 \%$ below 1990 levels. The greenhouse guses ate carbon dioxide, methane, nitrous oxide, and fluot-gases. Different countries have different commirments: The USA will have to cut emissions by $7 \%$, Japan $6 \%$, and the European Union as a whole by $8 \%$. In 2010 , the Wetherlands will have to cut its emission by $6 \%$.

The Dutch government ratified the Kyoto Protocol in 2002 and agreed to reduce its emissions of greenhouse gases in the period $2008-2012$ by an average of $6 \%$ per year as compared to the 1990 level. The Dutch government plans to realize $50 \%$ of its reduction obligations through so-called "Kyoto instruments": joint implementation $0 D_{3}$ clean development mechanism (CDM) and emission trading. The other $50 \%$ will be realized by domestic measures: $2 / 3$ by reducing $\mathrm{CO}_{2}$ emissions and $1 / 3$ by reducing the other greenhouse gases (Minnesma, 2003). In other words, to reduce the human causes of the global warming most effectively, we must reduce $\mathrm{CO}_{2}$ emissions. And energy conservation is one of the most effective measures to reduce the emission of $\mathrm{CO}_{2}$. For that reason, part of the Dutch environmental pollicy targets energy conservation.

Dutch governmental policy has focused on the development of energy conservation technology. Although wery necessary, energy conservation technology can only be effective if individual members of the target group invest in and use that technology. This, however, entails a change in the decision-making behaviour on the part of the target group members. In our case, the tatget group members are organizations and we target the decision-makers in these organizations.

This dissertation explores the possibilities on how the behaviour of specific target groups can be influenced. To understand the implications of the Dutch energy conservation policy, we present, in this introductory chapter, a sketch of its history. We then present and clarify our theoretical point-of-departure and a framework for planning interwentions to infuence behaviour and realize the desired change. And we theoretically discuss the change processes of target groups and artive at our central research questions. We close this chapter with an overnew of this dissertation.

\subsection{A short history}

Envitonmental policy is only 30 years old: a telative young sector of governmental policy. Before 1970, only initiatives to develop an environmental policy could be found. In the seventies, however, the development of environmental policy began because politicians recognized an environmental crisis. This tecognition was caused by the Limits to Growth report by the Club of Rome in 1972, and the first UN World Environmental Conference in 1972 . With the first governmental document on environmental policy, the Urgentie nota Milieuhygiene (Urgency Policy Document on the Environment), the 
beginning of the Dutch environmental policy in 1972 is often pinpointed (Beus and Doom, 1984).

During the last 30 years, the position of the envitonmental policy field was not questioned. Environmental policy developed as a process of institutionalization: structured actions and organization patterns entailing a growing and unquestioned policy (Tatenhove, 1993). In this institutionalization, the initial optimism about solving the environmental problems with policy changed into more modest expectations. At the same time a relative lack of clarity characterized the development of the environmental policy. In the thirty years of its devellopment, several changes in problem definition, goal setting, strategy, instrumentation and organization arose (Leroy, 1994).

Due to the first Oil Crisis of 1973, energy conservation policy in the 1970 s focused on a reliable supply of energy and energy sources. In the $1980 \mathrm{~s}$, an envitonmental point of view became more important - non-polluting energy sources and the climate probllem and energy policy became part of the environmental policy (Jong et al., 2005).

\section{The first period: 1972-1989, cleaning up environmental pollution}

The Urgentienota Milieuhygiene (Urgency Policy Document on the Environment) of 1972 addressed threats to the local and regional environment, and it demanded a largescale cleanup of the polluted environment. This was handled by a policy consisting of separate environmental compartments (soil, water, and air) aimed to directly fight pollution of the environment. The emphasis was on law and legislation.

In the mid-1980s, the focus shifted from the compartmental approach to an integral subject-oriented approach. The government chose a strategy to hold the originators of the environmental problems (target groups) responsible for solving these problems (Leroy, 1994). The envitonmental policy focused on several themes aiming at reducing pollution and annoyance. This focus on specific themes was charicterized by cohesion between the themes and an integral approach of the problems. Connections were made with the causers of the environmental problems and policy was translated into organizational terms. For energy conservation, wall insulation was the central theme.

Within organizations that faced several environmental problems simultancously, this theme-orientated policy caused "tuning" problems. "To solve these problems, a policy of target group approach was developed in the 1980s. Here, the focus was on prevention and making target groups responsible for causing environmental problems. "The government aimed to internalize the responsibility for the environment wo the target groups (NEPP.1, 1989). This resulted in the Nationaal Milieubeleid Plan-1 (National Environmental Policy Plan-1, NEPP-1), and enwironmental policy was placed high on the political agenda. 


\section{The NEPP-1 Period: 1989-1993, addressing target groups}

During the second period, the period of NEPP-1 and NEPP-2 (1989-1998), sustainable development was introduced as a main target for environmental management. NEPP-1 had a double message: large-scale cleanup and prevention. The approach was subjectoriented and addressed target groups, and it focused on geographical areas.

NEPP-1 formulated quantitative targets for the environment and, from these targets, derived national emission teduction targets. Based on these targets, relevant target groups made agreements on setting goals. Furthermore, to solve environmental problems, the government integrated environmental aspects in other policy fields. The government involved industry, social organizations, citizens and local authorities in the implementation. These parties carried out their responsibility by formulating and implementing environmental policy plans (NEPP-1, 1989).

\section{Scientific Council fot Governmental Advice}

Towards the end of the NEPP-1 period, in 1992, the Scientific Council for Governmental Advice formulated the core of the environmental policy as follows:

"Environmental problems originate from the behaviour of both persons and institutions. Environmental policy tries to influence this behaviour in such a way that the effects on the environment are acceptable." (p.47),... "Climate change, extinction of species or water pollution are all problems caused by human behaviour, so environmental policy, in essence, has to change this behaviour"'(p.121), (WRR, 1992).

But the Council concentrated mainly on policy instruments, and not on the relationship between policy instruments and behaviour. The Council based its analysis on a top-down policy approach and instruments were their point-of-departure, not the behaviour of persons and institutions.

\section{The NEPP-2 period: 1993-1998, strengthening implementation}

In 1993, the first conclusions were that environmental policy was fruitful. For the first time, economic growth was disconnected from pressure on the environment. And, if policy was powerfully maintained, environmental targets could be achieved within one gencration.

NEPP-2 focused mainly on strengthening implementation within target groups.

The central government set up standards and targets, but implementation was left to the responsible parties. Self-regulation within frameworks became central. Examples are integral environmental licenses, and covenants. In 1996, it became clear that the policy of permits and tacilitating subsidies successfully decreased the pollution of so-called "point sources": sources of pollution which can be pinpointed. Reducing $\mathrm{CO}_{2}$ emissions of big power stations, for example, was relatively easy. Reducing $\mathrm{CO}_{2}$ emissions from diffuse sources, such as households, remained more difficult. Here we have to handle millions of sources (NEPP-2, 1993). 
The main bottlenecks were:

- The environmental profit gained from environmentally frendly production methods was offet by the increased envitonmental burden caused by growth.

- Solwing environmental problems was slowed by the relative increase of difuse sources. Although pollution by point sources whs handled successfully, an increasingy large number of diffuse sources all over the country were adding its burden. Households, road users, agricultural producers, and middle and small-size businesses were more difficult to address - how to get them together, come to agreements and work out solutions?

- Upholding environmental laws and tules continued to be a problem. The organization structure was not clear, and the tasks of the responsible authorities were not explicitly and simply regulated (NEPP-2, 1993).

\section{The NEPP-3 period: 1998-2001, decoupling economic growth from environmental pressure}

The government was well aware the original pollution-teducing targets were not met. Environment policy aims to decouple pressure on the environment from economic growth. To that end, the NEPP-3 was released by the government in 1998. It was intended to further put into practice the goals of NEPP-1 and NEPP-2. NEPP-3 focused on sustainable development to meet the 2010 targets.

Its highlights included continuing improvement, focus on quality of-life, and making environmental issues part of economic life through pricing and taxes. It aimed to strengthen the powers of the matket mechanism.

The government tred to make actors responsible and stimulated actors to cooperate in solving environmental issues (NEPP-3, 1998). But at the end of NEPP-3, the government realized that many obstinate environmental problems could not be solved without system changes.

\section{The NEPP-4 period: 2001-2004, system innovation to solve obstinate environmental problems}

These obstinate envirommental problems required a more fundamental approach, and solving them required a systemic change (Grin et al, 2003). To that end, the NEPP-4 policy of transitions was developed to realize the central mission: quality-of life. Environmental problems endanger the health and lives of people. In 2003 , for example, 3400-5700 people died earlier in the Netherlands because of fine dust in the air, tratinly caused by the diesel engines of vehicles (RIVM, 2005).

Since 1972, environmental policy has been successful on some fronts. The quality of water and air is better than expected, and many environmental problems are controllable (NEPP-4, 2001). But obstinate problems have not been solved, and the policy to 
decouple economic growth and pressure on the etrvitonment has not been successful. Increasing population growth and wealth left their traces in the landscape: nature areas were lost or are disintegrating. And, sustainable development does not sustain itself.

The government considers the following environmental problems to be obstinate: (1) loss of biodiversiry, (2) climate change, (3) over-exploitation of natural resources, (4) threats to health, (5) threats to external safety, (6) damage to the quality of the living environment, and (7) possible unmanageable tisks (NEPP-4, 2001).

The desired situation in thirty years (the scope of NEPP -4) has been formulated to be: a healthy living environment, and a daily living envitonment which is safe, clean and attractive. In solving these problems the next barriers were encountered: (1) unequal distribution of wealth in the world, (2) short-term thinking, (3) compartmentalization and institutional faults, (4) instrumental shortcomings, and (5) the "problem causers" are not the "problem solvers".

To hurdle these barriers, the Dutch government developed a policy of systemic innovations, the somcalled "transition policy". Solving these major environmental problems requires system innovations. In mary cases, this can take on the form of a long drawn-out transformation process comprising technological, economic, social-cultural and institutional changes. "The "transition period" is the period until such a transformation is completed.

During the transition, objectives are formulated and modified, and interrelated policy instruments are applied. The policy of transitions focuses on two main influencable causes of climate change: (1) energy used to supply energy, and (2) mobility. To reduce these man-made causes, we have to realize a sustainable energy housekeeping in combination with a $\mathrm{CO}_{2}$-free energy supply. During the transition the role of the government changed. It began to link parties together and stimulate them, facilitate the right conditions, steer by providing the frameworks and establishing the conditions. And, of course, the government continued to enforce the law (NEPP-4, 2001).

\subsection{Policy implementation characteristics}

\section{Change of policy responsibility}

At the end of the $1990 \mathrm{~s}$, policy responsibility changed. This change was induced by a strong motivation to reduce $\mathrm{CO}_{2}$ emissions, considering the reduction targets and the expected economic growth. An absolute precondition to achieve such targets is that all energy consumets, all intermediate organizations and all authorities regard energy efficiency as one of their core tasks. Energy efficiency could no longer be regarded in isolation, but had to become an integral part of quality improvement in our production and consumption structure (Ministry of Economic Affairs, 1998). 
Until the late 1990s, the Ministry of Economic Affairs was responsible for energy conservation policy. But then the target group approach was gaining temtirory, and for many target groups, the Ministry of Economic Affairs was no longer the logical partner. This was especially true in the development of "Long Term Agreements" and other covenants. So the Ministry of Economic Aftairs transferred part of its tesponsibility for energy conservation to other ministries. The responsibility for energy conserwation in the buil environment, for example, went to the Ministry of Housing and Environmental Affairs, the responsibility for energy conservation in agriculture went to the Ministry of Agriculute and the responsibility for energy conservation in traffic went to the Ministry of Traffic and Transport.

This shift of responsibility entailed internalization of the energy conservation policy in other policy areas: housing and urban planning, industrial and technology policy, agricultural policy, and traffic and transport policy (Ministry of Economic Afrairs, 1998). This change of responsibility also involved a change of organization culture.

The culture of the Ministry of Economic Affairs was a culture of innowation and technology development, targeting the supply of technological solutions. It focused on the development of energy conservation technology. Although very necessary, technological solutions can only be effecrive if individual members of the target group, the building owners and users, for example, invest in and use that energy conservation technology ( $\mathrm{Kool}$ et al, 2002). Motivating members of the target group to use that technology was not the focus of their prolicy.

Because the Ministry of Economic Affairs focused on innovation and technology development, the ministry was interested in the members of a target group who first adopt innovative technology. With these forenunners, high-tech projects could be demonstrated. But the Ministry of Economic Affairs left the responsibility for implementing the imnovations to the matket parties. And so many high-tech innovations did not diffuse into the mainstream markets.

The culture of the Ministry of Housing, Spatial Planning and the Environment was driven by numbers and pragmatism - it had to build large numbers of houses cach year. The ministry was dealing with the mainstream members within target groups. So, when the policy responsibility shifted from the Ministry of Economic Affairs to the Ministry of Housing, the focus of policy implementation in energy conservation shifted from innovators to the mainstream of building owners and users (Kool et al., 2002).

\section{Shift from formulating policy to the results of policy}

At the end of the 1990s, the Second Chamber of the Dutch government shifted its attention from formulating policy to the results of policy; it focused on the results of funding invested in policy - does policy funding add value? Policy, in turn, began to focus 
on implementation programmes leading to specific eesults. This change of focus is called: WPITPR (From Policy Formulating To Policy Results), and is now applied to all mintstes.

The history of energy conservation policy and the orientation of the Ministry of Housing, Spatial Planning and the Environment towards the mainstream, combined with this focus on results, led to a new approach. Envitonmental policy in general and energy conservation policy in particular had been strongly instrament-oriented and top-down otilented; and did not induce behavioural change. Intervention strategies were not weli founded and were composed of the same old well-known instruments - knowledge transfer and subsidies.

This led the Ministry of Housing, Spatial Planning and the Environment to approach Nowem" with the following question: "Is it possible to develop a policy implementation programme that focuses on the mainstream of target groups in the built environment and their $\mathrm{CO}_{2}$ - emission teduction targets for the year 201.0 , and which consists of a rationally founded intervention strategy?" (Kool et al., 2002).

To develop a rationally founded strategy to change the behaviour of target groups to support gowernmental policy, Novem chose housing associations in the social housing sector of the built enviromment. The members of this target group are the owners of houses that are rented to families.

The housing associations are responsible for constructing and maintaining social housing and, therefore, they make far-teaching decisions in the field of energy conservation. In 1995, housing associations changed from a governmental organization to independent social enterprises. At that time, there were about 800 associations. Through mergers, the number of housing associations is decreasing (623 in 2002). In 2005, 565 housing associntions own and manage about 2.5 million houses: about $40 \%$ of the total housing stock in the Netherlands. They are major players in energy conservarion. Their housing stock emits about 5 Mton of $\mathrm{CO}_{2}$ yearly, and they must reduce this by 0.5 Mton in 2010 . With the question posed above, the energy conservation policy of the Minstry of Housing changed focus. It shifted from being instrument-oriented to being changeoriented. Energy conservation is the policy goal and, therefore, the first question was "what specific behaviour of housing associations has to change to realize the energy conservation policy goals?" And next "how can that specific behaviour of housing associations be influenced?"

\footnotetext{
1 Novem merged in 2003 with Senter to SenterNovem. SenterNovem is the Dutch Agency of the Ministry of Economic Affairs for Sustainable Development, and SenterNovem is active in the field of energy, environmental issues and innovation by means of advising, giving information and subsidies.
} 


\subsection{Theoretical point of departure}

Based on this change-oriented position, we formulated a theoretical point of departure leading to behavioural change. This section describes the basics of our theoretical point of departure and our motivation for choosing theoretical models of Green and Kreuter (1999), Rogers (1995), and Moore (2002). Influencing the behaviour of a target group of organizations is our primary goal. To that end, we assume that the behaviour of organizations is a product of the behaviour of individuals within those organizations.

If we want to influence the behaviour of organizations, we must influence the behaviour of individuals. The model of Green and Kreuter offers a rational framework to do this and, for that reason, it plays a central role in this thesis.

This model has an integral approach to behaviour and considers both internal and external behavioural-influencing factors. Internal factors, or predisposing factors, are of a social-psychological character and can be used to influence the behaviour of organizations. External factors include a complete spectrum of factors, the enabling and reinforcing factors, outside the organization, which can be used to influence the behaviour of organizations. The Green and Kreuter model also provides the means to operationalize these variables. Furthermore, the model provides a rational foundation to develop interventions according to a plan and work through the plan. In short, it provides a rational foundation for an intervention strategy.

Besides influencing the behaviour of organizations, we want to influence the behaviour of target groups of organizations. Specifically, we want those organizations that are slow to adopt energy-conserving innovations to more quickly adopt innovations. To study how this process of adoption differs between organizations within a target group, we applied the theory of Rogers (1995).

This theory provides a framework to compare the behaviour of organizations within a target group, especially with respect to their attitudes toward innovation. Rogers ${ }^{2}$ diffusion theory is about changes - the adoption of innovation - within a social system consisting of interacting individuals, and organizations. It provides a means to divide the target group into segments, each having its own behavioural characteristics regarding innovation.

Moore's theory (2002) provides a way to compare the characteristics of the eatly market segment, those who adopt quickly, and the mainstream market segment, those who adopt more slowly. Furthermore, the theory also provides a basis for developing an intervention strategy that specifically targets the behaviour of these segments of the target group. Thereby, it provides a first step to speed up the diffusion of innovations. 


\section{Adaptation of the Green and Kreuter model (1999)}

We begin our discussion with the core elements of the Green and Kreuter model (1999), because of the central role in our thesis, thereafter we discuss Rogers (1995) and Moore (2002) in relation to the process of change. Here we restrict our discussion to the core elements of the Green and Kreuter model (1999). In Chapter 2, we discuss its adaptation to our target group in detail.

The model of Green and Kreuter follows a logical underlying principle:

1. begin at the end - determine what the result should be, then

2. determine what has to be changed to bring the result about, and finally

3. determine how the change has to be induced.

In other words, begin with the desired outcome and then determine how to bring it about.

In our case, the desired energy-conservation behaviour of the members of the target group, as well as its determinants, had to be diagnosed, before designing the intervention. The intervention and choice of instruments could then be based on an analysis of behavioural determinants.

Although originally designed as a framework for planning interventions, and often used to influence the health related behaviour of individuals, we used the Green and Kreuter planning model to develop interventions to influence the behaviour of organizations.

To do this, we assumed the following:

- Organizations are, by definition, sets of individuals with common interests and with supporting coordination mechanisms (Silverman, 1970).

- Change in the behaviour of an organization often results from decisions made by a dominant coalition of individuals within the organization. That coalition of individuals has the most powerful position regarding certain decisions (Cyert and March, 1992).

- The behaviout of organizations is, in fact, a function of the behaviour of those individuals. Therefore, if we identify the behavioural determinants of this dominant coalition, we identify the behavioural determinants of the organization as a whole.

Green and Kreuter's PRECEDE-PROCEED model (1999) states, in essence:

first determine, develop and design an intervention (PRECEDE). And then implement and evaluate it (PROCEED).

In our case, implementation and evaluation was outside the scope of the project. We focused on the development and design of interventions. For that reason, we used only the PRECEDE part of the model.

Figure 1.1 illustrates how we adapted this PRECEDE part to fit our purposes. 


\section{Explanation of our adaptation of the PRECEDE-model of Green and Kreuter (1999)}

Green and Kreuter describe three general categories of factors that make up the determinants that affect behaviour and context. Each has a different influence on behaviour.

Figure 1.1: PRECEDE, (Modified from Health promotion planning, by Green and Kreuter, (1999))

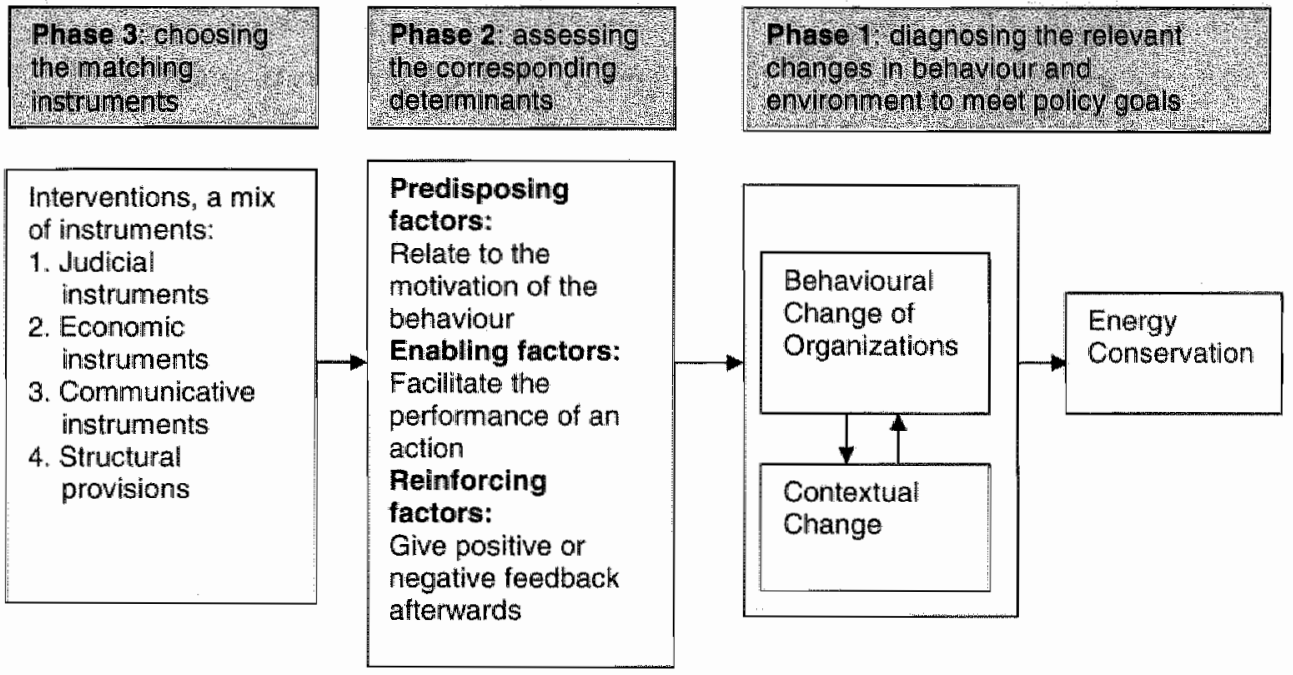

1. Predisposing factors. Predisposing factors provide the motivation for the behaviour and are found in the socio-psychological and cultural domain of otganizations. The factors within this category that can be influenced, include the cognitive and affective dimensions of knowing, feeling, believing, valuing, and having self-confidence or a sense of efficacy. Other factors, however, that also predispose some energy-related behaviour cannot easily be changed. These include socio-demographic factors such as size and wealth. Although these factors can be used to segment a target population for policy implementation or marketing purposes, they were not of interest in this study because they cannot be easily influenced by policy instruments.

2. Enabling factors. Enabling factors are conditions of the context and facilitate the performance or action of organizations. Two aspects of enabling factors must be taken into consideration: their availability and their accessibility. Enabling factors relate to resources, and new skills. Resources include external financial, technical and organizational resources. Examples are subsidies, engineering advice, specific advisors. New skills may have to be made available to realize the desired behaviour. For example, 
an organization may have to kewn how to transate its environmental policy into a specific plan of action.

3. Reinforcing fuctors. Remforcing factors ate thase consequences of an action which prowide the organzaton with positve or negative feedback, or support afterwads. Reinforcing fackors inchule: feedback of peer organizations, advice and feedback by powerful and significant organizations (e.g. authorites offering stimulating subsidies and enforcing obligations), and feedback of customers. The feedback can be given in several ways: througl social benefits, recognition, status, companison with peer organizations, financial rewards and reactions of customers.

Various combinations of these factors form determinants of behaviour, and the behaviour of an organization is a function of the collective influence of the determinants.

We made the model operational to develop an intervention strategy to influence the determinante of behaviout of housing associations and, thereby, induce behavioural change. We did this in three phases. (See Chapter 2 for more detals.)

Phase 1: Define the end. The policy goals have to be defined, as well as the relevant changes in behaviout necessary to meet those goals. TheNinistry of Housing, Spatial Planning and the Fnvironment defined the energy conservation policy goals, and set priotities and targets. The reduction target for housing associations is about 0.5 Mton $\mathrm{CO}_{2} \operatorname{in} 2010$

Phase 2: Establish the relevant determinants of behavioural and contextual change. We diagnosed the behaviour of the housing association target group and established the relative influence of determinants on their behaviour. We surveyed the housing associations with a questionnaite, analyzed the data and identified the most influential determinants.

\section{Phase 3: Choose the matching instruments.}

First, by revicwing theory, we determined which factors are influenced by policy instruments, and identifed their "active ingredients" - their specific influence on the determinants of behaviout.

We then identified instruments that could effectrely influence the determinants identified in Phase 2. Subsequently we matched the determinants influencing the behaviour of the target group with the corresponding active ingredients of the policy instruments.

In this way, we chose the potentially most effective set of instruments that influences the energy-conservation behaviour of housing associations.

After choosing the instruments, all the ingredients necessary to formulate an intervention strategy are available. In most cases, determinants are influenced by more than one instrument. We, therefore, chose an instrument mix and formulated an intervention strategy made up of various instruments. 
The process of change within target groups: the models of Rogers (1995) and Moore (2002)

To achieve energy conservation goals, target groups must be influenced to adopt energy conservation innowations on a large scale. In other words, the innovation must diffuse through the entire rarget group. We know, however, that target groups are not homogeneous in their behavioural change (Rogers, 1995). Often target groups perceive behavioural change as an innowation. According to the diffusion theory of Rogers (1995), an innovation is "an idea, practice or object that is perceived as new by an individual or another unit of adoption". Hil diffusion theory describes the process of up-scaling from small-scale to widespread implementation of innovations. An innovation's rate of diffusion depends on how quickly actors adopt the innovation. Actors within a target group, however, differ in their speed of adopting innovations, and they differ in adapting their behaviour to a new situation.

The behavioural change of target groups begins with a group of first-adopters, called the "innovators", and "early adopters" (Rogers, 1995). After this group, the rest follow stepby-step: the "early majority", the "late majority" and, finally, the "laggardis" (Rogers, 1995). Because of differences in adoption speed, the diffusion process of an innovation follows an S-shaped curve when the number of adopters is plotted against time (Figute $1.2)$.

Figure 1.2: S-shaped curve of adoption of innovations

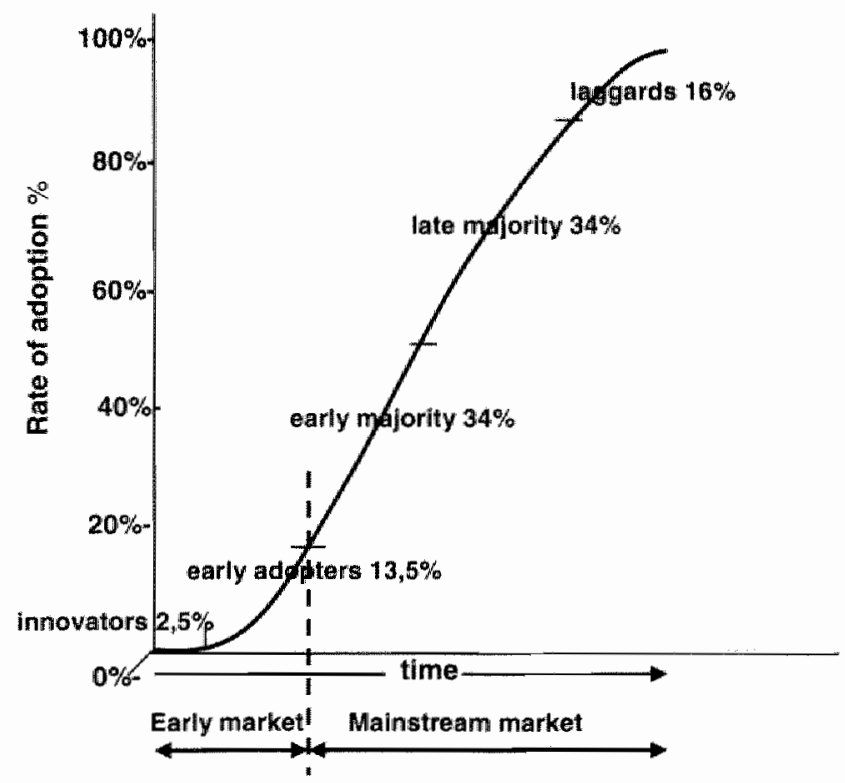


Diffusion is at first slow, as there are relatively few innovators and early adopters. As the early majority is reached, the diffusion rate increases, and it then decreases when the late majonity is reached, followed by the hard-ro-reach laggards.

Moore (2002) has condensed this classification into two segments: the early matket and the mainstream market.

The early market (innovators and eatly adopters) is vision driven, and often makes decisions based on strategic considerations.

'The mainsteam market (early and late majorities, and laggards), howewer, is basically motivated by a pragmatic attitude. The early majority actors adopt innovations somewhat eatlier than the mean, with willingness and caution, and for pragmatic reasons.

The late majority actors approach innowations sceptically and conservatively. The laggards feel suspicious about innovations.

From theory we know that the early market has a more visionary character and the mainstream has a more pragmatic attitude (Moore, 2002).

We operationalized these theoretical characteristics as follows.

Fitist, we defined "wisionarity" as:

The disposition of an actor whose decision-making behaviour, related to innovations, is guided by ideology and is related to strategy towards the future.

And we defined "pragmatism" as:

The disposition of an actor whose decision-making behaviour is guided by the judgement of facts as related to core business and problem solving.

Second., we constructed the variables "visionarity" and "pragmatism", from the data we obtained from our earlicr survey of the actors in housing associations. In the survey itself, these wariables were not made operational and, therefore, this was a retrospective analysis of the survey data. This implies that out conclusions have an explorative character; they give direction to further research.

Moore (2002) has used the diffusion theory of Rogers (1995) to develop an innovationmarketing model, the so-called "high-tech" markering model. Following Rogers" theory, this model states that the way to develop a high-tech market is to work from left to right on the S-shaped curve. Marketing companies should focus first on the innovators; get them to adopt the innovation. Then they should move on to the early adopters and increase their numbers, go on to the early majority, then the late majority and, finally, to 
the laggards. In this effort, companies marketing innowatve products or services should use each "captured" segment as a reference base for theit next strategy.

In practice this process does not move smoothly because of discontinaties in the S-curve, discontinuities between all market segments. In this respect, Moore deviates from Rogers and has developed his "chasm" theory. A large discontimuty between the early adopters and the early majority forms a "chasm" berween the segments. These two segments profoundly differ in their attitude towards innovations and change. Innovations often do not reach the mainstream - they cannot cross the chasm - because they do not meer the pragmatic needs of the early majority segment of the mainstream.

\subsection{Central research questions and overview of the dissertation}

\section{Central research questions}

We addressed three clusters of research questions in our study. These are answered in this dissertation.

1. How can we develop a well-reasoned intervention strategy to influence the behaviour of housing associations? Using the PRECEDE part of the planning and evaluation model of Green and Kreuter we formulated specific sub questions.

1.1 Which factors influence the energy-relevant behaviour of housing assaciations?

1.2 Which policy instruments are best suited to form an intervention strategy?

2. Because target groups are not homogeneous in their behavioural change, and because changes in target group behaviour follow a gradual pattem, we addressed the following sub-questions about the specific chatacteristics of segments within the target group. following Rogers diffusion theory:

2.1 Is it possible to identify different adopter segments within the target group of housing associations?

2.2 What ate the characteristics of these adopter segments?

2.3 What are the differences in the deteminants of behaviour of the adopter segments? Knowing the different segments and theit characteristics, we then wanted to know if pollicy instruments influence the segments differently. We exploted the differences berween these segments from a theoretical point of view. Specifically we asked:

2.4 In what way do existing policy instruments differ in influencing the behaviour of the early market and the mainstream market actors?

3. In order to intensify adoption of innovations in the field of energy conservation and renewable energy, we adapted Moore's marketing method to bring policy supporting innovations into the mainstream and, thereby, to cross the chasm between the early 
market and the manstream. The first step of this marketing method is to win a niche matket in the mainstream as a statting point for winning the rest of the mainstream. This raised the following research questions:

3.1 Is it possible to identify members of this niche market?

3.2 What are the characteristics of the niche mombers who form the first segment in the mainstueam no market?

3.3 How to develop an approach to stimulate the niche segment to adopt energy conservation innovations?

\section{Overview of the dissertation}

This chapter, Chapter 1, presents a short historical sketch of policy background and positions energy conservation as an effective pollicy to reverse the human causes of global warming. Further, our position is explained: instruments are part of an intervention strategy but change is our point of departure. Therefore, we start from a change oniented position and present a framework for planning interventions to achieve desired changes. This framework follows an underlying principle: "beginning at the end". One begins with the desired outcome and determines what behaviour of the target group must be influenced. Stated another way, the determinants of energy-conservation behaviour must be diagnosed first, before the intervention can be designed. This will lead to a well reasoned intervention strategy. The introductory chapter concludes with our central research questions and an overview of the dissertation.

Chapter 2 reports the development of an intervention strategy to influence the bohaviour of the target group of housing associations. To that end, after elaboration on the Green and Kreuter framework, we (1) surveyed the housing associations to identify the determinants that influence their energy-related behaviour and we established the factors that make up those determinants. And, (2) we identified the active ingredients in the four main types of policy instruments: judicial, economic and communicative instruments, and physical provisions. These active ingredients in the policy instruments specifically influence various behavioural determinants.

Based on the outcome of these two studies, policy instruments were chosen that should be suitable in an intervention strategy. The choice of instruments was based on the assumption that an instrument's active ingredients must match the determinants that influence the policy ${ }^{-d e s i r e d ~ b e h a v i o u r . ~}$

Chapter 3 presents the results of the segmentation analysis of the target group of housing associations. In order to address a target group properly, we must know which members of the target group belong to the early market, and which to the mainstream, and what their behavioural characteristics are. Based on our analysis, the target group was divided into two segments: the early market and the mainstream market. Also, the characteristics 
of these segments were investigated and are presented. Consistent with theory, we discovered that the early market actors and mainstream matket actors have differing behavioural deteminants: the early market actors are move vision driven and the mainstream market actors have a more pragmatic attitude.

Chapter 4 presents and discusses which policy instruments best fit the early marlet and the mainstream segments of the target group of housing associations. In this study, we analyzed the change processes of these segments and determined the active ingredients of policy instruments that best fit the characteristics of these segments.

Chapter 5 describes how the mainstream matket can be influenced to adopt energyrelated innovations more quickly. Innovations only appeal to the visionary early market and often do not meet the more pragmatic needs of the mainstream. For that reason, innovations often fall in a "chasm" between the early market and the mainstream, and fail to reach the mainstream. To cross this chasm and speed up adoption of innovations by the mainstream, we explored the marketing strategy of Moore and developed a protocol to cross this chasm.

Finally, Chapter 6 integrates the findings of our studies and discusses the contribution of these studies to the field of intervention development and planning, and to the field of policy development. 


\section{References}

Cyert R.M., March J.G., 1992.

A behavioural theory of the firm (2ed), Blackwell Oxford, UK.

Beus J.W. de, Doorn J.A.A. wan, 1984 .

De intervente stat (The intervening state), Boom, Meppel.

Green I.W., Kreuter M.W., 1999.

Health promorion planning, $3^{\text {rd }}$ edition, Mountain View, California.

Grin J., Graaf H. van der, Vergragt Ph. J., 2003.

Fen derde generatie milieubeleid: een sociologisch perspectief en een

belleidswetenschappelijk programma (A third generation environmental policy: a

sociological perspective and a policy scientific program),

Beleidswetenschap, 17, no. 1 , pp. 51-72, Kluwer, Alphen aan de $\mathbb{R i j n}$.

IPCC, 2001 .

Climate change 2001 synthesis report. An assessment of the intergovernmental

panel on climate change, approved by the IPCC plenary (XVIII), Wembley, 2001.

Jong J.J. de, Weeda E.O., Westerwoudt Th., Correlje A.F., 2005.

Dertig jaat Nederlands energiebelcid (Thirty years Dutch energy policy), Clingendael,

CIEP, Den Hag.

Kool R., Egmond C., Rijn D. van, Jenniskens S., 2002.

Strategisch kader gebouwde omgeving (Strategic tratmewotk built environment),

SenterNovem, Utrecht.

L.eroy P.L.M., 1994.

De ontwikkeling van het milieubeleid en van de milieubeleidtheorie (Development

of the environmental policy and environmental policy theory), in Glasbergen P. (ed.),

Milicubeleid, een beleidswetenschappelijke inleiding (Environmental Policy,

a policy-scientific introduction), Pp. 35-58, VUGA., Den Haag.

Ministry of Economic Aftairs, 1998.

Energy conservation white paper, Ministry of Economic Affairs, Den Haag. Minnesma M.E., 2003.

Dutch climate policy - a victim of economic growth, Climate Policy, 3, pp. 45-56.

Moore G., 2002.

Crossing the chasm, Harper Collins, New York.

NEPP - 1, 1989.

Nationaal Milieubeleidsplan 1 (NMP-1) (National Environmental Policy Plan),

Ministerie van Volkshuisvesting Ruimtelijke Ordening en Milieu, Den Haag. NEPP-2, 1993.

Nationaal Milieubeleidsplan 2 (NMP-2) (National Environmental Policy Plan 2),

Ministerie van Volkshuisvesting Ruimtelijke Ordening en Milieu, Den IJaag. 
NEPP-3, 1998.

Nationaal Milieubeleidsplan 3 (NMP-3) (National Environmental Policy Plan 3),

Ministerie van Volkshuiswesting Ruimtelijke Ordening Mitlieu, Den Haag. NEPP-4, 2001.

Nationaal Milieubeleidsplan 4 (NMP-4) (National Environmental Policy Plan 4),

Ministerie van Volkshuisvesting Ruimtelijke Ordening en Milieu, Den Haag. RIVM, 2005.

Environmental balance 2005, Milieu en Natuur Planbureau (MNP), Bilthoven. Rogers E.M., 1995.

Diffusion of innovations, $4^{\text {th }}$ edition, The Free Press, New York.

Silverman D, 1970.

The theory of organizations, Basic Books, London.

Tatenhove J.P.M., 1993.

Milieubeleid onder dak (Environmental policy under shelter), Wageningen

Universiteit, Wageningen.

Verbeek K., 2003.

De toestand van het klimaat in Nederland 2003 (The climate situation in the Netherlands 2003), The fourth national climate report 2003, KNMI, De Bilt.

Vellinga P., Verseveld J.W., 2000.

Climate change and extreme weather events, Institute for environmental studies, VU, Amsterdam, WWF.

WRR, 1992.

Rapport 41, Milieubeleid, strategie, instrumenten en handhartbaarheid (Environmental policy, strategy, instruments and enforcement), SDU, Den Haag. 


\title{
Chapter 2
}

\section{A strategy to encourage housing associations to invest in energy conservation}

\author{
This chapter is based on: \\ Egmond C., Jonkers R., Kokk G., 2005. \\ A strategy to encourage housing associations to invest in energy conserwation, \\ Energy Policy, 33, pp. 2374-2384.
}

\begin{abstract}
:
To meet the Dutch governmental goals of reducing $\mathrm{CO}_{2}$ emission, target groups must intensify their efforts to conserve energy. In commission of the Dutch Ministry of Housing and Environmental Affairs, Novem developed a strategy to effectively change the behaviour of target groups. "This chapter answers the questions: what are the determinants of energy-relevant behaviour of the target group housing associations; and which policy instruments are most suitable for an intervention strategy? Furom a survey off housing associations we determined the factors making up the deteminants of behaviour. The four main types of policy instruments - judicial, economical and communicative instruments and physical provisions - were analyzed for their active ingtedients. An intervention strategy was then based on matching the factors making up the target group determinants, and the active ingredients of the policy instruments. The factors: attitude, feedback of peer organizations and feedback from authorities, strongly influence the energy-relevant behaviour of housing associations. And the most effective policy instruments have a facilitating and encouraging character and include covenants with local authorities. We conclude that this method forms a solid basis for formulating an intervention strategy to change the behaviour of housing associations.
\end{abstract}




\subsection{Introduction}

Reversing the human causes of global warming concerns many governments. Reducing energy consumption and thereby reducing the emission of $\mathrm{CO}_{2}$ is an effective means for reaching this goal and is, indeed, stimulated by Government Policy. The Dutch Government has specifically argeted the users and owners of buildings as being large energy consumers. If this sector reduces its energy consumption then $\mathrm{CO}_{2}$ emission can, by the year 2010 , be reduced by about $3.5 \mathrm{Mton} \mathrm{CO}_{2}$ per year, about $16 \%$ of the estimated $\mathrm{CO}_{2}$ emission in 2010 (21,8 Mton).

The policy of the Dutch government has focused on the development of energy conservation technology which, although very necessary, can only be effective if individual members of the target group, the building owners and users, invest in and use that energy conservation technology. This, however, entails a change in decision-making behaviour on the part of building owners and users. If the government can stimulate the building owners and users to change their behaviour and decide to use energy conservation technology, then the goal of energy reduction will become more realistic.

In the past, intervention strategies were not well-founded and were composed of the same old well-known instruments, e.g. knowledge transfer and subsidies. In the light of this background, the Dutch Ministry of Housing and Environmental Affairs asked Novem to develop a well reasoned strategy to change the behaviour of target groups to support governmental policy and to develop an intervention strategy (Kool et al., 2002). Housing associations, the owners of the houses that are rented to families, were selected as the target group. These associations are responsible for constructing and maintaining social housing, and therefore, they make far-reaching decisions in the field of energy conservation.

Developing a policy that stimulates organizations to change their behaviour depends highly on knowing the determinants of their behaviour and knowing what methods effectively influence those determinants to stimulate such a change. We define a determinant to be a complex of factors that mediate or influence behavioural change of the target group. The factors malking up the determinants operate to change behaviour through predisposing, enabling or reinforcing changes. Consequently, policy instruments to stimulate change, must predispose, enable and reinforce the desired changes.

This explorative study addressed two questions:

(1) what factors influence the energy-relevant behaviour of housing associations, and

(2) what policy instruments are best suited to forming an intervention strategy.

To address these questions we adapted a model for planning interventions to influence individual behaviour (Green and Kreuter, 1999) to planning interventions to influence the 
behaviout of organizations. We then carried out wo studies. In the first study we surveyed the target group of housing associations to establsh the deteminants that infuence their energy-related behaviour and we established the tactots that make up those determinants. In the second study we analyzed policy instruments for their" "active" ingredients. Based on the outcome of these two studies we then chose instruments that should be suitable in an intervention strategy. Our choice of instmments was based on the assumption that an instrument's active ingredients must march the factors that influence behaviour. Implementation and evaluation of the chosen instruments were not investigated in this study.

\subsection{Theoretical assumption}

\section{The model}

Our approach to answering the two questions was based on Green and Kreuter's (1999) model of behavioural change. It is called the PRECEDE-PROCEED model and can be summarized with the slogan: "beginning at the end". In our study we applied it following a six-step plan with the assumption that if we influence the deteminants of behaviour, we eventually induce behavioural change. Our steps 1 and 2,3 and 4 , and 5 and 6 match the first, second and third phases respectively of the Green and Kreuter model. See figure 2.1 for an overview of the model.

Figure 2.1: PRECEDE (Modified from Health promotion planning, by Green and Kreuter, (1999)

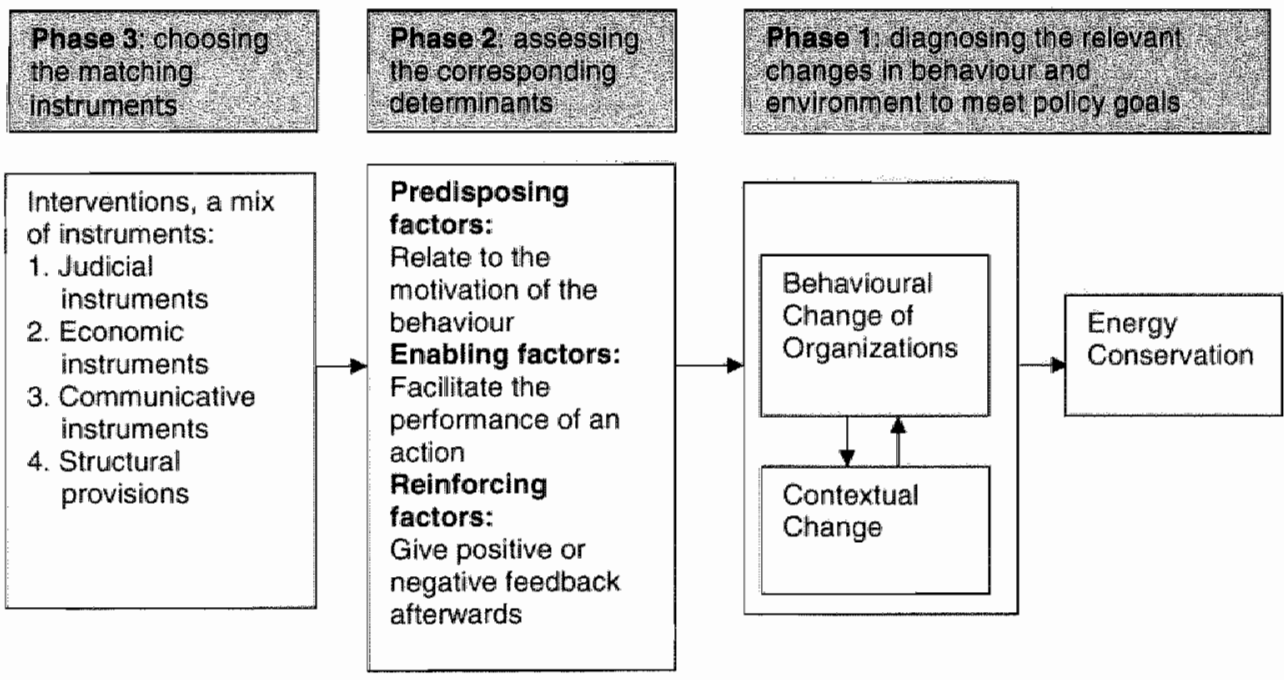




\section{Phase 1 contains step 1 and step 2}

\section{Step 1: Defining policy goals}

The Ministry of Housing and Environmental Affairs defined the energy conservation policy goals and set priorities and targets. The reduction target for housing associations is about 0.5 Mron $\mathrm{CO}_{2}$ emission in 2010.

\section{Step 2: Establishing the relevant determinants of behavioural and contextual change}

We diagnosed the behaviour of the target group and established the relative influence of determinants of behaviour of the target group. This step was done through interviews and questionnaires carried out by surveying the target group.

\section{Phase 2 contains step 3 and step 4}

\section{Step 3: Assessing the factors making up the target group determinants}

In this step we assessed the relevant predisposing, enabling and reinforcing factors that make up the determinants of the behaviour specific to the target group. Furthermore, we determined the relative influence of those factors on the behaviour of the target group. We did this by analyzing the data of the survey and resulted in a determinant map.

\section{Step 4: Determine which factors are inherent in policy instruments}

Based on a literature survey we analyzed policy instruments to determine their "active ingtedients": their specific influence on the determinants of behaviour.

\section{Phase 3 contains step 5 and step 6}

\section{Step 5: Choosing the matching instruments}

We established instruments that could effectively alter the determinants. This step was based on matching the factors influencing behaviour of the target group (Step 3) with the factors inherent in policy instruments (Step 4).

\section{Step 6: Formulating an intervention strategy}

In most cases determinants are influenced by more than one instrument, and therefore, we chose an instrument mix that led us to formulate an intervention strategy made up of various instruments.

Although Green and Kreuter's model was originally designed for influencing the behaviour of individuals, by making an assumption often used in policy science we adapted the model for the change of behaviour of organizations. This assumption is best explained in three logical steps. First, as described by Silverman, (1970) organizations are by definition sets of individuals with common interests and with supporting coordination mechanisms. Second, a change in the behaviour of an organization is preceded by a change in attitude of the organization (Bressers and Klok, 1988). Third, the behavioural attitude of an organization reflects the behavioural atritude of the dominant coalition of individuals within the organization, i.e. that coalition of individuals in the organization 
that has in respect to certain decisions in the organization the most powwerful, position. (Cyert and March, 1992). This assumption sharpened our focus on the behavioural options of the dominant coalitions within housing associations:

Green and Kreuter (1999) describe three general categories of factors that make up the determinants that affect behaviour and enwironment. Each has a different influence on behawiour.

1. Predisposing factors are especially internal antecedents to belaviour belonging to the organization; they motivate the behaviour.

2. Enabling factors are the external antecedents to behaviour belonging to the situation; they allow new behaviour to be realized.

3. Reinforcing factors are those consequences of an action which provide the organization feedback.

In context of this study we have made the factors operational as follows:

1. Predisposing factors. Predisposing factors provide the motiwation for the bethaviour and are found in the socio-psychological and cultural domain of otganizations. The factors within this category that can be influenced, include the cognitive and affective dimensions of knowing, feeling, believing, valuing, and having self-confidence or a sense of efficacy. Other factors, however, that also predispose some energy-related behaviour cannot easily be changed. "These include socio-demographic factors such as size and wealth. Although these factors can be used to segment a target population for policy implementation of marketing purposes, they were not of interest in this study because they cannot be easily influenced by policy instruments.

Fot this srudy we distinguished the following changeable predisposing factors:

Awareness and knowledge. Awareness and knowledge of a situation usually predisposes behavioural change. The factors by themselves, however, do not usually induce behavionral or organizarional change, nor do they necessarily llead to decisions favoutable for energy conservation.

Organzational noms: These factors form the basis for an organization to justify its actions in ethical terms. They underpin the right and wrong, the good and the bad dimensions of an organization's outlook on specific behaviour. Often organizations have them formulated as part of their mission statement or as an organization code.

Subjective wom: The subjective norm of an organization refers to the perception of the strength of the opinions of other organizations about the behaviour in question, and thereby motivates the organizarion to comply with the "approved" behaviour. 
Awtwle. An attitude is a form of evaluation directed toward an action or a situation. The evaluation is cognitwe, affective and connotwe in character. The evaluative aspect is the core element of an attitude and it has a pros-and-cons dimension. Organizations express their attitudes in policy guide-lines, policy plans and action plans on certain issues.

Self-fficacy. Self-efficacy is an organization's perception of its own capacity for successfully organizing and implementing a new patren of behaviour. Self-efficacy is largely based on experience with similat actions or circumstances encountered or observed in the past. Organizations express self-efficacy through its well-equipped staff that has the needed skills and experience.

2. Enabling factors. Fnabling factors are conditions of the context and facilitate the performance or action of organizations. Two aspects of enabling factors must be taken into consideration: their availability and their accessibility. Enabling factors relate to resources and new skills. Resources include external financial, technical and organizational resources. Examples are subsidies, engineering advice, specific advisors. New skills may have to be made available to realize the desired behaviour. For example, an organization may have to learn how to translate its environmental policy into a specific plan of action.

3. Reinforcing factors. Reinforcing factors are those consequences of an action which provide the organization with positive or negative feedback, or support afterwards. Reinforcing factors include: feedback of peer organizations, advice and feedback by powerful and significant organizations (e.g. authorities offering stimulating subsidies and enforcing obligations), and feedback of customers. The feedback can be given in several ways: through social benefits, recognition, status, comparison with peer organizations, financial rewards and reactions of customers.

Various combinations of these factors form the determinants of behaviout. And the behaviour of an organization can be explained as a function of the collective influence of the determinants.

\subsection{The Target Group Study}

In this part of our study we first surveyed the target group of housing associations to establish the determinants that influence their energy-related behaviour and we defined the desired outcome of energy related behaviour.

\section{Methods}

\section{Establishing the target group determinants of behaviour}

Our target group of housing associations in the Netherlands totals 623 organizations. To establish the target-group-specific determinants of their energy-related behaviour we interviewed 234 of these organizations (53\% of those approached) using a questionnaire. 
This questionnaite was developed after holding nine focus interviews whercin the responses to a checklist were recorded. We based the questionnaite on operationalizing the clusters of predisposing, enabling and reinforcing factors, and on the actual situation of energy conservation in the target group housing associatons. In the final questionnaite several items were added to establish the dependent variable, as well as to gather backgtound information. The questionnaire-guided interviews of the survey were carried out with a computer-aided telephone interview (CATT) system.

The interviews led to our establishing target-group-specific determinants of energy-related behaviour. During these interwiews we focused mainly on the "changeable" factors.

\section{Questionnaire}

The questionnaire addressed the following issues, and the answers to the questions were of an ordinal and nominal type (3-and 5-point scale).

A. Background variables of the interviewees and association (11 items) Interviewees (4 items): position in the organization, policy-function or implementationfunction, seniority), and the association ( 7 items): size and age of the housing stock, financial position general and for energy conservation (EC), number of staff members totally and for EC, working area: urban or country-side.

\section{B. Energy and environment related behaviour (19 items)}

These questions had both a general character (are measures taken), and a specific on the kind of measures. Example: Is there a yearly maintenance plan, including energy conservation? a. yes; b. no; c. don't know; d. yes, but without energy conservation.

C. Attention for energy conservation in the organizational policy and in covenants (17 items)

Example: The taking of energy conservation measures is in accordance with the policy of the association: a is part of the envirommental policy plan (yes or no); b. is patt of an energy conservation programme (yes or no); $c$ is part of large-scale maintenance planning (yes ot no); d. otherwise.

\section{Attitude towards energy conservation and environmental issues (32 items)}

Example: Please give notice if you agree on the following statements: Subsidies on wnergy conservation measures are too small. Agree very much, agree a little, or do not agree.

E. Impact and support of peer organizations and other intermediary organizations in making decisions about energy conservation ( 9 items)

Example: Are you informed on the investments done by other associations in the ficld of enetgy conservation? a. yes, good; b. yes, little; c. don't know; d. no, hardly.

\section{F. Determination of the adoption category ( 3 items)}

Based on the self-designating method (Rogers, 2003, p. 308).

Item 1: Compare the attitude of other housing associations with your association. 
Item 2: Compare the decision speed of your housing with other housings associations. Item 3: Compare your housing association with other housing associations on the degree of taking energy conservation measures.

\section{G. Chosen and preferted instruments, including the support of significant external parties (13 items)}

Example: Can you give for each instrument, an indication of the effect on taking energy conservation measures: a. a big stimulating effect; $b$, a moderate effect; $c$. none.

Instruments: a. improvement of subsidies; b. covenants; $c$. law and legislation; d. support at the implementation of technical measures; e. demonstration projects; $f$. introduction of an energy label for houses.

Trained interviewers from a professional call centre contacted the organizations and asked members of the dominant coalition, the decision-makers to answer the questionnaire. The respondents included members of the boards of clirectors $(7.3 \%)$, chiefs of the technical departments $(54.7 \%)$ and other staff members with a mandate on energy conservation or environmental issues $(38 \%)$.

\section{Defining the desired behavioural outcome}

In the focus interwiews we found that most housing associations were already taking measures to conserve energy in their stock of houses. The taking of these measures we defined to be the desirable outcome. We then included in the questionnaire nine items related to taking measures to conserve energy which allowed us to measure the dependent outcome-variable that we called: taking energy conservation measures in the housing stock. These nine items formed a scale (Cronbach's alpha of .75).'

This outcome-variable was measured by adding up the scores of the nine items on the questionnaire. This formed a scale of 0 (minimum) till 18 (maximum). These items were:

1. The attenrion that a housing association pays to taking energy conservation measures in their houses. Answers: a. much, (score=2) b. fairly, (score=1), c. little, (score=1), d. none, (score $=0$ ).

2. The implementation of demonstration projects in the field of energy conservation in the past. Answers: a. yes, (score=2), b. no, (score=0), c. don't know, (score=0).

3. The intensity of energy conservation measures taken in the scope of large-scale maintenance. Answers: a. always, (score $=2$ ), b. often, $($ score $=1$ ), c. sometimes, $($ score $=1$ ), d. never, (score $=0$ ).

4. The level of ambition related to taking energy conservation measures.

Answers: a. higher than usual, (score $=2)$, b. no, $($ score $=0)$, c. don't know, (score $=0$ ).

\footnotetext{
1 Cronbach's alpha is a model of internal consistency, based on average inter-item correlation. The alpha has a minimum score of 0 and a maximum of 1 . A Cronbach's alpha of $\geq .60$ is considered as an acceptable consistency rate, for this type of analysis.
} 
5. The consolidation of procedures for taking energy conservation measures in plans for large-scale maintenance. Answers: a. yes, (score $=2)$, b. no, (score $=0 \%$, c. don't know, (score $=0$ ).

6. The existence of a yearly maintenance plan that includes energy conservation measures. Answers: a. yes, (score $=2)$, b. no, (score $=0$ ), c. don't know, (scone $=0$ ).

7. Investments in renewable energy optons in the past.

Answers: a. yes, (score $=2)$ b. no, (score $=0)$, c. don't know, (scone $=0)$.

8. The number of renewable energy options. 4-5 measures, (score $=2$ ), 1-3 measures ( $\mathrm{score}=1)$, 0 measures (score $=0$ ).

9. Plans to invest in tenewable energy options in the future.

Answers: a. yes, (score $=2)$, b. no, (score $=0)$, c. don't know, $(\operatorname{score}=0)$.

\section{Method of analysis}

We then analyzed the data of the survey to determine which determinants best explained the variance found in the outcome variable. To determine the relative strength of the relations between the determinants and the outcome variable, we used one-way and stepwise analysis of variance, and single and multiple regression analyses. In a first step variables were entered if they showed a significant $(p \leq 0.05)$ correlation with the dependant variable. These variables were consequently used in the linear regression with a stepwise variable selection method. In this method the independent variable, not in the equation, which has the smallest probability of Fwralue, is entered at each step, if that probability is sufficiently small. With this analysis we established the relative importance of the determinants in explaining the variance within the outcome variable.

\section{Results of the target group study}

\section{Relative importance of the determinants of target group behaviour}

About $28 \%$ of the rotal variance could be explained by the stepwise analysis of variance of the determinants studied in the survey.

When taken separately the determinants explained the variance as follows. Priority of enetgy conservation in relation to quality-of-life, protection against burglary and adapted construction explained $10 \%$; having a covenant with a local authority explained $8.8 \%$; housing cost saving explained $6.7 \%$; housing comfort $5.3 \%$; the imago of the organizacion $4.4 \%$; the competition position of the organization $5.3 \%$; and the presence of an encrgy conservation champion $6.7 \%$, the presence of knowledge on energy conservation $6.4 \%$ (Iable 2.1 ).

To process the data in the next step we ondered the percentages of explained variance on a scale of "low (1)", "medium (2)" and "high (3)". A percentage of 1 to 5 we rated ats low, 5 to 8 as medium and 8 to 10 as high. "Two items were of high xelative importance, 8 of medium importance and 8 of low importance (Table 2.1). 
Table 2.1: Explaining determinants with explained variance and relative importance

\begin{tabular}{|c|c|c|}
\hline explaining determinants: & $\begin{array}{l}\% 6, \\
\text { explained } \\
\text { variance. } \\
\text { molividual }\end{array}$ & $\begin{array}{l}\text { relative } \\
\text { importance }\end{array}$ \\
\hline Priority of Energy Conservation (EC) related to other fields & $10.0^{* *}$ & 3 \\
\hline Having a covenant with a local authority & $8.8^{*:+17}$ & 3 \\
\hline Using housing cost saving as a motive for $E C$ & $6.7^{\text {:nitit }}$ & 2 \\
\hline The presence of a champion for EC & $6.7^{* * * *}$ & 2 \\
\hline Kriowledge of the National Agreement Housing (NAH) & $6.4 * * * *$ & 2 \\
\hline The presence of specific knowledge in the area of EC & $6.4^{\text {*tw }}$ & 2 \\
\hline Plans to get an energy performance advice & $5.3^{* * *}$ & 2 \\
\hline Housing comfort as a motive for energy conservation & $5.3^{* * *}$ & 2 \\
\hline EC as argument for competifive position & $5.3^{* * *}$ & 2 \\
\hline Priarity of EC in policy & $5.1 * *$ & 2 \\
\hline Improvement of the imago as a motive for $\mathrm{EC}$ & $4.4^{* * *}$ & 1 \\
\hline Attitude of the management to Renewable Energy (RE) options & $4.3^{* *}$ & 1 \\
\hline Having an environmental policy plan with EC & $4.0^{* * *}$ & 1 \\
\hline Influence of the government on EC & $3.3^{* * *}$ & 1 \\
\hline Support in realization EC measures & $3.1 * * n$ & 1 \\
\hline Stimulation of intersectoral cooperation & $3.1^{* *}$ & 1 \\
\hline Investments in EC are not cost-effective & $2.9^{1 * * *}$ & 1 \\
\hline Perceived influence of the branch organization & $2.1 *$ & 1 \\
\hline${ }^{*}=p \leq 0.05 ;{ }^{* *}=p \leq 0.01 ; *{ }^{* * *}=p \leq 0.001$ & & \\
\hline
\end{tabular}

\section{Mapping the determinants of the survey on the factors of the model}

In order to establish which factors from the model make up the determinants of the target group, we mapped the determinants on the factors of the nodel (Table 2.2). A "match" - grey cell - indicates that a determinant found in the survey contains a factor as defined by the model. The match was done by analyzing if there is a relation between the determinants of the target group and the factors of the model. In this analysis the desk rescarch and focus interviews played a complementary role.

To illustrate the mapping process, the match of the determinant "priority of energy consetwation in policy" was done as follows. If a housing association has a policy of energy conservation then the association is aware of energy conservation, has knowledge about it, and therefore, the factors awareness and knowledge do not play a role in this determinant. 'The fact that the association has a policy of energy conservation expresses social responsibility and the factor organizational nom does play a role. In addition, the housing association has made a choice, so the factor attitude plays a role. If policy is 
formulated, there must be a perception of how to put the policy into practice, so selffefficacy is already there.

Table 2.2: Determinant map, determinants of the target group mapped on the factors of the model

\begin{tabular}{|c|c|c|c|c|c|c|c|c|c|c|c|c|c|c|c|}
\hline \multirow{3}{*}{$\begin{array}{l}\text { The grey cells represent the match } \\
\text { of the determinants of the target group on } \\
\text { the factors of the model }\end{array}$} & \multicolumn{15}{|c|}{ factors of the model } \\
\hline & \multicolumn{7}{|c|}{$\begin{array}{l}\text { Predisposing } \\
\text { factors }\end{array}$} & \multicolumn{4}{|c|}{$\begin{array}{l}\text { Enabling } \\
\text { factors }\end{array}$} & \multicolumn{4}{|c|}{$\begin{array}{l}\text { Reinforcing } \\
\text { factors }\end{array}$} \\
\hline & $\begin{array}{l}8 \\
\frac{\pi}{7} \\
\frac{8}{2} \\
\frac{5}{0} \\
\frac{\pi}{0} \\
\frac{\pi}{0}\end{array}$ & & $\frac{8}{8}$ & & 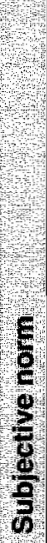 & & & 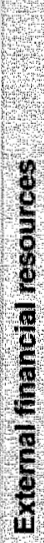 & 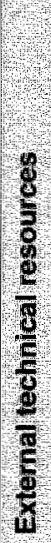 & 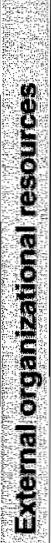 & & $\begin{array}{l}\frac{2}{5} \\
\frac{5}{2} \\
\frac{5}{6} \\
\frac{8}{6} \\
\frac{8}{8} \\
\frac{8}{8} \\
\frac{8}{4}\end{array}$ & 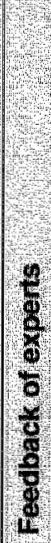 & $\frac{2}{8}$ & 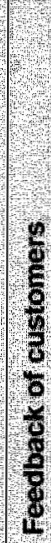 \\
\hline Relative priority Energy Conservation (EC) & 3 & & & & & 3 & & & & & & 3 & & 3 & \\
\hline Having a covenant & & & & & 3 & & & & & & & 3 & & & \\
\hline Housin & & & & & & & & & & & & & & & 2 \\
\hline The presence of & 2 & & & & & & & & 2 & 2 & & & & & \\
\hline Knowiedge of the NAH & 12 & 2. & 2 & & & & & & & & & 2 & & 2 & \\
\hline Presence & & & 2 & & & & & & 2 & & & & & & \\
\hline Plans for carrying out an EPA & & & & & & & & & 2 & & & & 2 & & \\
\hline Housing $\mathrm{c}$ & & & & & & & & & & & & & & & \\
\hline$E C$ as ar & & & & & 2 & 2 & & & & & & 2 & & & \\
\hline Priority of $(E C)$ in policy & & & & 2 & & 2 & & & & & & & & 2 & \\
\hline Improvement of imago as a motive for EC & & & & & 1 & & & & & & & 1 & & & \\
\hline Attitude of manage & & & & & & & & & & & & & & & \\
\hline Have an en & & & & & & & & & & 1 & & & & & \\
\hline nflues & & & & 7 & & & & & & & & & & 1 & \\
\hline Support it & & & & & & & 1 & & 1 & & 1 & 1 & 11 & & \\
\hline Stimulation of intersectoral cooperation & & & & & 1 & & & & & & & 1 & & & \\
\hline Investments in EC are not cost-effective & & & & 1 & & & & 1 & & & & & & & \\
\hline Perceived influence of the branch organization & & & & & 1 & & & & & & & 1 & & & \\
\hline elative weight per factor of the model & & 2 & 4 & 4 & 8 & 16 & 8 & 1 & 7 & 3 & 1 & 14 & & 11 & \\
\hline
\end{tabular}

'Energy performance Advice(EPA): a subsidized advice on energy conservation. 
Enabling factors play no role of importance while formulating policy. Furthermore, wuthorities encouraged formulating policy on energy conservation matters in the whole sector, so the factor feedback of authorities comes into play, and the factor feedback of peer organizations. This mapping process was executed with the input of target-group experts and members of the target group.

Because the identification of the determinants was based on the factors of the Green and Kreuter model, we could convert most determinants found in our study into the most important factors. We fitst made the analysis and prepared the determinant map. This determinant map (table 2.2) was first discussed with target group experts and members of the target group in a workshop session. And they confirmed the determinants and their relative importance. A grey cell is filled with the corresponding number for the relative importance of the determinant taken from table 2.1 .

The addition in the columns yields the relative weights of the factors of the model in explaining the variance of the outcome variable.

Of the predisposing factors attritude is the most important (weight score $=16$ ), followed by subjective norm and self-efficacy (weight 8); knowledge (weight 4) and awareness (weight 2) do not play important roles. Of the enabling factors, financial resources play a minor role (weight 1). Technical resources are the most important enabling factor (weight 7). New skills do not play a tole (weight 1). Feedback of peer organizations (weight 14) and the feedback of authority (weight 11) are the most important teinforcing factors.

\subsection{The Policy Instrument Study}

\section{Method}

Based on a review of literature in the field of policy instruments and interventions (Bartholomew et al, 2001; Bruijn et al, 2003; Bressers and Klok, 1988; Bressers and Lulofs, 2002; Doelen, 1989; Klok, 1991; Latour, 1997; Ligteringen, 1999; Lulofs and Lettinga, 2003; Schuddeboom, 1990; Vermeulen, 1992; WRR, 1992), we analyzed the various instruments in terms of their influence on the factors of the model that make up the determinants of behaviour. In this way we determined the "active ingredients" of the instruments. A number of experts in the field of behavioural change and policy instruments also judged the active ingredients, and delivered input into the instrument table (Table 2.3). We discussed the instrument table individually with the experts, especially the effects of instruments on the factors, and if the effect has a primary or secondary character. We incorporated their comment in the version, shown here in table 2.3. 


\section{Results of the policy instrument study}

\section{Four main types of instruments}

The Scientific Counsel for Govermment Policy, in their report about policy instruments (WRR, 1992), distinguishes four main types of instruments: judicial, economic and communicative instruments, and structural provisions. This classification is broadly accepted in policy sciences (Klok, 1991; Doelen, 1989). In general:

- Judicial instruments are mainly based on the mechanism of force,

- Economic instruments are characterized by financial transaction,

- Communicative instruments are characterized by persuasion,

- Structurall provisions work in two ways: they work by force or as facilitators.

The details of the instruments related to selecting instruments that will support an effective intervention strategy are described below.

\section{Judicial instruments}

In general, legislation works only if it is accompanied by communicative instruments. Communication about the law and sanctions is a necessary condition for the worlling of the law. Furthermore, public support, or at least a shared awareness of the issues, is necessary. Judicial instruments prescribe behaviour and set a norm (Klok, 1991). This means that public support is a prerequisite. Legislation creates an external motivation. It expresses a public value or social interest. Something has a public value or a social interest, and therefore it imposes itself on the organization as a norm. This causes the normative character of legislation. "The following subcategories can be distinguished.

Law and legislation create a model for the desired behaviour of the whole target group and consolidate the intended policy effect (Schuddeboom, 1990). In environmental policy, the Dutch government relies heavily on law and legislation to achieve its policy goals. Enforcement of laws and regulation is of special importance and without it laws often do not work at all.

Voluntary agreements are a mild form of judicial instruments. They are used by the government to avoid law and legislation because legislation cloes have disadvantages such as long realization times, rather rigid approach, and expensive to cnforce. Covenants are an example of voluntary agreements. In the 1990 s the Dutch government used this type of instrument quite a lot and research has shown that an agreement works well if a clear result-riented obligation is made and not just an effort-oriented obligation. (Bruijn et al., 2003). The effect increases if sanctions are possible when the results agreed upon are not achieved. Furthermore, agreements motivate because of group pressure. The target group itself joins voluntarily in a covenant and avoids legislation by doing so. In order to stimulate agreements the government often offers flanking subsidies. 


\section{Economic instruments}

Steering with economic instruments is usually directed at influencing financial considerations in such a way that an organization will behave in an environmentally favourable way (Vermeulen, 1992). It provides (1) advantages in the form of subsidies, (2) disadvantages in the form of levies, and (3) it makes environmental topics part of the econotnic traffic by giving environmental issues an economical value, e.g. emission trade and tax-differentiation.

The government offers subsidies to directly influence the process of decision-making. Subsidies decrease the additional cost of environmentally favourable behaviour as compared with less favourable alternatives, and create sufficient financial room for the desired behaviour that, otherwise, would not be financially feasible.

Levies are rather effective instruments (Bressers and Lulofs, 2002). There are levies by allocation, regulating levies, and environmental taxes. Their effect, however, depends of the behaviour in question.

Experiences with tax-differentiation for unleaded petrol give a rather positive picture of their effect on behaviour and environmental results (Klok, 1991). Also tax-differentiation and emission trade systems can be mentioned as types of economic instruments. These instruments also try to penetrate in the financial domain of decision-making and try by cost-optimizing to influence the decision.

Decisions can only be influenced, however, if the financial stimulus is strong enough to penetrate into the decision-process. If the decision-process is too much a core process, then the financial stimuli do not penetrate (Vermeulen, 1992). Investments in energy conservation measures always cost money and sometimes the financing problem can be facilitated by supplying financial constructions.

\section{Communicative instruments}

Communicative instruments rransfer knowledge for the purpose of persuasion, convincing or tempting. These instruments can also be used in combination with and to support other types of instruments. Creating social support and realizing disclosure are then the targets. Examples are information and promotion documents, labels and benchmarks. Two forms of communicative instruments are (1) witten information and (2) personal communication.

Written information has a greater effect on behaviour when the message is specific to the organization and target group, and the effect of a communicative instrument is larger if the message is tailored (Greer et al, 2000). A message can be tailored by making it relevan:

- to the target group (e.g. benchmarks);

- to the stage of change of the recipient organization;

- to the knowledge, norms and circunnstances of the recipient organization. 
In change processes two channels of communication play a central role: firstly, mass media and, secondly, interpersonal communication (Rogers, 1995). Communication often works as follows. Mass media reach the targeted organizations and the leading organizations in the target group pick up the signals first. These organizations, in turn, pass the message on to other organizations, often in the form of demonstration projects. Personal communication then plays a major role to start and continue processes of change in organizations. Examples are coaching, guidance and training. Personal advice seems more effective than promotion especially in supporting implementation processes.

\section{Physical provisions}

Some physical provisions, such as infrastructural provisions in the field of Spatial Planning, are clearly influencing behaviour (Doelen, 1989). Also on an individual level this can be seen. We call this last type of influencing behaviour; technical steering of behaviour (Latour, 1997). Structural provisions can have a compulsory character. On the level of a residential area we know the sun-oriented design and building of houses, and the provision of an energy infrastructure. On an individual level there are the toundabout and the speed ramp. Also many devices, such as thermostats and time switches exemplify structural provisions. Physical provisions have also a facilitating character: designing and building residential areas with public transport facilities and bicycle tracks and, on an individual level, cruise-control and bottle banks.

\section{Matching instruments and factors that influence determinants:}

\section{the instrument table}

Based on the above considerations, we analyzed the various instruments in terms of their influence on the predisposing, enabling and reinforcing factors of the model that make up the determinants of behaviour, and determined their "active ingredients". We present this in the form of an instrument table (Table 2.3), where the grey cells indicate the active ingredients of the instruments.

Judicial instrument have their effect mainly on the organizational norm, and attitude (Klok, 1991). Furthermore, judicial instruments affect the factor feedback of the authorities (Schuddeboom, 1990). Covenants and agreements have a broader impact, and affect awareness, subjective norm and feedback of peer organizations (Bruijn et al., 2003). Economical instruments have little effect on awareness, but mainly affect the enabling factor financial resources. They also affects attitude because economical instruments positively influence decisions about investments (Vermeulen, 1992; Bressers and Lulofs, 2002). Communicative instruments have the broadest impact; they have effect on 
awareness, knowledge, atritude and self-efficacy, but not a big effect on organizational norm and subjective norm (Bartholomew er al, 2001; Greer et al., 2000).

Furthermore the communicative instruments have effect on a number of enabling factors: technical and organizational tesources, and new skills. Benchmark and demonstration have clearly a reinforcing effect (Bartholomew et al., 2001). In the instrument table (Table 2.3) the active ingredients are reported in detail.

Table 2.3: Instrument table, match of instruments and determinants: the active ingredients.

\begin{tabular}{|c|c|c|c|c|c|c|c|c|c|c|c|c|c|c|}
\hline 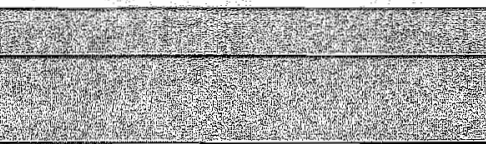 & fac & dis & $\frac{01}{0 s i n}$ & $\begin{array}{l}\text { he } \\
\text { Ig to }\end{array}$ & $\begin{array}{l}\mathrm{mod} \\
\mathrm{ctor}\end{array}$ & & & irilis & & & & nfor & cing & \\
\hline policy instruments: & 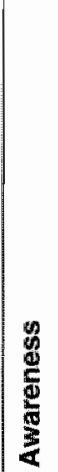 & 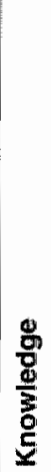 & 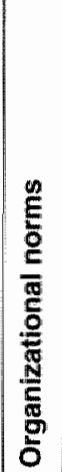 & 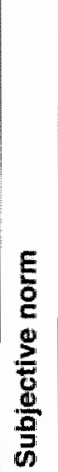 & 旁 & 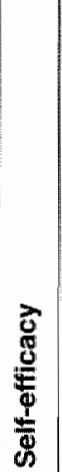 & 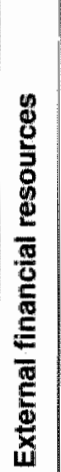 & 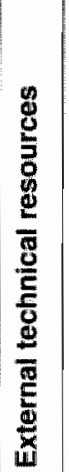 & 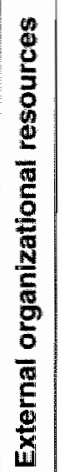 & 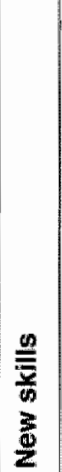 & 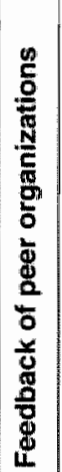 & 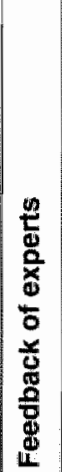 & 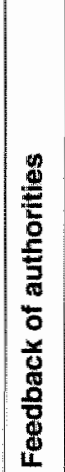 & 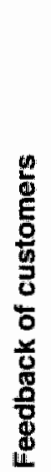 \\
\hline 1.1 General Laws and Rules & & & 2 & & 1 & & & & & & & & 1 & \\
\hline 1.2 Specific permits & & & 2 & & 11 & & & & & & & & 1 & \\
\hline 1.3 Enforcement & 1 & & 2 & 1 & 2 & & 11. & $11^{2}$ & & & & & 2 & \\
\hline 1.b Covenants and Agreements & 12 & & 12 & 1 & 2 & & & & & & 2: & & 10 & \\
\hline 2.1 Subsidy & $1 \%$ & & & & 12 & & 2 & & & & & & 11 & \\
\hline 2.2 Levy & 11 & & & & 1.2. & & 27 & & & & & & 12 & \\
\hline 2.3 Tax differentlation & & & & & 17 & & 1. & & & & & & 1. & \\
\hline 2.4 Financial Constructions & & & & & 11 & & 2. & & 1. & 1. & & 1 & & \\
\hline 3.1 Information and promotion & 2 & 112 & 112 & 1 1) & 2. & II & & 17m & & 2.7 & T1) & 1 & 11 & 11 \\
\hline 3.2 Training & & 2 & & & & 11 & & 1 & 2 & 2 & & 118 & & \\
\hline 3.3 Personal advice & & 2 & & & 1 & 2 & & $1:$ & 22. & 110 & & 11. & & \\
\hline 3.4 Demonstration & 11 & 112 & & & 1. & 2 & & 11 & & 19 & 2 & 1 & & \\
\hline 3.5 Benchmarks & 11 & & & 11 & & & & & & & 2 & 1. & & 2] \\
\hline 4.1 Infrastructural Provisions & 1 & & & & 11. & $11^{2}$ & & & & & & & & \\
\hline 4.2 Technical behavioural steering & 13 & & & & 11. & 11 & & & 1. & & & & & \\
\hline
\end{tabular}




\subsection{Combination and intervention strategy}

If we now combine the instrument table (Table 2.3) with the results of determinant map (Table 2.2) we get a list of instruments matching the importance of the factors in the combination Map (Table 2.4). In the third row we note the total weight of the factors of the model from the determinant map - the lower row of table 2.2 .

Table 2.4: Combination map of the determinant map (Table 2.2) and instrument table (Table 2.3)

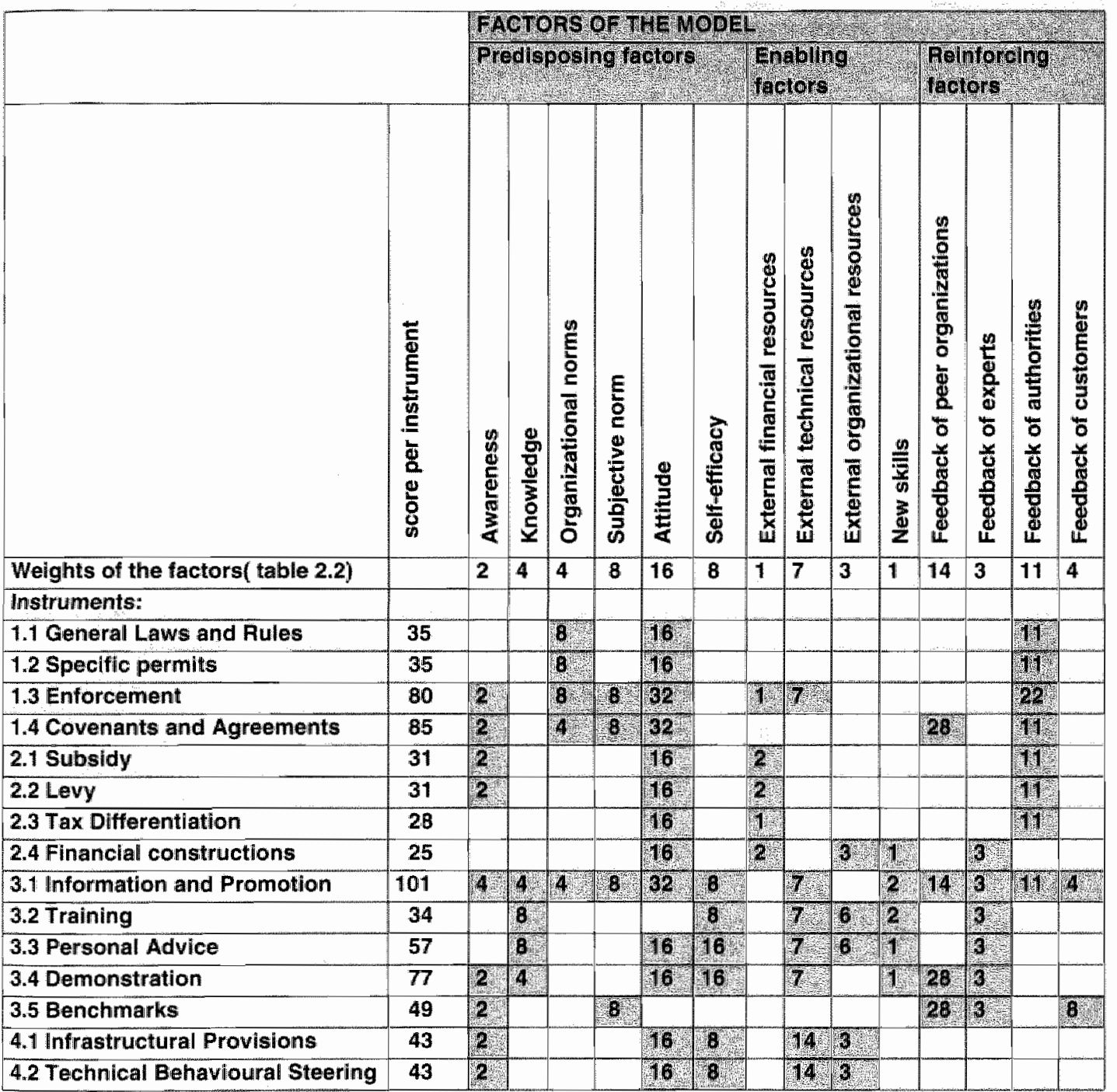


A grey cell indicates that a tactor is also an actwe ingredient of an instrument. The number in a grey cell is the score of the factor, as appeats in row 3 , "weights of the Factors" "but to distinguish main effects from side effects the score has been doubled when there is a main effect. Finally we add the scores in each row and we got a total score that is noted in the second column. The higher this score the more effective the instrument is likelly to be.

The most likely to be effective as ingredients of an intervention strategy are: information and promotion (score $=101$ ), covenants and agreements (score $=85$ ), enforcement (score $=80)$, demonstration $($ score $=77)$, personal advice $($ score $=57)$, benchmark (score $=49$ ), and infrastructural provisions ( $\operatorname{score}=43$ ). Of the judicial instruments are only covenants and agreements combined with enforcement relevant. The economical instruments are hardly relevant for housing associations.

\subsection{Discussion and conclusion}

This study addressed two questions: (1) what factors influence the energy-relevant behaviour of housing associations, and (2) what policy instruments are best suited to an intervention strategy. "The influencing factors of energy-telated behaviour of housing associations can be globally categorized into "changeable" and "non-changeable", and in this study we focused only on factors which can induce changes in behaviour. The study used empirical data and theoties, but the chatacter of the study is explorative.

Our study showed that the factors: attitude, feedback of peer organizations and feedback from anthorities strongly influence the energy-relevant behaviour of housing associations. Also the subjective norm, self-efficacy as well as the availability of technical resources play influencing toles. These factors have, for the most part, an enabling or reinforcing charactet. Housing associations do not have to be convinced to take energy-conservation measures, but they need good arguments such as housing cost-saving, housing comfort, increasing imago, and comperition advantages.

Policy instruments best suited to an intervention strategy have a facilitating and encouraging character. Furthermore, because housing associations are sensitive to external parties such as the local authorities and peer associations, interventions should be implemented by the networks around the housing associations. Our resulting intervention. strategy consists of mix of instruments, the core of which consists of covenants with local authorities. This instrument requires that special attention is given to their enforcement. "The covenants should be accompanied by personal advice, information, benchmark and demonstrations. If possible authorities should use infrastructural provisions in order to force housing associations in taking energy-conservation measures. 
Instruments do not affect just one determinant, but have effect on several determinaints through their active ingredients. For example, demonstrations contain a predisposing ingredient; they make the target group awate of the demonstrated possibility, and they make the choice more attractive because "seeing is believing". Demonstrations also have a reinforcing ingredient: an example is better than precept.

The results of our target group survey justify the conclusion that the answers given express the opinions and practices of the housing associations. The response was $53 \%$ and at least $62 \%$ of the respondents were decision-makers and members of the dominant coalition. From table 1, it could be argued that only a relatively small portion of the variance in the outcome variable is explained by the determinants. We were, however, only interested in "changeable" determinants and many other "unchangeable" determinants of behaviour can easily account for the unexplained portion of the variance. For example, we know that large and wealthy housing associations are more active in taking energy conservation measures. Size and wealth are not changeable determinants of behaviour and, therefore, were not considered in our analysis. Size and wealth do, however, cause variance in the outcome variable.

It should be noted that our instrument map is of a tentative character, and more research is necessary to establish the active ingredients more precisely. This part of our study was based on a review of literature and the judgement of experts. But more hard evidence is needed to strengthen the method and make it more generally applicable. A research proposal has been prepared and delivered to the ministry of Housing and Environmental affairs to seek for evidence-based conclusions about the active ingredients of the instruments. Plans are to investigate the effect of the proposed interventions in a quasiexperimental design.

We believe that this method forms a substantial basis for developing well reasoned intervention strategies which can be monitored and evaluated. The intervention strategy reported here is now being implemented in the target group of housing associations and the process is being monitored and evaluated. 


\section{References}

Bartholomew I.K. Parcel G.S., Kok G., Gotlieb N.H., 2001.

Interwention Mapping, Mayfield, Mountain View, California.

Bressers J.Th. A, Klok P J., 1988.

Fundarnentals for a theory of policy instruments International Joumal of Social

Economics, Vol 15 , no3/4, pp. 22-41.

Bressers ].Th.A, Lulofs K.R. 2002.

Charges and other policy strategies in Dutch water quality management, CSTM, Enschede.

Bruinin T.J.M.M., Bressers J.Th.A., Lulofs K.R.D., van de Veer A., 2003.

The use of covenants in target group policy. CSTM, Enschede.

Cyert R.M., March J.G., 1992.

A behavioural theory of the firm (2ed), Blackwell, Oxford, UK.

Doelen F.C.J., 1989.

Beleidsiristrumenten en energiebesparing (Policy instuments and

energyconserwation), Universiteit Twente, Enschede.

Green L.W., Kreuter M.W., 1999.

Health promotion planning (3ed), Mountain View, California.

Greer H., Jonkers R., Smits A., Görts C., Papadopolou K., Begley S., 2000.

The guide to change, a SAVE study, Aeneas, Best.

Klok P-J., 1991.

Een instrumenttheorie voor milieubeleid, (Instrument theory for environmental policy, Universiteit Twente, Enschede.

Kool R., Egmond C., van Rijn D., Jenniskens S., 2002.

Strategisch kader gebouwde omgeving (Strategic framework in the built chvironment), Novem, Utrecht.

Latour B., 1997.

De Berlijnse sleutel (The Berlin key), Van Genmep, Amsterdam.

Ligteringen J.J., 1999.

The feasibility of Dutch envitonmental policy instruments, Twente University

Press, Finschede.

Lulofs K.R.D., Lettinga B., 2003.

Instrumenten "mainstream market": $\mathrm{CO}_{2}$-reductie in de gebouwde omgewing,

Anstruments "mainstream market": COz reduction in the built environment), CSTM,

Universiteit Twente, Enschede.

Rogers E.M., 1995.

Diffusion of innovations, $4^{\text {th }}$ edition, The Free Press, New York.

Rogers E.M., 2003.

Diffusion of innowations, $5^{\text {th }}$ edition, The Free Press, New York. 
Schuddeboom J., 1990.

Milieubeleid in de praktijk (Environmental policy in practice), Universiteit Twente, Enschede.

Silverman D., 1970.

The theory of organizations, Basic Books, London.

Vermeulen W., 1992.

De vervuiler betaald, onderzoek naar de werking van milieusubsidies op vier deelterreinen van het milieubeleid (The polluter pays, research on the effect of subsidies in four fields of the environmental policy), Universiteit van Utrecht, Utrecht.

WRR, 1992.

Rapport 41, Milieubeleid, strategie, instrumenten en handhaafbaarheid

(Environmental policy, strategy, instruments and enforcement), SDU, Den Haag. 
Chapter 3

\title{
Target group segmentation makes sense: if one sheep leaps over the ditch all the rest will follow
}

This chapter is based on:

Egmond C., Jonkers R., Kok G., 2005.

"Target group segmentation makes sense" If one sheep leaps over the ditch, all the rest will follow, Energy Policy, accepted for publication.

\begin{abstract}
To meet the Dutch gowernmental goals of reducing $\mathrm{CO}_{2}$ emission, tatget groups must increase their rates of adoption of energy conserving innovations. In commission of the Dutch Ministry of Housing, Spatial Planning and the Environment, SenterNovem developed a strategy to effectively change the adoption behaviout of target groups. To develop strategies that take different rates of adoption into account, this study answers the questions: (1) how can different segments of the adopter market be categorised, (2) what are the characteristics of adopters in the different categories, (3) how do the determinants of behaviour of the adopter categoties differ, and (4) what policy instruments can be used to change them?

We conducted a secondary analysis of the data from the survey of housing associations. Based on the so-called self-designating method we constructed a scale of adoption rate, and we measured the rate of adoption of housing associations. Segments of this target group with different adoption rates and correspondingly diffetent characteristics were found: first adopters in a target group have a more visionary atutude, whereas the later adopters have a less visionary and more pragmatic attitude. We conclude that the selfdesignating method used in a survey provides explanation for the adoption speeds of different market segments. This explanation, in turn, can lead to more effective interventions.
\end{abstract}




\subsection{Introduction}

In meeting the requirements of the Kyoto-Protocol to reverse the human causes of global warming, the reduction of energy consumption and thereby reducing the emission of $\mathrm{CO}_{2}$ is a target of governmental policy. In 2004, the Dutch Government specifically established upper limits for $\mathrm{CO}_{2}$ emission for the year 2010. Heteby, the upper limit of $\mathrm{CO}_{2}$ emission from the built environment sector has been set at 29 Mton.

Against this background, the Dutch Mrrstry Housing. Spatial Planning and the Environment asked SenterNovem to develop a strategy to change the behaviour of target groups to support the governmental policy, and to develop an intervention strategy (Kool et al., 2002). Developing a policy that stimulates organizations to change their behaviour depends highly on knowing determinants of their behawiour and knowing what methods effectively influence those determinants to stimulate such a change. In 2004, we elaborated an approach aimed at the target group of housing associations in A Strategy to encourage housing associations to invest more in energy conservation (Egmond et al., 2005a). In that study we established the determinants of behaviour by surveying housing associations. We found that specific determinants strongly influence the energy-relevant behaviour of housing associations: attitude, feedback of peer organizations, and feedback fitom authorities. Furthermore, we found that the most effective policy instruments, including covenants with local authorities, have a facilitating and encouraging character.

We know from literature that target groups are not homogeneous in their behavioural change (Rogers, 1995; Kotler, 2003). Target groups can be segmented: on adoption speed, size and geographic location. Interventions to influence the behaviour of target groups will be mone effective if they take into account that actors differ in the speed with which they are ready to accept new circumstances or to adapt their behaviour to a new situation. In his "diffusion theory" Rogers (1995) denotes this as different rates of adoption.

Changes in target group behaviour always follow a gradual pattern. There is always a relatively small group of first adopters, followed by later adopters. In a nutshell, this theory states that some people or organizations are more receptive to changes and adopt these changes relatively fast, while others "wait and see" whether others implement the changes and what the consequences are.

To address the target groups properly, it is important to know which members of the targer group belong to the early market and which to the mainstream, and what their: characteristics are.

In the explorative study reported here, we investigated how the target group is segmented into categories based on speed of adoption (adopter categories) and how the behaviour of adopters belonging to those different categortes is effectively influenced. Specifically, we 
addressed four questions: (1) how can the different segments of the adopter matket be categorised, (2) what are the characteristics of the adopters in the different categories, (3) how do the determinants of behaviour of the adopter categoties differ, and (4) what policy instruments can be used to change them?

To address these guestions, we further analyzed the data from the survey of housing associations mentioned above to distinguish between adopters on the basis of speed of adoption (Egmond et al, 2005a). We then categorised them as early market and mainstream market adopters. We constructed two variables: adoption rate and visionarity. Note that we follow Rogers' definition of adoption rate as "the relative speed at which members of the target group adopt an innovation". We then compared the differences in behavioural determinants between the adoption categoties. In section 3.2 , we discuss the theoretical assumptions about adoption theory in mote detall.

\subsection{Theoretical assumption the diffusion theory of Rogers, and the high-tech marketing model of Moore}

According to the diffusion theory of Rogers (1995), an "innovation is an idea, practice or object that is perceived as new by an individual or another unit of adoption". "The diffusion theory describes the process of up scaling from small-scale to widespread implementation. And an innovation's rate of diffusion depends on the speed at which actors adopt new innovation.

Actors differ in their speed of adopting innovations, their adoption speed (Rogers, 1995) and they differ in adapting their behavionr to a new situation. The behavioural change of target groups often begins with a group of first-adopters, often called the "innovators", and "early adopters". After this group, the rest follow step-by-step: the "early majonty" * the "late majority", and finally, the "laggards" (Rogers, 1995).

Because of differences in adoption speed, the diffusion process of an innovation follows an S-shaped curve (Figure 1.2) when the number of adopters in a target group is plotted against time. Diffusion is at first slow, as there are relatively few innovators and early adopters. As the early majority (the mainstream) is reached, the diffusion tate increases, and it then decreases when the late majority is reached, followed by the hard-ro-reach laggands.

Rogers (1995) emphasizes that these adopter categories, described below, are ideal concepts. Although based on observations of reality, they are designed to make compatisons possible, and not simply an average of all observations about an adopter category. 
1. Innovators (2.5\% of the target group) have a venturesome character. They are gatekeepers with respect to the flow of innovations to the target group. They introduce innovations into a target group. They are acrively looking for new ideas and adopt the innovation first.

2. Early adopters (13.5\% of the target group) have a respectful character. They are fully integrated in the target group and have the highest degree of opinion leadership. They decide to adopt the innovation on a deliberate basis, inspired by vision.

3. Early majority ( $34 \%$ of the target group) have a deliberate character: they adopt new icleas just before the average member of the target group and adopt with willingness and prudence.

4. Late majotity ( $34 \%$ of the target group) have a sceptical character. They adopt new ideas just after the average members of the target group. The adoption is often an economic necessity resulting from peet pressure. The late majority does not adopt until most other members in the target group have already done so.

5. Laggards ( $16 \%$ of the target group) have a traditional disposition.

Moore (2002) has condensed this classification into two segments: the early market and the mainstream market. The early market (innovators and early adopters) is vision driven, and takes decisions based on strategic considerations. The mainstream market (early majority and late majority, and laggards), however, is basically motivated by a pragmatic attitude. The early majority adopts innovations somewhat earlier than the mean, with willingness and caution, and has a pragmatic orientation. The late majority approach innovations sceptically and conservatively. The laggards feel suspicious about innovations.

Moote (2002) argues that there is a distinct difference in attitude and willingness to adopt innovations between the early market actors and the mainstream market actors. This difference leads, in practice, to the situation that the early market actors give a warm welcome to innovative products, processes and ideas that are brought to the market for the first time.

Moore (2002) has used the diffusion theory of Rogers (1995) to develop a marketing model for innovations, the so-called "high-tech" marketing model. This model states that the way to develop a high-tech market is to work from left to right on the S-shaped curve (see figure 1.2). Marketing companies should focus first on the innovators; get them to adopt the innovation. Then move on to the early adopters, and increase their numbers, and so on, to the early majority, late majority, and even to the laggards. In this effort, companies which market innovative products or services, should use each "captured" segment as a reference base for their next strategy. 
In practice this process does not move smoothly because of discontinuities in the $S$-curve between the market segments. And the discontinuity between the early adopters and the early majority is a "chasm" because of the profound differences in attitude.

The early adopters expect to gain a lead on the competition through either lower product cost, faster time to the market, more complete customer service, or some other comparable business adwantage. They expect a radical discontinuity between the old ways and the new, and they are prepared to champion this cause against resistance. Being first, they are also prepared to bear with the inevitable bugs and sebacks that accompany any innovation just coming to the market. "The early majority, however, wants to buy a productivity improvement for existing operations. They aim to minimize the discontinuity with the old ways.

Moore (2002) compares the early market and the mainstream market as follows, see table 3.1 .

Table 3.1: Comparison early market actors and mainstream market actors (Adapted from Wieffels, 2002)

\begin{tabular}{|l|l|}
\hline Characteristics of the actors: & \\
\hline Early Market, visionarles & Mainstream, pragmatists \\
\hline $\begin{array}{l}\text { seek revolutionary advances: innovation, } \\
\text { creation }\end{array}$ & $\begin{array}{l}\text { seek evolutionary advances, } \\
\text { maintenance, problem solving }\end{array}$ \\
\hline motivated by future opportunities & motivated by current problems \\
\hline self-referencing & reference others perceived as similar \\
\hline avoid the herd & stay with the herd \\
\hline risk-taking & risk-aversion \\
\hline intuitive & analytic \\
\hline contrary & conformist \\
\hline seek what is possible & pursue what is probable \\
\hline will seek best technology, and innovative \\
products & will seek the best solution or functionality to \\
\hline momentary, local and specific & buy, they focus on leader of the market \\
\hline not better, but different & continuously, everywhere and everybody \\
\hline often curative & more of the same \\
\hline fast & preventive \\
\hline
\end{tabular}

Innowations often do not reach the mainstream because they do not meet the pragmatic needs of the mainstream. This causes the above-mentioned chasm between the early market and the mainstream market.

The mainstream market, dominated by pragmatists and conservatives, is not really interested in innovative technology; this group wants applications to solwe problems. The following example of the "green-label stable" illustrates this issue. "This example comes 
from an enwironmental and not an energy conserwation situation, but it illustrates exacty What we mean.

R\&R Systems developed a floor system to reduce the ammonia and manure problems in poultry farms. A simple system of tubes in the floor resulted in a constant temperature in the strable by withdrawing heat from the manute and storing it with a heat purnp. This "energy floor" also improved the chickens" well being, it resulted in more meat and lower mortality, and it also reduced the emission of ammonia to $50 \%$. A pay back period of 4 to 6 years was acceptable for the farmers. In this way about 1000 stables are now equipped with a heat pump under the rraclemark of the green stable (AgriHolland, 2001). Most of those farmers, howewer, do not even know that they have an energy-saving innovation, a heat pump, in their stable; they only know that their production increased and an environmental problem, the emission of ammonia, is solved!

An innovative product can successfully cross the above mentioned chasm between the early market and the mainstream market.

This chasm between the early market and the mainstream is not the result of "bad" technology or products, but rather of "incomplete" technology or products. (Wieffels, 2002). Moore (2002) has developed a method to cross the chasm: approach a small segment of the mainstream market (a niche market); consider which problem of this niche the innovative product or service should solve at a reasonable price. Then change and augment the intnovation in such a way that the product solves the problem (Levitt, 1986). In other words, win this niche to win the rest of the mainstream.

In the field of energy conservation we often encounter the problem of the chasm. Many innovative products reach only some parts of the early market and do not reach the mainstream. Many products in the field of sustainable energy are stayng in the chasm, i.e. solat-water heaters, photovoltaic systems. In order to solve the problem of climate change we need this method of crossing the chasm in the ficld of energy conservation. Therefore we choose the segmentation approach of Moore (2002), and focus on the segments of the early market and manstream market.

\subsection{Method}

To measure the adoption rate, we used Rogers" (2003) "self-designating" method. We have applied this method in the survey reported in A Strategy to encourage housing associations to invest more in energy conservation (Egmond et al, 2005a). In the survey, a questionnaire was used to interview 234 housing associations in the Netherlands (53\% of those approached). This target group totals 623 organizations. 


\section{Questionnaire}

The questionnaire addressed the following issues, and the answers to the questions were of an ordinal and nominal type (3- and 5-point scale).

\section{A. Background variables of the interviewees and association (11 items)}

Interviewees (4 items): position in the organization, policy-function or implementationfunction, seniority), and the association ( 7 items): size and age of the housing stock, financial position general and for energy conservation (EC), number of staff members

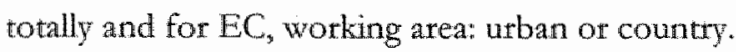

\section{B. Energy and environment related behaviour (19 items)}

These questions had both a general character (are measures taken), and a specific on the kind of measures. Example: Is thete a yearly maintenance plan, including energy conservation? a. yes; b. no; c. don't know; d. yes, but without energy conservation.

C. Attention for energy conservation in the organizational policy and in covenants (17 items)

Example: The taking of energy conservation measures is in accotdance with the policy of the association: a. Is part of the environmental policy plan (yes or no); b. is part of an energy conservation programme (yes or no); $c$. is part of large-scale maintenance planning (yes or no); d. otherwise.

D. Attitude towards energy conservation and environmental issues (32 items)

Example: Please give notice if you agree on the following statements: Subsidies on energy conservation measures are too small. Agree very much; agree a little; and do not agree.

E. Impact and support of peer organizations and other intermediary organizations in making decisions about energy conservation ( 9 items)

Example: Are you informed on the investments done by other associations in the field of energy conservation? a. yes very well; b. yes little; c. don not know; d. no, hardily.

F. Determination of the adoption category ( 3 items)

Based on the self-designating method (Rogers, 2003, p. 308).

Item 1: Compare the attitude of other housing associations with your association.

Item 2: Compare the decision speed of your housing with other housings associations. Item 3: Compare your housing association with other housing associations on the degree of taking energy conservation measures.

G. Chosen and preferred instruments, including the support of significant external parties (13 items)

Example: Can you, for each instrument, give an indication of the effect on taking energy conservation measures: a. a big stimulating effect; $b$, a moderate effect; $c$ none.

Instruments: a. improvement of subsidies; b. covenants; $c$. law and legislation; $\mathrm{d}_{\text {. support }}$ at the implementation of technical measures; e. diemonstration projects; $f$. introduction of an energy label for houses. 
Trained interviewers from a professional call centre contacted the organizations and asked members of the dominant coalition, the decision-makers to answer the questionnaire. The interviewers carried out the interviews with a Computer-Aided Telephone Interview (CATI) system. The respondents included members of the boards of directors $(7.3 \%)$, chiefs of the technical departments $(54.7 \%)$ and other staff members with a mandate on energy conservation or environmental issues $(38 \%)$.

The self-designating method consists of asking each respondent a number of questions to determine the degree to which he perceives himself or his organization to be an early adopter. In the reported survey we had included some items related to this subject.

To establish the adoption rate, we analyzed the responses to the following items in the questionnaire:

1. If you compare the attitude towards taking energy conservation measures of other housing associarions with your association. Do you find: (a) other housing associations more positive than your own association (score $=0$ ), (b) more negative than your own association (score $=2$ ), c. equal to your own association (score $=1$ ), (d) don't know (score $=0$ ).

2. If you qualify your association as to the speed with which decisions are made about encrgy conservation, is your association: (a) a trend-setter (score $=2$ ), (b) a trendfollower (score $=1$ ), (c) a laggard (score $=0$ ), (d) don't know ( score $=0$ ).

3. Is your housing association more active in taking energy conservation measures: (a) yes, we thave a higher ambition level than most others (score $=1$ ), (b) No (score $=0$ ), (c) don't know. (score $=0)$.

These three items form a scale of adoption rate having a minimum score of 0 and maximum score of 5 , see table 3.2 (Cronbach's alpha is .60).

Based on table 3.1, we categorised the items of the questionnaire in indicating visionarity. We used this categorization to construct the variable "visionarity", and used Cronbach's alpha to establish the consistency of the variable.

\section{Adoption rate and visionarity}

To compare the differences on visionarity between the two groups of adopter - the early market and mainstream market - of our sample we performed an analysis of variance between groups. We used Chi square test per item of the variable "visionarity" to asses if the adopter groups have a different score on the variable visionarity. 


\subsection{Results reviewing the target group study survey housing associations}

\section{Introduction}

We first present and discuss the results of the constructed variables, adoption rate and visionarity, and show how these variables ate related.

Secondly, we present an analysis of the determinants (Egmond, et al., 2005a) related to the adoption categories "early-market" and "mainstream-market" in order to assess if we have to implement different policy instruments.

\section{Establishing the adoption rates}

In table 3.2 we show the proportions of respondents that fell into each of the categories of adoption rate.

Based on the score on the adoption rate we know which housing associations belongs to the early market or to mainstream. Housing associations with an adoption rate $4-5$ belong to the early market, housing associations with an adoption rate of $0-1,2$ and 3 belong to the mainstream market.

Table 3.2: Adoption rate ands adoption categories

\begin{tabular}{|c|c|c|c|c|}
\hline $\begin{array}{l}\text { Adoption } \\
\text { rate }\end{array}$ & $\begin{array}{l}\text { Aoloption category according } \\
\text { Rogers }\end{array}$ & $n=205$ & $\begin{array}{l}\text { Adoption category } \\
\text { according Noore }\end{array}$ & $n=20$ \\
\hline Score 4-5 & $\begin{array}{l}\text { adoption speed fast: innovator } \\
\text { or early adopter, a trend-setter }\end{array}$ & $\begin{array}{l}22.9 \% \\
n=47\end{array}$ & early market & $\begin{array}{l}22.9 \% \\
n=47\end{array}$ \\
\hline Score 3 & $\begin{array}{l}\text { adoption speed higher than average: } \\
\text { early majority containing the niche } \\
\text { actors }\end{array}$ & $\begin{array}{l}28.3 \% \\
n=58\end{array}$ & \multirow[t]{3}{*}{$\begin{array}{l}\text { mainstream } \\
\text { market }\end{array}$} & \multirow[t]{3}{*}{$\begin{array}{l}77.1 \% \\
n=158\end{array}$} \\
\hline Score 2 & $\begin{array}{l}\text { adoption speed average } \\
\text { late majority }\end{array}$ & $\begin{array}{l}33.7 \% \\
n=69\end{array}$ & & \\
\hline Score $0-1$ & adoption speed slow or laggard & $\begin{array}{l}15.1 \% \\
n=31\end{array}$ & & \\
\hline
\end{tabular}

\section{The variable "visionarity"}

We constructed a variable sisionarity based on an analysis of the items used in the survey. The 14 items contributing to the variable visionarity were:

1. Did your housing association ever implement demonstration projects in the field of energy conservation?

Answer: Yes (score $=2)$, no (score $=0)$, don't know (score $=0$ ).

2. Did your housing association take more energy conservation measures than what is usual in large-scale maintenance? 
Answer: Yes, with more than awerage ambition (score=2), no (score=0), don't know $(s \cos e=0)$.

3. Has in the past your housing association invested in renewable energy?

Answer: Yes (score $=2$ ), no (score $=0$ ), don't know (score $=0$ ).

4. Has your association plans to invest in renewable energy? Answer: Yes (score=2), no (score $=0$ ), don't know (score $=0$ ).

5. Has your housing association invested in the following measures? (a) Solar-boilers; (b) Photovoltaic systems; (c) Heat pumps; (d) Low Temperature Heating, (d) Heat-recovery? Answer: Yes, no, don't know. (Minimum 0:0 measures, maximum score 5: 5 measures).

6. Has your housing association an investment plan for:

(a) Solar-boilers; (b) photowoltaic systems; (c) heat pumps; (d) low temperature heating systems, (e) heat-tecovery?

Answer: Yes, no, don't know. (Minimum 0: 0 measures, maximum score 5: 5 measures).

7. Has youm housing association established energy conservation measures or renewable energy options in an envitommental policy plan?

Answer: Yes (score $=2$ ), no (score $=0$ ), don't know (score $=0$ ).

8. Can you indicate if the following specific options are included in the policy plans?

(a) Solar boillers; (b) PV systerns; (c) heat pumps; (d) low temperature heating systems, (e) heat-recovery?

Answer: Yes, no, don't know Minimum 0 for don't know and 0 measures, maximum score $=5: 5$ measures $)$.

9. Does your housing association consider energy conservation as part of social entrepreneurship?

Yes (score $=2$ ), no (score $=0$ ), don't know (score $=0)$.

10. Does your housing association consider energy conservation strengthening the competition position?

Answer: Yes (score $=2$ ), no (score $=0)$, don't know (score $=0$ ).

11. Does your housing association consider taking energy conservation measures a prionity?

Answer: Yes (score $=2)$, no (score $=0)$, don't know ( $\operatorname{scote}=0)$,

12. Has your association a staff member responsible for energy matters?

Answer: Yes (score $=2)$, no $($ score $=0)$, don't know (score $=0)$.

13. Does your management have a positive attitude towards renewable energy?

Answer: Yes $(\operatorname{score}=1)$, no (score $=0$ ), don't know (score $=0)$.

14. Has SenterNovem, as change agent, impact on the decisions on taking energy conservation measures?

Answer: Yes $($ score $=2)$, no ( $\operatorname{score}=0$ ), don't know (score $=0)$.

"These 14 items form the variable "visionarity" of which the internal consistence Cronbach"s alpha $=.69$. The scale ranges from 0-38: from "no vision" to "very 
wisionary". About $5 \%$ (score $1-5)$ is little visionary, $75 \%$ is medium wisionary $(6-20)$, and about $20 \%$ is highly visionary (21-31). In table 3.3 we show the distribution of the scale.

Table 3.3: Visionarity scale

\begin{tabular}{|l|l|l|l|l|l|l|}
\hline Visionarity & $1-5$ & $6-10$ & $11-15$ & $16-20$ & $21-25$ & $26-31$ \\
\hline$\%$ & 4.3 & 23.7 & 28.9 & 20.8 & 15.2 & 7.1 \\
\hline
\end{tabular}

\section{Relationship between "adoption speed" and "visionarity"}

In the next step we determined the relationship between the variables adoption speed and visionarity. Moore's (2002) categories of adopters, the early market and the mainstream market, have respectively an adoption speed of $4-5$, and $0-3$. We related the variable "visionatity" to these categories (Table 3.4).

Table 3.4: Relation visionarity and adopter categories (Moore)

\begin{tabular}{|c|c|c|c|c|}
\hline \multirow{2}{*}{ adopter categories Moore } & \multirow[b]{2}{*}{$n$} & \multirow[b]{2}{*}{ mean } & \multicolumn{2}{|c|}{$\begin{array}{l}95 \% \text { confidence interval for } \\
\text { mean }\end{array}$} \\
\hline & & & lower bound & upper bound \\
\hline early market & 44 & 21.56 & 20.12 & 23.02 \\
\hline malnstream & 142 & 13.56 & 12.63 & 14.51 \\
\hline total & 186 & 15.45 & 14.53 & 16.39 \\
\hline
\end{tabular}

With Chi-square-test we determined the differences of all the items (criteria) of visionarity between the early market and the mainstream. Amost all items differed significantly, see table 3.5. Only for items 13 and 14 , respectively "the management has a positive artude towards renewable energy", and "has SenterNovem, as change agent, impact on the decisions on taking energy conserwation measures?" There was no significant difference between the early and mainstream market. In other words, SenterNovem had no extra influence on the early market, and the attitude of the management of all actors in the whole target group for renewable energy is positive.

Specifically, we found that the early market is more involved in demonstration projects, has investment plans in renewable energy, has implemented ranewable energy measures, and renewable energy is part of their policy plan.

The early market gives energy conserwation ptiority, sees energy conservation as part of social entrepreneurship, and has a staff member for energy conservation. 
Table 3.5: Chi-square values for the items of visionarity

\begin{tabular}{|c|c|c|}
\hline criteria for visionarity $n=234$ & $x^{2}-$ value & Df/p \\
\hline $\begin{array}{l}\text { 1. Did your housing association implement demonstration } \\
\text { projects in the field of energy consenation? }\end{array}$ & 19.99 & $1^{* * *+4}$ \\
\hline $\begin{array}{l}\text { 2. Do you think that your housing association takes in average } \\
\text { more energy conservation measures in large-scale } \\
\text { maintenance? }\end{array}$ & 47.98 & $1^{\text {m**; }}$ \\
\hline $\begin{array}{l}\text { 3. Has in the past yout housing association invested in } \\
\text { renewable energy? }\end{array}$ & 20.97 & 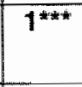 \\
\hline $\begin{array}{l}\text { 4. Has your housing association plans to invest in renewable } \\
\text { eniergy? }\end{array}$ & 8.39 & $1 * *$ \\
\hline $\begin{array}{l}\text { 5. Has your housing association invested in: a. Solar-bollers; } b \text {. } \\
\text { Photovoltaic (PV) systems; c. Heat pumps; } d \text {. Low Temperature } \\
\text { Heating, a. Heat- recovery? }\end{array}$ & 33.01 & $5^{+\infty+1+4}$ \\
\hline $\begin{array}{l}\text { 6. Has your housing association plans to invest in : a. solar- } \\
\text { boilers; } b \text {. PV systems; } c \text {. heall pumps; } d \text {. low temperature } \\
\text { heating systems, e. heat- recovery? }\end{array}$ & 12.70 & 5 \\
\hline $\begin{array}{l}7 \text { Has your housing association the taking of energy } \\
\text { conservation or renewable energy measures laid down in an } \\
\text { environmental policy plan? }\end{array}$ & 15.18 & 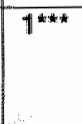 \\
\hline $\begin{array}{l}\text { 8. Has the policy plan chosen for: a. salar-boilers; } b \text {. PV } \\
\text { systems; c. heat-pumps; d. low temperature heating systems, } \\
\text { e. heat- recovery? }\end{array}$ & 28.45 & $5^{* \pm *}$ \\
\hline $\begin{array}{l}\text { 9. Energy conservation is considered a part of social } \\
\text { entrepreneurship? }\end{array}$ & 15.71 & 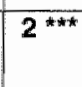 \\
\hline 10. Energy conservation strengthens the competition position? & 8.35 & $2^{*}$ \\
\hline 11. Taking energy conservation measures has priority? & 15.21 & $2^{* * *}$ \\
\hline $\begin{array}{l}\text { 12. The association thas a staff member responsible for energy } \\
\text { matters? }\end{array}$ & 13.45 & $2^{* * * *}$ \\
\hline $\begin{array}{l}\text { 13. The Management has a positive attitude towards renewable } \\
\text { energy? }\end{array}$ & 6.00 & $1^{\text {ns }}$ \\
\hline $\begin{array}{l}\text { 14. Has SenterNovem, as change agent, impact on decisions on } \\
\text { taking energy conservation measures? }\end{array}$ & 7.78 & $2^{\text {nis }}$ \\
\hline
\end{tabular}

\section{Determinants related to adoption categories}

In table 3.6 we present the results of a one-way anallysis of variance of the differences of the determinants of behaviour between the early market and mainstream market.

The measurement level of not all the determinants did not allow ws to use the ANOVA method for all the determinants.

Therefore we checked for all the determinants the differences between the determinants for the early and mainstream market with a Chi-square test. For readability purposes we only present the results of the ANOVA method: the differences of the means per determinant for the early and mainstream market. 
Table 3.6: Determinants related to adoption categories

\begin{tabular}{|c|c|c|c|}
\hline Determinants & $\begin{array}{l}\text { Early } \\
\text { market } \\
\text { mean }\end{array}$ & $\begin{array}{l}\text { Maln- } \\
\text { stream } \\
\text { mean }\end{array}$ & $\begin{array}{l}F \text {-value } \\
d f=1\end{array}$ \\
\hline 1 Priority of Energy conservation (EC) related to other fields & 1.83 & 1.48 & $11.75 *$ \\
\hline 2. Having a covenant with a local authority & 0.55 & 0.42 & $2.16^{\text {ns }}$ \\
\hline 3. Using housing cost saving as a motive for $E G$ & 2.79 & 2.51 & $9.03^{* *}$ \\
\hline 4. The presence of a champion for $E C$ & 2.30 & 1.68 & $20,20^{* * k}$ \\
\hline 5 Knowledge of the National Agreement Housing & 0.77 & 0.53 & $8.45 * *$ \\
\hline 6 The presence of specific knowledge in the area of EC & 2.76 & 2.48 & $6.89^{* *}$ \\
\hline 7 Plans to get an energy performance advice & 2.79 & 2.55 & $3.99^{\mathrm{nI}}$ \\
\hline 8 Housing comfort as a motive for energy conservation & 2.91 & 2.68 & $9.18^{\text {** }}$ \\
\hline $9 \mathrm{EC}$ as argument for competitive position & 1.17 & 0,84 & $8.29^{* *}$ \\
\hline 10 Priority of EC in policy & 272 & 2,01 & $43.76^{* * *}$ \\
\hline 11 improvement of the imago as a motive for $\mathrm{EC}$ & 1.51 & 1.32 & $3.31^{\text {मS }}$ \\
\hline 12 Attitude of the management to Renewable Energy options & 1.74 & 1.37 & 6.13 \\
\hline 13 Having an environmental policy plan with EC & 0.98 & 0.41 & 16.23 \\
\hline 14 Influence of the government on EC & 2.23 & 2.23 & $0.00^{\text {ตะ }}$ \\
\hline 15. Support in realization EC measures & 2.63 & 2,42 & $3.81^{\text {min }}$ \\
\hline 16. Stimulation of intersectoral cooperation & 1.45 & 1.71 & $10.65^{* * i 1}$ \\
\hline 17. Investments in Energy Conservation are not cost-effective & 2.32 & 2.07 & $3.00^{\text {nis }}$ \\
\hline 18. Perceived influence of the branch organization & 1.62 & 1.88 & $1.94^{\text {ns }}$ \\
\hline $\begin{array}{l}\text { Method ANOVA: }(n=205) \\
{ }^{*}=p \leq 0.05^{* *}=p \leq 0.01 ;{ }^{* * *}=p \leq 0.001^{m s i}=\text { non significant }\end{array}$ & $n=47$ & $n=158$ & \\
\hline
\end{tabular}

We found the early market to be significantly more involved than the mainstream as evidenced by the following determinants.

The early market actors give more priority to energy conservation related to other fields, they make energy conservation part of the policy of the organization, and have in generat enough specific knowledge in the area of energy conservation. They make energy conservation part of their core business by using, housing cost saving and housing comfort as arguments for investments in energy conservation. They use energy conservation as an argument for competitive position. Often they have a champion for energy conservation in their organization.

The manstream wants to "stay in the herd", preferring intersectoral cooperation much more so than the early market that opetates more autonomously.

The early market is active in renewable energy, has plans, and projects. On the issue of stimulation of intersectoral cooperation (determinant 16) we see that the mainstream market is more involved than the early market. The influence of the government is for both segments the same. 


\subsection{Discussion and conclusion}

Our study addressed four questions: (1) how can the different segments of the adopter market be categorised, (2) what are the characteristics of the adopters in the different categonies, (3) how do the determinants of behaviour of the adopter categories differ, and (4) what policy instruments can be used to change them?

The review of the survey of housing associations shows that the self-designating method resulted in a consistent scale, which measures the adoption category. The adoption categories of Rogers (1995) are related to the matket segments of Moore (2002). Moore's "early market" corresponds to Rogers "innovators and early adopters", and Moore's "mainstream market" corresponds to Rogers" "early majority, late majority and laggards".

We found that the early market is characterised by a highly visionary attitude. Their innovation decisions are based on strategic considerations. The early market of housing associations is more involved in demonstration projects, and is more oriented toward renewable energy. The early matket gives energy conservation priotity, sees energy conservation as part of social entrepreneurship, and has a staff member for energy conservation.

From the analysis of behavioural determinants, we conclude that policy matters are very important for the early market: they have an environmental policy plan including energy conservation and renewable energy, which is positively regarded by their management. Their decision-making is not largely influenced by third parties. And the early market is not very open to the activities of others in the sector. They perceive no influence from the branch organization.

The mainstream has a weakly developed policy or no policy at all. The mainstream wants to "stay in the herd", preferting intersectoral cooperation much more than the early market that operates more autonomously. Renewable energy is not an important issue for the mainstream. "The mainstream market is not very interested in innovative technology. And their decision-making is more influenced by the branch organization, and they are mote susceptible to governmental influence.

\section{Some conclusions for interventions}

When an innovation is being introduced into the market, the early market should be targeted. To reach this early market, instruments should be based on the visionaty artitude of the early market. Furthermore, instruments should support the activities of the early market such as feasibility studies and demonstration projects. Because money is not a motivating factor for early market organizations, general subsidies do not stimulate this segment. These subsidies do not influence their decision-making process. If there are subsidies, they will, of course, apply for them: they perceive this as a reward. This effect is 
the so-called "free rider" effect (Jeeninga et al., 2002). Moreover, because they act mainly on their own, broad covenants are not appropriate for this segment. However, agreements with the individual organizations are effective.

In order to reverse the human causes of global warming it is necessary that more innovative energy conservation technology is adopted on a large scale and reaches the mainstream. To realize this, the method of crossing the chasm can be very helpful.

When an already-introduced innovative technology has to be scaled up in order to reach policy goals of reducing $\mathrm{CO}_{2}$ emissions, the intervention strategy should target the mainstream. Instruments should use more pragmatic arguments such as reliability and quality. Because the mainstream is more interested in solving problems, they will adopt an innovation that solves a problem. Innovations should make their lives easter in a reliable way.

Furthermore, the mainstream is more interested in products rather than innovative technology. They are especially interested when market leaders provide the products and, therefore, interventions should be developed together with market lenders to reach the mainstream. To teach the mainstream the slogan should be: "Don't tell them, sell them?"

To cross the chasm between the early market and the mainstream, aim the first interventions almost exclusively at a well-defined niche in the mainstream, the opinion leaders, for example. Then provide good support for organizations that adopt the innovation. These organizations will start word-of-mouth advertisement, which is very effective because organizations in the mainstream use each other as reference for the adoption of innovations. These organizations, and their experience, can then be used to influence the rest of the mainstream.

As mentioned, mainstream organizations like to stay with the herd. For that reason, an effective strategy shows that other members of the target group invest in the innowation and it informs about market developments and the relative position of the member in relation to the rest of the herd. Reference figures as benchmarks work well. Furthermore, covenants effectively reach the mainstream, because mainstream organizations, wanting to stay with the herd, are susceptible to peer pressure.

Furthermore, stimulate the intersectoral cooperation of mainstream organizations, and position energy conservation as part of the core business of housing associations by relating energy conservation to housing costs, housing comfort and quality.

In this chapter we have only sketched some examples of how instruments can meet the different characteristics of different market segments. In table 3.7 we show some examples. 
Table 3.7: Early market and mainstream instruments

\begin{tabular}{|l|l|}
\hline Eariy Market Instruments & Mainstream Instruments \\
\hline Individual agreements & Covenants \\
\hline Subsidies for feasibility studies & Rebates for investments \\
\hline Contests as incentive. & ndividual advice \\
\hline Demonstration project as demonstrator & Demonstration projects showing possibilities \\
\hline Knowiedge about innovative products & Benchmarks \\
\hline
\end{tabular}

In general, we conclude that the differences in attitude towards and thus different perception of innowations between the early matket and mainstream seem to justify using different instruments to target these segments. Interventions aimed at the early market should focus on the visionary attitude of this group, while interventions aimed at the mainstream should focus on pragmatic atguments: solving problems and reliability

This study suggests that the two groups base their decisions on different factors and therefore, in chapter 4 we will focus on the difference between early market and mainstream instruments from the perspective of decision-making process. 


\section{References}

AgriHolland, 2001.

Broeikasgasemissie door veehouderij blijft afnemen (Emission of greenhouse gases decreases steadily), Article in electronic Newsletter Of AgriHolland, (15-02-2001).

Egmond C., Jonkers R., Kok G., 2005a.

A strategy to encourage housing associations to invest in energy conservation, Energy Policy, 33, pp. 2374-2384.

Jeeninga H., Honig E., Dril A., Harmsen R., 2002.

Effect van energie- en milieubeleid op broeikasgasemissies in de periode 1990-2000

(Results of energy and environmental policy on greenhouse gas emissions in the period 1990-2000), ECN, Petten.

Kool R., Egmond C., Rijn D. van, Jenniskens S., 2002.

Strategisch kader gebouwde omgeving, (Strategic framework in the built environment), SenterNovem, Utrecht.

Kotler P., 2003.

Marketing management, $11^{\text {th }}$ Edition, Prentice-Hall, Pearson Education, New Jersey.

Levitt T., 1986.

The marketing imagination, The Free Press, New York.

Moore G., 2002.

Crossing the chasm, Harper Collins, New York.

Rogers E.M., 1995.

Diffusion of innovations, $4^{\text {th }}$ edition, The Free Press, New York.

Rogers E.M., 2003.

Diffusion of innovations, $5^{\text {th }}$ edition, The Free Press, New York.

Wieffels P., 2002.

The chasm companion, Harper Collins, New York. 


\title{
Chapter 4 \\ One size fits all? \\ Policy instruments should fit the segments of target groups
}

\author{
This chapter is based on: \\ Egmond C., Jonkers R., Kok G., 2005. \\ One size fits all? \\ Policy instruments should fit the segments of target groups. \\ Energy Policy, accepted for publication.
}

\begin{abstract}
In order to meet the Kyoto $\mathrm{CO}_{2}$ reduction targets, technical innowations in the field of energy-efficiency must be diffused more tapidly and on a larger market scale. Markets develop gradually however, especially if innovations are involwed. Diffusion starts with the innovators and early adopters (the early market), followed by the mainstream market (the early and late majority), and ends with the laggards. The actors in these matkets differ in their willingness to adopt innovations: the early market actors have a visionary attitude, and the mainstream market actors are more pragmatic. In order to choose policy instruments that will most effectively influence these two markets with the target group of housing association, we addressed the following two questions: (1) what are the differences between the early and mainstream matket actors from a behavioural-change point of view, and (2) in what way do existing policy instruments differ in influencing the behaviour of these actors? We analyzed early market and mainstream decision-making behaviour, and how the active ingredients in policy instruments specifically target the characteristics of the two markets. Mainstream instruments should intervene as early as possible in the decision-making process and emphasize communication about advantages such as comfort and quality in addition to money and energy savings, and present energy conservation as a solution to an actual problem. Instead of bureaucratic subsidy systems for the mainstream, the motto should be "cash on the barrel-head". Early market actors are highly internally motivated, implying that early market interventions have to be challenging and facilitating.
\end{abstract}




\subsection{Introduction}

To reverse the human causes of global warming, the Dutch government has established $\mathrm{CO}_{2}$ reduction targets within the framework of the Kyoto Protocol. As a means to reduce $\mathrm{CO}_{2}$ emissions, the Dutch government stimulates reducing energy consumption. The Dutch Ministry of Housing, Spatial Planning and the Environment has especially targeted the users and owners of buildings as being large energy consumers.

To meet the emission limits set for the Built Environment, which amounts to 29 Mton $\mathrm{CO}_{2}$ for 2010, measures and innovations in the field of energy-efficiency must be implemented on a large scale. In chapter 3 we concluded that target groups implement energy-efficiency only gradually, and this is especially so if they must adopt innovations (Egmond et al, 2005b). Against this background, the Dutch Ministry of Housing and Environmental Affairs asked SenterNovem to develop an intervention strategy to change the behaviour of target groups to more quickly adopt energy conservation innovations and, thus, support governmental policy.

Developing a policy that stimulates organizations to change their behaviour depends highly on knowing the determinants of their behaviour and knowing what methods effectively influence those determinants to stimulate such a change. In chapter 2 , we elaborated on this approach as it was applied to the target group of housing associations (Egmond et al., 2005a).

As members of a target group adopt an innovation, the innovation diffuses into the target group market. It is generally accepted that diffusion starts with the "innovators" and "early adopters" of the market. The "early" and "late majority" then follow, and finally the "laggards" complete the process (Rogers, 1995). Furthermore, Moore (2002) points out that, although the adoption of innovations starts in the so-called "early market", the "mainstrean marker" follows only if certain conditions are met. In other words, the mainstream narket members differ from the early market in their willingness to accept innovations. While the early marker is more strategic and visionary, the mainstream has a much mote pragmatic attitude. 'To effectively influence the decision-making behaviour of these target groups, their differences in accepting new circumstances or adapting their behaviour to new simuations must be taken into account. In his "diffusion theory", Rogers describes these groups as having "different rates of adoption" (Rogers, 1995).

Civil servants preferably choose policy instruments that have a so-called generic character - one size fits all (VROM-raad, 2001). But we think that a more effective strategy would be to choose existing instruments that fit the characteristics of the target group. In a previous study, reported in chapter 3 , we focused on the different characteristics of the 
early and mainstream markets within the sector of housing associations. We showed how to establish the early and mainstream markets and establish their characteristics (1.gmond et $a$, , 2005b). In this chapter we report on our analysis of this study where we specifically addressed the following questions: (1) What are the differences between the early and mainstream matket from a behavioural-change point of view, and (2) In what way do existing policy instruments differ in influencing the behaviour of early market and mainstream market actors?

The theoretical and, in a sense, reflective research consisted of two parts: (1) an analysis of early market and mainstream decision-making behaviour (section 4.2), and (2) an analysis of how the active ingredients in existing policy instrwments (Egmond et al, 2005a) specifically target the characteristics of the early and mainstream markets (section 4.3). This analysis is party based on a study by Lalofs and Lettinga (2003) concerning existing mainstream market instruments. We combined their analysis with the results of an analysis of the effects of some actual policy instruments. In section 4.4 we combine the results of (1) and (2) in an overview of instruments suited for the early market and mainstream market.

\subsection{Process of change in early market actors and mainstream market actors}

To understand and analyze the decision-making processes of early and mainstream market actors within the housing association target group, we developed a behavioural model based on the planning model of Green and Kreuter (1999). This model prowides a framework to study and find the behaviour-explaining factors of target groups through surveying the target group. With this model we described the characteristics of the early and mainstream market actors within target group of housing associations. We then analyzed the characteristics and, especially, the differences between the wo groups. This analysis answered the first research question.

In this section we report the results of an analysis of the behaviour of the target group of housing associations. This makes clear that the energy-conservation behaviour of housing associations is planned behaviour: housing associations have plans, invest, take part in demonstration projects (Egmond et al., 2005a).

Having established that the behaviour is rational, we went on to adapt Green and Krevter's model of rational individual behaviour to otganizations. This model clearly identifies where, in the process of behavioural change, different types of interventions will be most effective. This model is presented later on in this section. 
In this section we also report on our comparison of the behavioural characteristics of the early market actors and mainstream actors within the target group of housing associations. These characteristics we then combined with our behavioural model, and this led to a list of "sensitive" behavioural determinants for each segment, related to the process of change, that policy instruments can mosteffectively target.

\section{Analysis of the behaviour of housing associations}

In chapter 2 , we defined the desired behaviour of each housing association to be "taking energy conservation measures in their housing stock" (Egmond et al, 2005a). In that study we surveyed the target group of housing associations using a questionnaire. The sum of the scores of nine items on the questionnaire resulted in the value of the variable "taking energy conservation measures in the housing stock". This formed a scale of 0 (minimum) till 18 (maximum) and Cronbach's alpha was 0.75 . The nine items were:

1. The attention that a housing association pays to taking energy conservation measures in their houses. Answers: a. much, (score=2) b. fairly, (score $=1)$, c. little, (score=1), d. none, (score $=0$ ).

2. The implementation of demonstration projects in the freld of energy conservation in the past. Answers: a. yes, (score $=2)$, b. no, (score $=0)$, c. don't know, (score $=0)$.

3. The intensity of energy conservation measures taken in the scope of large-scale maintenance.

Answers: a always, (score $=2)$, b. often, (score $=1$ ), c. sometimes, (score $=1)$, d. never, (score $=0$ ).

4. The level of ambition related to taking energy conservation measures.

Answers: a. higher than usual, (score $=2)$, b. no, (score $=0)$, c. don't know, (score $=0$ ).

5. The consolidation of procedures for taking energy conservation measures in plans for latge-scale maintenance.

Answers: a. yes, (score $=2)$, b. no, ( (core $=0)$, c. don't know, (score $=0)$.

6. "The existence of a yearly maintenance plan that includes energy conservation measures. Answers: a. yes, (score $=2)$, b. no, (score $=0)$, c. don't know, (score $=0)$.

7. Investments in renewable energy options in the past.

Answers: a. yes, (scone $=2$ ) b. no, (score $=0)$, c. don't know, (score $=0$ ).

8. The number of renewable energy options, 4-5 measures, (score $=2$ ), 1-3 measures ( $\operatorname{score}=1), 0$ measures ( $\operatorname{score}=0$ ).

9. Plans to invest in renewable energy options in the future.

Answers: a. yes, (score $=2), b$. no, (score $=0)$, c. don't know, $(\operatorname{score}=0)$.

From the survey, we concluded that housing associations behave rationally when it comes to energy conservation. They make plans, invest, take part in demonstration projects, and 
they draw attention to their activities. Green and Kreuter's model is especially sutable for rational, and planned behaviour. In the next section we elabotate on how we applied this model to the energy conservation behaviour of housing associations.

\section{The behavioural model}

Green and Rreuter (1999) have modelled change processes of individuals, often used to influence their health situation. By making an assumption often used in policy science we adapted the model for the change of behaviour of organizations. This assumption is best explained in three logical steps. First, as described by Silverman (1970), organizations are by definition sets of individuals with common interests and with supporting coordination mechanisms. Second, a change in the behaviour of an organization is preceded by a change in attitude of the organization. Third, the behavioural attitude of an organization reflects the behavioural attitude of the dominant coalition of individuals within the organization. This coalition of individuals has the most powerful position regarding certain decisions in the organization (Cyert and Marcla, 1992). In our further analyses we consider a housing association as one subjective tational actor (Bressers and Klok, 1988). Green and Kreuter's model provides a framework to study and to find the behaviourexplaining factors by surveying the target groups. "The model is based on the assumption that if we change the rational and situational determinants of behaviour, we eventually induce behavioural change. It assumes that there are three main clusters of behavioutal determinants and an empirical study can reveal what the relevant determinants are for a specific behaviour of a specific target group (Figute 4.1).

As we saw in chapter 2 operationalizing the Green and Kreuter model yielded a partial explanation of total variance of behaviour and, specifically, of the variable "taking energy conservation measures in their housing stock". In that study, we could explain $28 \%$ of the variance of that variable (Egmond et al, 2005a).

\section{The model of Green and Kreuter (1999)}

In their PRECEDE-PROCEED model. Green and Kreuter (1999) describe three general categories of factors (determinants) that affect behaviour and the context that influences it. Each factor has a different influence on behaviour.

(1) Predisposing factors: the internal antecedents to behaviour, belonging to the organization. They predispose the behaviour: awareness and knowledge, organizational norms, subjective norms, attitude, self-efficacy and intention.

(2) Enabling factors: the external antecedents to behaviout. "They are conditions of the context and facilitate the performance of action of organizations. Enabling factors relate to resources and new skills. Resources include financial, rechnical and organizational (judicial) resources. 
(3) Reinforcing factors: are those consequences of an action that determine whether the actor teceives positive or negative feedback and support afterwards. Reinforcing factors include feedback from peer organizations, advice and feedback from experts and feedback from powerful and significant organizations (e.g. authorities offering subsidies with a stimulating purpose and enforcing obligations), and feedback from customers. In figure 4.1 "Determinants and behaviour" we sketch the relationships between the various factoris.

Figure 4.1: Determinants and behaviour (this figure is adapted from Green \& Kreuter (1999) p.155, PRECFDE-PROCEED model)

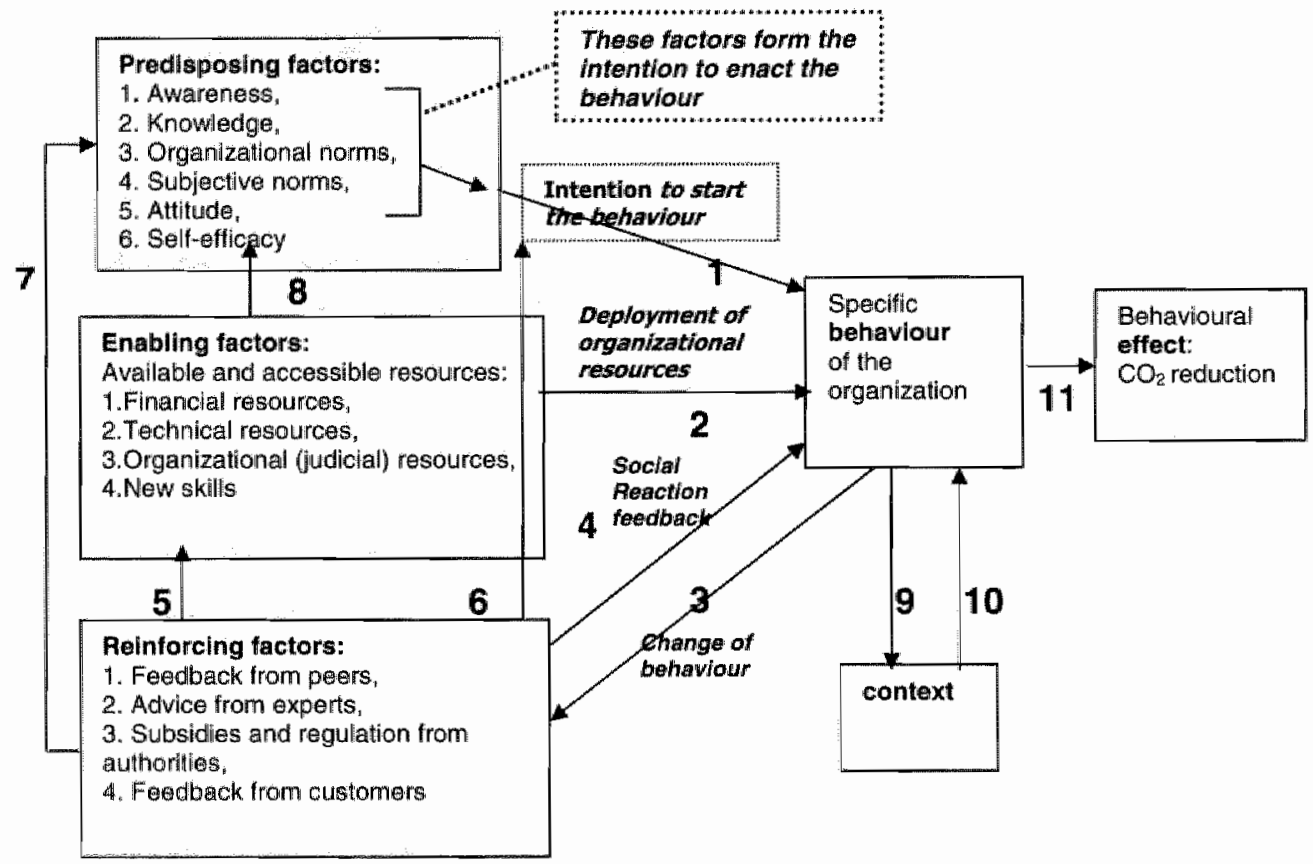

Normally the sequence of actions within an organization is as follows (Steckler et al., 2002). First, the organization becomes aware of a problem or need giving the organization an initial reason or motivation to pursue a given course of action. "The organization becomes aware of this problem or need through internal information or analyses by experts (Daft, 2001). Sometimes experiences of peers raise the organization's awareness of a problem, and sometimes the authorities cause a problem with new legislation. A need ot a problem is a state of dissatisfaction or frustration that occurs when an organization's desires outweigh the organization's actualities (Rogers, 1995). Most of these problems or needs are routine, so most problems are solved in a routine way following standard protocols (Cyert and March., 1992). This is what we call "habitual 
behaviour". If an problem is new or does not regularly occur, than a search for solutions starts.

In the search for solutions knowledge of alternatives is gathered and evaluated. The organization weighs the advantages and disadvantages of behawiounal alternatives and makes a decision. Organizations see advantages and disadwantages (costs and benefits) in terms of the self-interest of the organization. But organizations are not only concerned with money, but also with other costs and benefits such as comfort, quality, image and perceived uncertainty. Also organizational norms ot the regulations of the authorites influence their assessments of advantages and disadvantages (Bressers and Klok, 1988), the subjective norm describes the influence of the behaviour of peer organizations.on the weighing of the importance of the behaviour.

And this makes up their attitude. If an organization perceives its own capacity for successfully organizing and implementing the behaviour as positive (self-efficacy), then it will more easily adopt that behaviour (Bandura, 1986).

\section{Explanation of Figure 4.1 "Determinants and behaviour".}

All the predisposing factors - awareness, knowledge, organizational norms, subjective norms, attitude and self-efficacy - form the intention (1) for making the decision to implement the solution. This intention may suffice to start the behaviour, but it will not be carried out unless the organization has the required resources and skills.

After the intention (1) to implement is decided, and if no bartiers occur, the organization deploys organizational resources (2) to enable the action. This leads to a change in behaviour (3) followed by an emotional, physical or social reaction to the behaviour, the reinforcing factor. This reinforcing factor (feedback) directly strengthens (4) the behaviour and strengthens (5) the search for mobilization of future resources, and it strengthens (6) the intention. Similarly, tewards and positive feedback make the behaviour more attractive on the next occasion - today's reinforcing factor becones tomorrows predisposing factor (7). Also the factors predisposing the behaviour are positively influenced by the availability of resources (8).

Furthermore, the behaviour of organizations affects the context (9), and a change in context will influence behaviour. If, for example, organizations wnite in buying energy, the price they pay for energy may decrease. On the other hand, if outdoor temperatures drop - a change in the context - energy prices may rise and influence behaviour; organizations will invest in energy conservation measures (10). After implementation, the actor actively seeks for confirmation of his or her decision by feedback from peers or experts, (3) and (4).

The model implies that various types of interventions at various points can lead to the desired change in behaviour, adopring energy conservation innovations, and reduce $\mathrm{CO}_{2}$ emissions (11). 


\section{Characteristics of the early market and mainstream market actors}

Actors differ in their speed of accepting innovations and differ in adapting their behaviour to a new situation. Rogers (1995), in his diffusion theory, calls this the "adoption speed". The adoption of new behaviour by target groups often develops in the following way. A group of "innovators and early adopters" (Rogers, 1995) or the "early market" (Moore, 2002) change their behawiour.

After this group, the rest follows step by step: Rogers calls this group the "early majority, the late majority and the laggards" and Moore calls them the "mainstream market". Because governmental policy in the Netherlands wishes the mainstream of housing associations to adopt more innovative technology, we stick to the Moore two-segment classification: the "early market" and the "mainstream market". In chapter 3 we found that $22.9 \%$ of the housing associations belonged to the early market and $77.1 \%$ to the mainstream market (Egmond et al., 2005b).

According to Moore (2002), the early market actors can be characterised as vision driven, and take decisions based on strategic considerations. In contrast, the mainstream market actors are motivated by a pragmatic attitude. Moore argues that a "chasm" in atritude between the early market actors and the mainstream market actors causes a clear difference in the willingness of the two groups to adopt innovations. We confirmed this in our earlier analysis (Egmond et aL,, 2005b) where we found that sometimes innovations are not accepted by the mainstream actors because these innovations are not yet ready for the mainstream actors. This phenomenon is not the result of bad technology or bad producrs, but rather the result of incomplete products (Wieffels, 2002).

The early market actors, being the first to implement a change in their sector, expect to get a jump on the competition, whether from lower product cost, faster time to the market, more complete customer service, or some other comparable business advantage. They expect an radical discontinuity between the old ways and the new, and they are prepared to champion this cause against resistance. Being first, they are also prepared to bear with the inevitable bugs and setbacks that accompany any innovation just coming to the market.

The mainstream actors, on the other hand, want to buy a productivity improvement for existing operations. They are looking to minimize the discontinuity with the old ways. In table 4.1 we present Moore's comparison of the early market and the mainstream market, and their orientation towards change (Caluwe and Vermaak, 2002).

The mainstream actors are not interested in innovative technology as such; they want applications to solve problems. If, however, the innovative technology solves a problem, they will buy and use the innovative product as part of a problem-solving application. 
Table 4.1: Comparison early market actors and mainstream market actors (Adapted from Wieffels, 2002)

\begin{tabular}{|c|c|}
\hline \multicolumn{2}{|c|}{ Charaoteristics of the actors: } \\
\hline Early Narket, visionarles & Mainstream pragmatists \\
\hline $\begin{array}{l}\text { seek revolutionary advances: } \\
\text { innovation, creation }\end{array}$ & $\begin{array}{l}\text { seek evolutionary advances, } \\
\text { maintenance, problem solving }\end{array}$ \\
\hline motivated by future opportunities & motivated by current problems \\
\hline self-referencing & reference others perceived as similar \\
\hline avoid the herd & stay with the herd \\
\hline risk-taking & risk-aversion \\
\hline intuitive & analytic \\
\hline contrary & conformist \\
\hline seek what is possible & pursue what is probable \\
\hline $\begin{array}{l}\text { will seek best technology, and } \\
\text { innovative products }\end{array}$ & $\begin{array}{l}\text { will seek the best solution or functionality } \\
\text { to buy, they focus on leader of the market }\end{array}$ \\
\hline momentary, local and specific & continuously, everywhere and everybody \\
\hline not better, but different & more of the same \\
\hline often curative & preventive \\
\hline fast & slow \\
\hline
\end{tabular}

An illustrative example of this occurred in the agricultural sector where, at frest, the marketintroduction of the heat pump as an innovative product in sustainable energy was hardly successful. Thereafter, $R$ \& $R$ Systems developed it into a floot system to treduce the ammonia and manure problems in poultry farms. A simple system of tubes in the floor resulted in a constant temperature in the barn by withdrawing heat from the manure and storing this heat with a heat pump. This "energy lloor" was better for the well being of the chickens, which resulted in more meat and less mortality. But also the emission of ammonia was reduced by $50 \%$. A pay back period of 4 to 6 years was acceptable for the farmers. In this way about 1000 barns are equipped with a heal pump under the trademark of the "green stable" (AgriHolland, 2001).

\section{Change processes for early market actors and mainstream market actors}

We combined the characteristics of the early matket actors and manstream market actors with the alements of the behavioural model described in figure 4.1. The results of the combination are presented in table 4.2 beween brackets we refer to the characteristics of the early market and mainstream actors from table 4.1). 
Table 4.2: Change process for early market and mainstream actors

\begin{tabular}{|c|c|c|}
\hline & Eary manket achors & Mainstream maiket actors \\
\hline 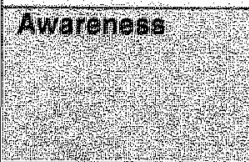 & $\begin{array}{l}\text { - Active information seeker } \\
\text { - Looking for fulure chances } \\
\text { - Finds the reason himself } \\
\text { (seek advances) }\end{array}$ & $\begin{array}{l}\text { - React to current problems, caused by internal } \\
\text { or by external sources such as laws and } \\
\text { permits } \\
\text { (motivated by current problems) }\end{array}$ \\
\hline Trowidge & $\begin{array}{l}\text { - About innovative and revolutionary } \\
\text { products } \\
\text { About strattegic projects } \\
\text { (Motivated by future opportunities) }\end{array}$ & $\begin{array}{l}\text { - About experiences of peers } \\
\text { - About standard products and solutions for } \\
\text { standlard problems } \\
\text { - Market leader proposals } \\
\text { (Seek best solutions to buy) }\end{array}$ \\
\hline organizanional & $\begin{array}{l}\text { Sensitive for corporate social } \\
\text { responsibility } \\
\text { (seek revolutionary advances) }\end{array}$ & $\begin{array}{l}\text { Comply to what the government wants } \\
\text { - Experiences of others } \\
\text { - Branch standards are important }\end{array}$ \\
\hline Subjectuenorm & $\begin{array}{l}\text { - Self referencing } \\
\text { - Watching other early adopters } \\
\text { (seek advances) }\end{array}$ & $\begin{array}{l}\text { - Influenced by experiences of peers } \\
\text { (reference others perceived as similar and stay } \\
\text { with the herd) }\end{array}$ \\
\hline 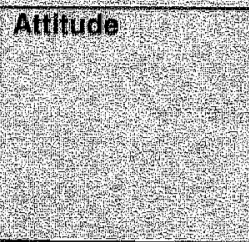 & $\begin{array}{l}\text { - Risks are not so important } \\
\text { - Visionary and strategy minded } \\
\text { - Imago important } \\
\text { - Long-term oriented } \\
\text { - Entrepreneur } \\
\text { - National or global oriented }\end{array}$ & $\begin{array}{l}\text { - Awoid risks } \\
\text { - Are pragmatic } \\
\text { - Weigh pros and cons } \\
\text { - Short-term oriented } \\
\text { - Administrator } \\
\text { - Locall orientation }\end{array}$ \\
\hline Sorreficacy & $\begin{array}{l}\text { - Often trust own expertise } \\
\text { - Staff can solve own problems } \\
\text { (self-referencing, seek best } \\
\text { technology) }\end{array}$ & $\begin{array}{l}\text { - Rely more on external experts } \\
\text { (seek besit solutions, risk-aversion) }\end{array}$ \\
\hline Wirition & $\begin{array}{l}\text { - Work with strategic policy plans } \\
\text { - Have specific goals and planning } \\
\text { (revolutionary advances, often } \\
\text { curative) }\end{array}$ & $\begin{array}{l}\text { - Have simple implementation plans and } \\
\text { standard protocols } \\
\text { (more of the same, preventive) }\end{array}$ \\
\hline Enabing ractors & $\begin{array}{l}\text { - External resources are not really } \\
\text { needed, they have own financial } \\
\text { resources } \\
\text { (risk-taking) }\end{array}$ & $\begin{array}{l}\text { - Financial resources play a major role } \\
\text { - Expert advice is often needed } \\
\text { (risk-aversion) }\end{array}$ \\
\hline $\begin{array}{l}\text { Reinforing } \\
\text { factors }\end{array}$ & - They like rewarding gestures & $\begin{array}{l}\text { Are sensitive for feedback of peers } \\
\text { - Feedback of experts is often needed, } \\
\text { - Like advice from the branch-organization } \\
\text { (stay with the herd) }\end{array}$ \\
\hline $\begin{array}{l}\text { Ebhavioural } \\
\text { mharpotertstos. }\end{array}$ & $\begin{array}{l}\text { - Work on their own } \\
\text { - Decide and implement fast } \\
\text { - They like projects } \\
\text { - Take risks }\end{array}$ & $\begin{array}{l}\text { - Stay with the herd } \\
\text { - Seek for intersectoral cooperation with peers } \\
\text { - Solutions that peers have implemented } \\
\text { - Choose for the best solution available sold by a } \\
\text { market leader } \\
\text { - Take time and are more reactive }\end{array}$ \\
\hline $\begin{array}{l}\text { Environmental } \\
\text { characteristics }\end{array}$ & $\begin{array}{l}\text { Often meet institutional barriers } \\
\text { (Contrary, self referencing) }\end{array}$ & $\begin{array}{l}\text { - Follow institutional paths } \\
\text { (stay with the herd) }\end{array}$ \\
\hline
\end{tabular}




\subsection{Analysis of policy instruments}

Our second question asks: in what way do existing policy instruments differ in intuencing the behaviour and decision-making process of early market and mainstream actors? This question addresses the active ingredients of policy instruments. In the decision making process of organisations regarding the perception of advantages and disadvantages of behavioural alternatives plays a major role. Governmental policy gives some of these altematives priority; therefore policy instruments can infuence this process in several ways. Firstly by increasing the information within the organisation about alternatives and the involved momentary and future costs and benefits of those altematives. Secondly by changing the costs and benefits of them. And thirdly by influencing the appreciation of involved costs and benefits (Bressers and Klok, 1988).

We answered the question by linking the active ingredients of policy instruments to our behavioural model. There are four main types of instruments: judicial, economic, communicative, and structural provisions. In chapter 2 we discussed the four types and their effects on behavioural determinants (Egmond et al., 2005a). Here we discuss their specific effects on the early market and mainstream actors.

\section{Judicial instruments}

Judicial instruments - laws and legislation - prescribe behaviour and set norms. Not complying with the norms causes a problem. Therefore, a judicial instrument creates an external motivation. It expresses public values or social interests that do not allways coincide with the organization's values and, thereby, it imposes itself on the organization as a problem to sollve.

A judicial instrument creates a norm for the desired behaviour of the entre target group and consolidates the intended policy effect. Judicial instruments infuence behawiour of both the mainstream actors and eatly market actors. An example in the Netherlands is the Energy Performance Standard (EPS). The EPS is a calculated dimensionless value that indicates the annual energy use of the building. An EPS of 1.4 indicates $1200 \mathrm{~m}^{3} \mathrm{gas}^{2}$ consumption per year, an EPS of 1.0 indicates $1000 \mathrm{~m}^{3}$ gas consumption per year. The EPS was implemented in 1995 and shappened from 1.4 in 1995 to 1.2 in 1998 and to 1.0 in 2000.

The EPS rargets the decision-making process at the start: when applying for a building permit (Essers and Mooij, 2001). It is therefore suited to getting the mainstream on the move. We see that for new buildings the conditions are met, but for cxisting buildings we see that the instrument is not so effective, because of the complexity of the situation for an existing building. 
We assume that the active ingredients of regulations are twofold. Firsty, the normative aspect or societal agenda-setting infuences the evaluation of the costs and benefits of the alternatives. And, secondly, monitoting and enforcement activities actually change the costs and benefits of compliance and non-compliance. Success depends, of course, on strict monitoring and enforcement, and severe penalties. Factors that hinder success include little policical support, especially on the local leve, little bureaucratic capacity and regulatory captute (Lulofs, 2001).

Voluntary agrements are a milder form of judicial instruments. A covenant, which is an example of voluntary agreernents, works well if a clear result-oriented obligation is made and not just an effortoriented obligation. "This instrument meets the specific characteristics of the mainstream: staying with the herd and using others as reference.

Furthermore, the implementation of a covenant takes time and requires a lot of discussion. A covenant often has a long-term walidity, so fewer tisks are involved, and the policy is stable for a long time. The target group itself joins voluntarily in a covenant and avoids legislation by doing so. Agreements also motivate because of group pressure, and this group pressure might be mote effective under a regulatory threat.

In stimulating covenants the government often imposes a regulatory threat and, at the same time, offers flanking subsidies. These subsidies, of course, change the costs and benefits of the alternative of joining the covenant. Success factors of covenants are a bold approach of authorities during negotiations, a credible regulatory threat, a mechanism to punish free tiders, a rather homogeneous target group, and careful process management to built and foster a climate of turst and cooperation (Bressers et al., 2004).

Judicial instruments are appropriate for the mainstream market: they cause problems and they approach the target group as a herd. Especially covenants are good mainstream instruments. "They take time and consideration and entail no long-term risks.

\section{Fconomic instruments}

An economic instrument usuatly aims to influence financial considerations in such a way that an organization will behave in an environmentally favoutable way. Economic instruments can present organizations with either positive or negative incentives to change their behaviour.

Positive incentives take the form of subsidies. An example in the Netherlands is the Energy Premium Regulation (EPR) that subsidizes buying energy efficient appliances and technology. If one had bought an energy efficient appliance, a premium was granted several months later. The effect of such a premium regulation on the mainstream is not optimal because of the time delay between paying for the appliance and receiving the premium, often several months. 
The perceived complexity and bureaucracy of many subsidy procedures is not appealing for the mainstream. Therefore, the free-rider effect for subsidies is relatively high, estimated to be $60 \%$ (Jeeninga et al, 2002). The eaty market actors are responsible for this effect; they choose for the energy efficient appliances anyrway, so a subsidy is just a reward afterwards.

Instruments having negative incentives take the form of levies. These instruments make environmental issues part of the economic traffic by giving them an economic value. Examples are emission trade and tax differentation. And, by making environmental issues part of the economic traffic, these instruments are especially appropriate for the mainstream because, before making choices, the mainstream actors weigh costs and benefits.

It is clear that the active ingredient of economic instruments change the costs and benefits of alternatives. By issuing incentives, governments also communicate societal priorities. And, therefore, economic instruments also influence the process of weighing alternatives.

\section{Communicative instruments}

Communicative instruments transfer knowledge for the purpose of informing, persuading, convincing or tempting. These instruments can also be combined with and support other types of instruments. They often create social support and increase awareness. Examples are information and promotional material, labels and benchmarks.

Two forms of communicative instruments are (1) written information and (2) personal communication. A successful example of written communication is the A-label (Belastingdienst, 2002). Since its introduction, sales of A-Label appliances increased by $70 \%$. A-label appliances are purchased by mainstream actors. Another example of written information is the European Union's Energy Performance Directive (EPD) for buildings $(2002 / 91 / \mathbb{E G})$. This directive requires an energy certificate label at relevant transaction moments such as building, sales and rent. It contains recommendation for improventent of the energy performance.

Demonstration projects are effective to convince mainsteam actors. The early marliet actors often take an active part in demonstrations as demonstrators. The mainstream actors, especially the early majotity, like to visit demonstration projects.

Personal communication also contributes to starting and continuing processes of changes in organizations. Examples are coaching, guidance and training. Especially mainstream actors like training and being informed by peers. Personal advice seems more effective than promotion, especially in suppotting implementation processes.

The Netherlands has its Energy Performance Advice (EPA). Organizations can request subsidized voluntary advice given by certified advisors. 'The advice, however, comes too 
late to be effective. Because energy conservation is often one of the last points to decide during a project's design, often no budget is left when the EPA comes into the picture. The argaments for energy conservation, quality and comfort, are suited for the mainstream (Jeeninga et al., 2001). If the advice (EPA) would be available earlier in the investiment process, it would more effectively influence the mainstream.

The active ingredients of communicative instruments go far beyond just processing information on alternatives and their costs and benefits.

We know that change-oriented programmes influence and convince organizations that change is necessary. If practical help is also offered, the costs and benefits of implementing the required behaviour are changed and uncertainty is reduced. Furthermore, any regulation or incentive will also be accompanied by communication. Longitudinal studies have shown that the effect of communicarive instmuments accompanying levies are very influential (Bressers and Lulofs, 2004).

\section{Physical provisions}

Some physical provisions, such as infrastructural provisions in spatial planning, clearly influence behaviour. Also at an individual level technical steering influences behaviour. Structural provisions can have a compulsory character, for example, a residential area with sun-oriented houses and an energywefficient infrastructure. Energy Performance of a Location (EPL) yields results: the calculated annual reduction on $\mathrm{CO}_{2}$ realized in new locations was $0.17 \mathrm{Mton}$ (Kool and Egmond, 2004).

This type of intervention influences especially the mainstream because, for a given location, an energy-efficient infrastructure, such as combined generation of heat and electricity for a building area, leads to cooperation of all of the individual actors, and by cooperating they spread the risks.

\subsection{Early market and mainstream market instruments}

In table 4.3 we have combined the results of the behavioural. analysis of the early and mainstream market (Table 4.2) with the active ingredients of existing instruments (Table 2.3) The table summarizes the effects of specific early market and mainstream instruments.

The early market is best influenced through knowledge transfer about innovative technology and products, and through stimulating communication. Demonstrations challenge these actors to play the role of demonstrator. 
The mainstream market is influenced by specific permits: they cause a problem that the target group has to solve. Cowenants orient the actors toward the group. Subsidies can influence the cost/benefit reasoning of the mainstream, and the most effective subsidies deliver cash-on-the-barrelhead.

Table 4.3: Early market and mainstream market instruments

\begin{tabular}{|c|c|c|}
\hline Instrument & Early market & Malnstream market \\
\hline $\begin{array}{l}11 \text { General Laws and } \\
\text { Rules }\end{array}$ & Not especially: they obey & Not especially: they obey \\
\hline 1.2 specific permits & Not especially: they obey & $\begin{array}{l}\text { Causes a problem and activates } \\
\text { The mainstream obeys and solves the } \\
\text { problem. }\end{array}$ \\
\hline 13 Enforcement & Necessary & Necessary \\
\hline $\begin{array}{l}1.4 \text { Covenants and } \\
\text { Agreements }\end{array}$ & $\begin{array}{l}\text { Only agreements with the } \\
\text { individual actor }\end{array}$ & $\begin{array}{l}\text { Good because or the deliberate effect on } \\
\text { group action, relation with government }\end{array}$ \\
\hline 21 Subsidy & $\begin{array}{l}\text { Only as reward, } \\
\text { (NB. the free rider effect), } \\
\text { Specific irvestments subsidies }\end{array}$ & $\begin{array}{l}\text { Can have effect if not too much red-tape is } \\
\text { involved, the rebate should be cash on the } \\
\text { barrelhead. }\end{array}$ \\
\hline 2.2 Levy & Not appropriate & Has effect if actors are informed \\
\hline 2.3 Tax differentiation & Not especially: they obey & Often too complicated, and too postponed \\
\hline 24 Financial constructions & Not appropriate & $\begin{array}{l}\text { Helpfully, i.e. lease constructions, energy } \\
\text { services }\end{array}$ \\
\hline 2.5 Emission trading & Not appropriatle & $\begin{array}{l}\text { Emission reduction becomes economic } \\
\text { function, with mainstream trading }\end{array}$ \\
\hline 3.1 Knowledge transfer & $\begin{array}{l}\text { Innowative technology and } \\
\text { products } \\
\text { Strategic advantages }\end{array}$ & $\begin{array}{l}\text { Target group magazines: } \\
\text { About products (labels) and market leaders } \\
\text { offering best solutions, }\end{array}$ \\
\hline 3.2 Training & Not appropriate & $\begin{array}{l}\text { With peers and from peers, they learn from } \\
\text { peers }\end{array}$ \\
\hline 9.3 Personal advice & Not appropriate & Has effect if on-time in decision process \\
\hline 3.4 Demonstration & $\begin{array}{l}\text { As demonstrator, and in the } \\
\text { form of contests. }\end{array}$ & As visitor \\
\hline 3.5 Benchmarks & $\begin{array}{l}\text { Appropriate: they watch } \\
\text { their competitors }\end{array}$ & $\begin{array}{l}\text { If specific enough: They like to compare with } \\
\text { peers }\end{array}$ \\
\hline $\begin{array}{l}4.1 \text { Infrastructural } \\
\text { provision }\end{array}$ & Not appropriate & Stimulates the active co-operation \\
\hline $\begin{array}{l}4.2 \text { Technical behaviloural } \\
\text { steering }\end{array}$ & Not appropriate & They buy if it makes things easler \\
\hline
\end{tabular}

\subsection{Discussion and conclusion}

Large differences between the characteristics of the early market and the mainstream market actors determine their motivations for behavioural change. With their vision and 
Enthusiasm for technology, the early market actors are intemally motivated. They actively seek information, talke risks and often have enough financial resources.

Furthermore, they are interested in innovative technologies and products, and they are self-referencing rather than being one-of-the-herd. The mainstream market actors, on the other hand, are more pragmatic and have a problem-solving attitude: innovations should solve problems. These actors are careful decision-makers with routines and habits. They avoid risk and stay with the herd. They seek functionality and buy the best solution, whenever possible, from a market leader.

From our review of instruments and analysis of the behavioural processes of mainstream and eatly market actors, we conclude that Moore's model of market segmentation (2002) is applicable to the effects of policy instruments.

And, specifically, to influence the mainstream segment of housing associations to adopt. energy conserving innovations, policy makers must consider a number of crucial requirements:

- Reduce the uncertainty about future higher levels of ambition in national policy and reduce of the uncertainty about trends in energy prices.

- Make rules more ambitious, but do not upset the positions of competing organizations within the market.

- Enforce law and specific nules.

- Follow the aclage" "cash-on-the-barrelhead". Financial stimuli work best for mainstream actors by direct and visible settlement at the cash register.

- Give information about experiences of peers, standard products, and solutions for standard problems.

- Fave an overview of alternatives to make choosing easy.

- Label energy-efficient buildings.

- Create a bronder supply of standard efficiency-improving and sustainable altemarives.

- Crente new habits, or influence the set of existing habits with new regulations.

- Stimulate energy-systems for several buildings simultaneously in a location-oriented approach.

In summary: one size does not fit all ! Despite the efforts of the government and the deployment of its many policy instruments, mainstream actors often do not adopt innovative products because the policies do not fit them. Therefore the preference of policy makers to use instruments of a so-called generic character does not lead to the most effective interventions.

Mainstream interventions should act early in the change process, be less complex and offer more standard options. Subsidies, tax reductions and other financial stimuli must pay off more quickly. 
We also conclude that there are few instruments that fit the early market actors. These actors are highly internally motivated, implying that early market interventions have to be challenging and facilitating. And because the early market is active and dynamic, it often encounters institutional barriers. In this case, the best intervention is to remove the institutional barriers.A wide chasm exists between the early market actors and the mainstream market actors. To increase diffusion of innorations into the mainstream we must cross that chasm. And is subject of the next chapter. 


\section{References}

AgriHolland, 2001 .

Broeikasgas emissie door veehouderij bliftr afnemen (Emissions of greenhouse gases in poultry farms are steadily decreasing), article in electronic newsletter of Agrifolland, (15022001).

Bandura A. 1986.

Social foundations of thought and action, Prentice Hall, Englewood Cliff, New Jersey.

Belastingdienst, 2002.

Rapportage van onderzoeksbevindingen in het kader van de evaluatic van de EnergiePremieRegeling (Research results of the evaluation of the Energy Premium Regulation), Belastingdienst, Centrum voor proces- en productontwikkeling, Utrecht.

Bressers J.Th.A., Klok P-J., 1988.

Fundamentals for a theory of policy instruments, International Journal of Social Economics, Vol. 15, no3/4, pp. 22-41.

Bressers J.Th.A., Bruijn T.J.M.M. de, Lulofs K.R.D., 2004.

Evaluatie van de Nederlandse Milieu Convenanten (Evaluation of the Dutch environmental covenants), Beleidswetenschap, 18, no 3, pp. 242-260, Kluwer, Alphen aan de Rijn.

Bressers J.Th.A., Lulofs K.R.D., 2004.

Industrial Water Pollution in the Netherlands: A Fee-based Approach, in: Harrington W., Mlorgenstern R.D., and Sterner T. (Eds.), Choosing environmental policy, comparing instruments and outcomes in the United States and Europe, pp.91-110, Resources for the future, Washington DC.

Caluwe L, Vermak $\mathbb{H}_{\text {, }}, 2002$.

Leten veranderen (Learth to change), Kuwwer, Deventer.

Cyert R.M., March J.G., 1992.

A behavioural theory of the firm, 2 nd Edition, Blackwell, Oxford, UK.

Daft R., 2001.

Organizations theory and design, $7^{\text {th }}$ Edition, South west college Publishing.

Eigmond C., Jonkers R, Kok G., 2005 a.

A strategy to encourage housing associations to invest in energy conservation, Energy Policy, 33, pp. 2374-2384.

Egmond C., Jonkers R, Kok G., $2005 b$.

Target group segmentation makes sense: if one sheep leaps over the ditch, all the rest will follow, Energy Pollicy, accepted for publication.

Essers I., Mooij M., 2001. 
Secundaire effecten van de EPN (Secundary effects of the EPS), Ecofys, Utrecht. Green L.W., Kreuter M.W., 1999.

Health promotion planning, $3^{\text {th }}$ edition, Mountain View, California. Jeeninga H., Beeldman M., Boonekamp P., 2001.

Nadere invulling van de EPA doelstelling voor woningen (Definition of the Energy Performance Advice targets), ECN, Petten.

Jeeninga H., Honig E., Dril A., Harmsen R., 2002.

Effect van energie- en milieubeleid op broeikasgasemissies in de periode 1990-2000, (Results of energy and environmental policy on green house gas emissions in the period 1990-2000), ECN, Petten.

Kool R., Egmond C., 2004.

The energy performance of a location: successes, setbacks and new approach, proceedings ACEEE summer study on energy efficiency in buildings, ACEEE, Washington DC.

Lulofs K. R.D., 2001.

Implementing command and control directives: the case of directive

89/429/EEC, in Glachant, M., Implementing European environmental policy, The impacts of directives in the member states, Cheltenham/Northampton. Lulofs K.R.D., Lettinga B., 2003.

Instrumenten mainstream market (Instruments mainstream market): $\mathrm{CO}_{2}$ reductie in de Gebouwde Omgeving. CSTM - SR202, Twente Universiteit, Enschede. Moore G., 2002.

Crossing the chasm, Harper Collins, New York.

Rogers E.M., 1995.

Diffusion of innovations, $4^{\text {th }}$ Edition, The Free Press, New York. Silverman D., 1970.

The theory of organizations, Basic Books, London.

Steckler A., Goodman R.M., Kegler M.C., 2002.

Mobilizing organizations for heal th enhancement: theories of organizational change, in Glanz K., Rimer B.K., Lewis F.M. (Eds.), Health behavior and health education: theory, research and practice, $3^{\text {th }}$ edition, pp. 335-360, Josey Bass, San Francisco. VROM-raad, 2001.

War een wil is, is een weg (Where there is a will, there is a way), advice on the

National Environmental Policy Plan 4 , Den Haag.

Wieffels P., 2002.

The chasm companion, Harper Collins, New York. 


\title{
Chapter 5 \\ A strategy and protocol \\ to increase diffusion of energy related innovations into the mainstream of housing associations
}

\author{
This chapter is based on: \\ Egmond C., Jonkers R., Kol: G., 2005. \\ A strategy and protocol to increase diffusion of enetgy related innovations into the \\ mainstream of housing associations. \\ Energy Policy, accepted for publication.
}

\begin{abstract}
To reduce human causes of global warming, large-scale implementation of innovative products that save energy is necessary. Innovative products first reach the early market actors who are driven by a visionary attitude. Hereafter, the products must reach the much larger mainstream market whose actors are driven by a pragmatic atritude. Many innowations, however, only appeal to the visionary early market and do not meet the more pragmatic needs of the mainstream. For that reason, innovations often fall in a "chasm" between the early market and the mainstream and fail to reach the mainstream. We developed a strategy and a protocol to aid governmental agencies in influencing the mainstream members of housing associations to adopt energy conservation innovations. Our method is an adaptation of an existing marketing method and applicable to other. target groups. The first step in crossing this chasm is to find a niche segment in the mainstream as the starting point for winning the rest of the mainstream. By surveying the target group and analyzing the data, we identified 29 housing associations (234 interviewed) that belong to this niche segment. Identifying the niche segment and its determinants of behaviour is part of our 4-step protocol that leads to adapting the innovative product to meet the needs of the niche and setting up a marketing plan to win the rest of the mainstream.
\end{abstract}




\subsection{Introduction}

In agreement with the Kyoto Protocol, the Datch government has developed a policy to reverse human causes of climate change. This climate policy aims to reduce energy consumption and thereby reduce the emission of $\mathrm{CO}_{2}$. The Dutch government has specifically targeted the users and owners of buildings as being large energy consumers and, in 2004, set an upper limit of 29 Mton for their $\mathrm{CO}_{2}$ emission for the yeat 2010. Against this background, the Dutch Ministry of Environmental Affairs asked SenterNovem to develop an intervention strategy to change the energy related behawiour of users and owners of buildings.

Specifically, we want to stimulate large numbers of housing associations to adopt and use new technology. Obviously, energy conservation innovations have walue only when they are adopted and used. To this end, we developed an intervention strategy based on applying policy instruments that influence the specific behavioural determinants of housing associations to invest more in energy conservation and to adopt energy conservation innovations (Egmond et al., 2005a). That strategy consists of the following actions: (1) identify the behavioural determinants of adoption of the members of the target group, (2) identify the "active ingredients" in existing policy instruments: their influence on specific determinants, (3) compare the active ingredients of the policy instruments with the behavioural determinants of the target group, and (4) select a set of instruments containing active ingredients that target the behavioural determinants of the target group, thereby influencing their behaviour.

We cannot assume, however, that the behavioural change of housing associations develops homogeneously throughout the entire target group. Studies in the field of diffusion of innovations conclude that many energy conservation innovations are adopted only by the first-adopting segment of a target group, the so-called "early market". In other words, innovations hardly ever reach the vast majority of the target group, the so-called "mainstream market" (Silvester, 1996). Apparently the behavioural determinants of these two marker segments differ in such a way that innovations do not diffuse across a "chasm" between the early market and the mainstream market. This non-homogeneity" implies that to effectively apply our strategy described above, we must focus on mainstrearn actors.

This chapter reports on a further analysis of data collected and reported in chapter 2 (Egmond et al., 2005a) and further develops the strategy of focusing on specific segments of target groups, reported in chapter 3 and chapter 4 (Egmond et al., 2005b, and Egmond. et al., 2005c), and can be considered as a follow up of the research we reported earlier. 
This research was part of a program that developed an intervention strategy to influence the behaviour of target groups to achieve energy conservation in the built environment. We have charted the energy-related behaviour and determinants housing associations and of other target groups: owners and tenants of office buildings, and local authorities, and developed intervention strategies.

We identified the differences between the behawioural determinants of the mainstream and the early market segments of housing associations. Then, based on these differences and applying marketing theory, we present a step-by-step protocol for influencing the mainstream to invest in energy conservation innovations. The purpose of our work reported here is twofold: (1) to further develop our strategy described above into a method to cross the chasm and influence the mainstream of housing associations to adopt energy conservation innovations, (2) to develop a protocol that can serve as a guideline for stimulating the diffusion of energy related innovations into the mainstream of other target groups.

To achieve these purposes, we applied the rationale that underlies the diffusion theory of Rogers (1995) and the marketing theory of Moore (2002). Their rationale is built on the "behaviour of specific segments of target groups" and is, therefore, directly applicable to choosing the policy instruments that most effectively change the behaviour of target groups. Simply stated, the so-called "early market" actors adopt innovations first and "mainstream marker" actors follow only if their own specific needs are met. Indeed, in our earlier study, we discovered that the early market and mainstream market actors have their own specific characteristics and that their behavioutal determinants differ. 'The early market actors are more vision-driven and the mainstream market actors have a more pragmatic attitude (Egmond et al., 2005b). And these differences are the cause of the above-mentioned chasm.

According to Moore (2002), the first step in crossing this chasm is to win a niche market in the mainstream as the starting point for winning the rest of the mainstream. 'To win a niche market in the mainstream, with its more pragmatic needs, an innovation must be adapted to meet those needs. This, in turn, implies that we must iclentify a suitable niche segment and its needs. Then we must determine how innovations can be adapted to meet the needs of the niche market.

Specifically, in developing our method we (1) identified the members of a suitable niche segment within the mainstream market by analyzing the data from the survey reported in chapter 2 (Egmond et al., 2005a), and (2) developed a protocol to stimulate the niche segment to adopt energy conservation innovations. 


\subsection{Theoretical considerations}

Moore (2002) developed the concept of crossing the chasm based on the diffusion theory of Rogers (1995). According to Rogers, an innovation is "an idea, practice or object that is perceived as new by an individual or another unit of adoption." Diffusion of an innovation through an entire market starts with the "innovators" and "early adopters", is eventually followed by the "early and late majority" and ends with the "laggards". Because of differences in adoption speed, the cliffusion process of an innovation follows an Sshaped curve when the number of adopters is plotted against time (Figure 5.1).

Figure 5.1: S-shaped curve of the adoption of innowations

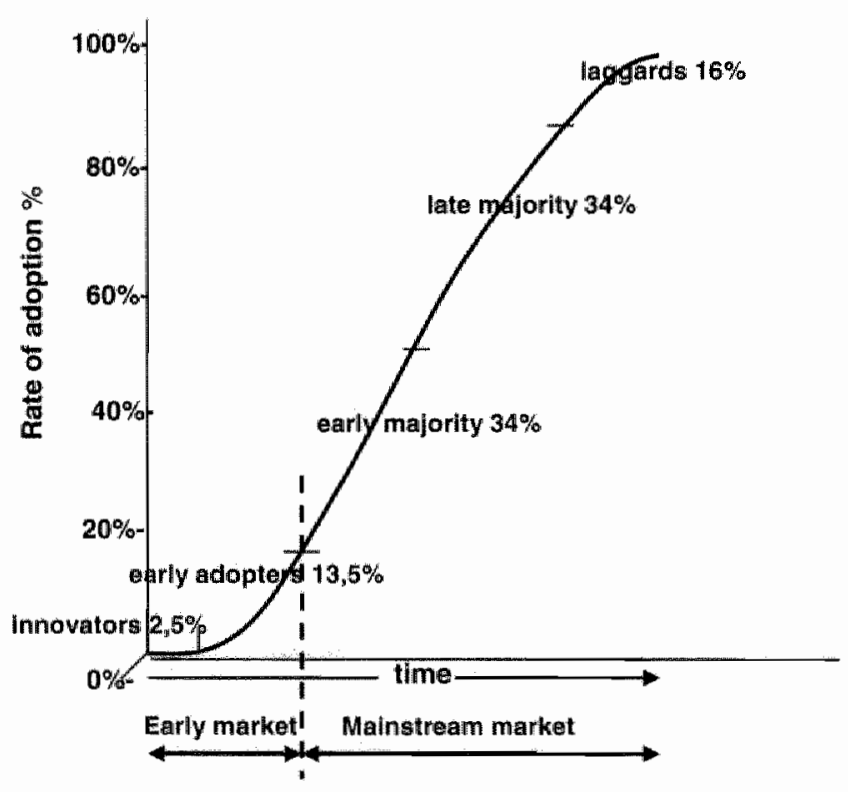

To stimulate diffusion of an innovation through an entire market, marketers should first focus their activities on the innovators and get them to adopt the innovation. The innovators are driven by enthusiasm for technology. Then the marketers should move on to focus on the early adopters, who are driven by vision and strategy. The marketers finally go on to the mainstream which is subdivided into the "early majority" who will adopt an innovation if it solves a problem - they are driven by pragmatism - and the "late majority" who do not adopt an innovation until most others in the target group have done so - they are driven by competitive pressure. The "laggards" will not adopt an 
innovation unless forced to do so (Rogers, 1995). Organizitions marketing innowative products or services should use each "captured" segment as a reference base for their strategy to approach the next segment.

Rogers points out that the adopter's perception of an innowation determines the character of an innovation. So when potential adopters are introduced to products that requite them to change their current mode of behaviour, their attitide towards innovation determines their behaviour. For that reason, Moore (2002) differentiates between two types of innovations from a behavioural point of wiew:

1. Discontinuous innovations, which requite the adopters to change their current mode of behaviour. An example of this type of innovation is the introduction of the word processor that replaced the typewriter. Computers changed text writing and users required training in word processing software.

2. Continuous innovations, which require no change of behaviour of the adopter and are related to the normal upgrading of products. An example is buying an upgrade of the word-processing software.

As we showed in chapter 3 , the mainstream actors of housing associations ate not very open to innovations. They do not easily change their behaviour, because they are less visionary than the early market and they are just minding their core business (Egmond et al., 2005b). In contrast to the carly market actors, they see energy conservation innovations as discontinuous, and adoption requires a behavioural change. And this is the basis of the chasm between the early and the mainstream markets. Moore's so-called "high-tech" marketing model is especially suited for marketing discontinuous innovations and is suited to crossing the chasm in our target group of housing associations.

\section{The chasm}

In practice, diffusion of innovation does not move smoothly from left to right on the Sshaped curve. Discontinuities in the Sucurve cause diffusion to stop before renching the next market segment. And a discontimuity between the early adopters, which is part of the early market, and the early majority, which is part of the mainstream is a wide chasm. It is caused by profound differences in attitude towards change and, thus, different perceptions of innovations, as summarized in table 5.1 .

The early market actors expect to gain a lead on the competition through either lower product cost, faster time to the market, more complete customet service, or some other business advantage. They are looking for strategic advantages. They expect a radical discontinuity between the ofd ways and the new, and they are prepared to change their behaviour. Being first, they are also prepared to bear with the inevitable bugs and setbacks that accompany any innovation just arriving on the market. The early market actors have a more visionary attitude: they are motivated by future opportunities, are self-referencing; avoid the herd, and will seek the best technology. We define "visionarity" as the 
disposition of an actor whose decision-making behaviour, related to innovations, is guided by ideology and is related to strategy towards the future.

Table 5.1: Comparison of the early market and mainstream market (Adapted from Wieffels, 2002

\begin{tabular}{|c|c|}
\hline Characteristics of the actors. & 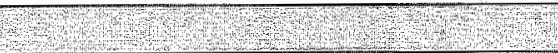 \\
\hline Early Market, visionarles & Malnstream pragmatists \\
\hline $\begin{array}{l}\text { Seek revolutionary advances: innovation, } \\
\text { creation }\end{array}$ & $\begin{array}{l}\text { seek evolutionary advances, } \\
\text { maintenance, problem solving }\end{array}$ \\
\hline motivated by future opportunities & motivated by current problems \\
\hline self-referencing & reference others perceived as similar \\
\hline avoid the herd & stay with the herd \\
\hline risk-taking & risk-aversion \\
\hline intuitive & analytic \\
\hline Eontrary & canformist \\
\hline seek what is possible & pursue what is probable \\
\hline $\begin{array}{l}\text { will seek best technology, and innovative } \\
\text { products }\end{array}$ & $\begin{array}{l}\text { will seek the best solution or functionality to } \\
\text { buy, they focus an leader of the market }\end{array}$ \\
\hline momentary, local and specific & continuously, everywhere and everybody \\
\hline not better, but different & more of the same \\
\hline often culrative & proventive \\
\hline fast & sllow \\
\hline
\end{tabular}

The manstream actors, however, want to buy a productivity improvement for existing operations. They aim to minimize discontinuity with the old ways: they simply want to solve their problems. The mainstream market actors have a pragmatic attitude. They are motivated by curtent problems, seek and buy the best solution or functionality from a market leader. They identify with others petceived as similar, and they stay with the herd. But the mainstream is not homogeneous: as we saw before. The early majority actors as part of the mainstream, are driven by pragmatism, and afe interested in innovations insofar as they contribute to solving problems. Often these innovations are of the continuous type. The late majority actors are driven by competitie pressure: they adopt an innovation only after most others in the market have done so. And the laggards will not adopt an innovation unless forced to do so (Rogers, 1995). We define "pragmattsm" as the disposition of an actor" whose decision-making behaviour is guided by the judgement of facts as telated to core business and problem solving.

The more discontinuous the technology and the more it deviates from the status quo, as perceived by the mainstream actors, the more likely that a chasm will occur. This chasm is situated between the early market and the segment of the mainstream that is nearest to the early market. This segment is called the "early majority". The chasm is not the result of bad technology or bac products, but rather the result of "incomplete" products 
(Wieffels, 2002). The products are incomplete insofar that they do not meet the pragmatic needs of the mainstrean actors: they are not reliable enough, they are not serviced will, they are too expensive etc. And because the mainstream actors do not identify with the early market actors who have adopted the innovation, they will not follow. Chasms can persist for indefinite periods, and as Wieffels (2002) smes: "Given the pace of innovative developments, product categories that remain in the chasm for longer than two years can be considered lost in the chasm, sometimes irretrievably so."

\section{Crossing the chasm}

In his "high-tech" marketing model, Moore (2002) developed his method to cross the chasm between the early market and the mainstream market. In our case, this means to induce mainstream actors to adopt an innovation which has already been adopted by the early market actors. In essence, his method consists of (1) identifying a small segment of the mainstream market (a niche segment, which is part of the early majority), (2) determine which "problem" of this niche the innovative product or service could solve and (3) making the innovation complete so that it solves that problem of the niche segment and, thereby, gives the niche actors a compelling reason to buy (Moore, 2002). According to Moore, the marketing and sales of the innovation will then reach the rest of the early majority segment within the mainstream. And after the early majority, the late majority will follow because the late majority will adopt an innovation after mainstream actors, with whom they identify, have done so.

Moore advises us to find a group of customers in the mainstream, the "niche", for which the innowation can have a compelling reason to buy. The actors of this niche segment belong to the early majority, the segment of the mainstream nearest to the early market, and are, thenefore, less change resistant. To be compelling for the pragmatic mainstream, the innovative product must solve a problem or provide an efficiency improvement. "This often means that the innovative product has to be "completed", or augmented with a variety of services and ancillary products to become the "whole" product: a product that solves a problem or improves efficiency. Moore emphasizes that we nust focus on the pragmatists in the mainstream; they want, evaluate and buy "complete" products. Sevetal partners often have to work together to complete a product (Moore, 2002).

The niche, being part of the mainstream market, consists of actors with common nceds, wants and problems. They usually use common or similar technology, and they reference each other when making a decision to buy. In general, actors in this niche of the mainstream market need applications that meet specific requirements. They do not weigh. alternative solutions on the basis of technology or the product itself, but rather on how complete each altermative is compared to others. They evaluate alternatives based on demonstrable results and, especially, return on investment. 
Moore (2002) presents numerous cases to illustrate his method and we summarize one of them here. This illustrates how "making an innovative product complete" can meet the needs of the niche segriment and promote diffusion into mainstream. 'The innovation was the Personal Digital Assistant (PDA). Various manufacturers produced them, but only one of them, the Palm-pilot, exentually crossed the chasm and was adopted by the mainstream market. The niche segment within the mainstream was identified to be the members of management teams of enterpises. These people spend $100 \%$ of their time either in meetings or on the road. They needed applications to support them in communication and maintaining contacts such as a telephone and e-mail functions. And for setring up meetings and keeping appointments, they needed a calendar-function. The first PDA's, the Sharp Wizard and Casio Boss, were priced right, but were too limited in functionality; they had no calendars, their phone books could only be updated manually, and they had no backup.

This led the market to a compurer-oriented solution. HP came with its $L X$ line of palmtop computers and Apple came with its Newton. HP could not let go of the PC. The $95 \mathrm{LX}$ had a phone list and calendar, and also a spteadsheet and a word processor with a very small but full keyboard. And it costs $\$ 695$. In sum, it was neither fish nor fowl. The Newton was not a PC but based on the video-oriented vision of Apple, and therefore the form was a problem: it resembled a brick rather than a small booklet. And because it was an Apple, it was not compatible with calendars in the Microsoft world.

Palm saw these shortcomings and knew what to do to adapt their PDA, the Palm-pilot, to fit the needs of the mainstream. First, its form was designed to fit in a shirt pocket. Palm developed its own operating system, compatible with both Apple and Microsoft with an intuitive application interface. Palm also provided a convenient computer-docking station to facilitate uploading and downloading phone numbers and coordinate calendars. And, at at price of less than $\$ 400$, consumers considered it to be cost-effective. In short, the Palmo-

pilot reached the mainstream by meeting the needs of the niche segment of managers. Later on, other mainstream segments, such as consultants, liked the functionality of the PDA's and bought them on a large scale. Furthermore, competitors of Palm developed PDA's having similar form and functionality as the Palm-pilot, increasing diffusion of the original innovation even more.

\subsection{Identifying the niche in the mainstream of housing associations}

\section{Method}

Our target group of housing associations in the Netherlands totals 623 organizations. To establish the target-group-specific determinants of their energy-related behaviour: we interviewed 234 of these organizations (53\% of the 441 organizations approached in our 
study) using a questionnaire. These questionnaire-guided interviews were carried out with a computer-aided telephone interview (CATT) system. The respondents included members of the boards of directors $(7.3 \%)$, chiefs of the technical departments $(54.7 \%)$ and other staff members with a mandate on energy conservation or environmental issues $(38 \%$ ). We described the construction of the questionnaire in chaptet 2 (Egmond et al., 2005a) and we summarize its construction here. Briefly, we first held focus interviews wherein the responses to a checklist were recorded. We then constructed the questionnaire around clusters of predisposing, enabling and reinforcing factors of behaviour as defined in our behavioural model. Because we were interested in influencing the behaviour of the target group, we focused on the predisposing factors of the interviewed organizations. Predisposing factors are internal and, therefore, more easy to influence in the short run than external factors that are often institutional in character.

In the final questionnaire, several items were added to establish the dependent outcome variable taking energy conservation measures in housing stock, as well items to establish the variable adoption rate.

\section{Questionnaire}

The questionnaire addressed the following issues, and the answers to the questions were of an ordinal and nominal type (3- and 5-point scale).

\section{A. Background variables of the interviewees and association (11 items)}

Interviewees (4 items): position in the organization, policy-function or implementationfunction, seniority), and the association ( 7 items): size and age of the housing stock, financiall position general and for energy conservation (EC), number of staff members totally and for EC, working area: urban or country.

\section{B. Energy and environment related behaviour (19 items)}

These questions had both a general character (are measures taken), and a specific on the kind of measures. Example: Is there a yearly maintenance plan, including energy conservation? a. yes; b. no; c. don't know; d. yes, but without energy conservation.

C. Attention for energy conservation in the organizational policy and in covenants (17 items)

Example: The taking of energy conservation measures is in accordance with the policy of the association: a. Is part of the environmental policy plan (yes or no); $b$. is part of an energy conservation programme (yes or no); $\mathrm{c}$. is part of large-scale maintenance planning (yes or no); d. otherwise.

D. Attitude towards energy conservation and environmental issues (32 items)

Example: Please give notice if you agree on the following statements: Subsidies on energy conservation measures are too small. Agree very much, agree a little, and do not agree. 
E. Impact and support of peer organizations and other intermediary organizations in making decisions about energy conservation ( 9 items)

Dixample: Are you informed on the inwestments done by other associations in the field of energy conservation a yes good; b. yes little; c. don not know; d. no, hardly.

\section{F. Determination of the adoption category (3 items)}

Based on the self-designating method (Rogers, 2003, p. 308)

Item 1: Compare the atutude of other housing associations with your association.

Item 2: Compate the decision speed of your housing with other housings associations. Item 3: Compare yout housing association with other housing associations on the degree of taking energy conserwation measures.

G. Chosen and preferred instruments, including the support of significant external parties (13 items)

Example: Can you, for each instrument, give an indication of the effect on taking energy conservation measures: a. a big stimulating effect; b, a moderate effect; $c$, none. Instruments: a. improvement of subsidlies; b. covenants; $c$. law and legislation; $d$. support at the implementation of technical measures; e. demonstration projects; $f$. introduction of an energy label for houses.

\section{Analysis}

To cross the chasm between the early market and the mainstream, we followed the rationale "build the bridge where the chasm is narrow". The chasm is nartow between the early market and early majority because the difference in adoption rate between these two segments is relatively small. To let an innovation cross the chasm to the mainstream we have to identify a niche segment in the mainstream that has an adoption rate approaching that of the early market, and then we have to target that niche with our marketing acrivities.

From our analysis of our sample of 234 housing associations in the Nethetlands (Egmond et al., 2005b), we identified 158 housing associations (77\%) that form the mainstream mattket (see table 5.2). "To identify actors of the niche segment we used two characteristics. Firstly, we used the organization's adoption rate as the indicator to distinguish the market segment to which it belongs. The adoption tate is the relative speed with which an actor adopts an innowation. The actors in the early majority segment of the mainstream marlet have an adoption rate that closely approaches that of the early market. Secondly, we constructed the variable pragmatism to identify those actors within the early majority, having a high level of pragmatism. This follows Moore's assumption that the mainstream market is dominated by the pragmatic early majority. And the early majority actors are accepted as leaders by the rest of the mainstream (Moore, 2002). 


\section{The adoption rate variable}

In our survey, we asked the respondents a number of questions to determine the degree to which they perceive themselves or their organizations to be fast adopters. To construct the variable adoption rate, we analyzed the responses to the following questionnaire ititems.

Item 1: If you compare the attitude towards taking energy conservation measures of other housing associations with your association, do you find: (a) other housing anssociations more positive than your own association (score $=0$; (b) more negative than your own association (score $=2$ ); (c) equal to your own association (score $=1$ ); (d) do not know (score $=0)$.

Item 2: If you qualify your association as to the speed with which decisions are made about energy conserwation, is your association: (a) a trendsetter (score $=2$ ), (b) a trendfollower (score $=1$ ), (c) a laggard (score $=0$ ), (d) do not know (score $=0$ ). Item 3: Is your housing association more active in taking energy conserwation measures: (a) yes, we have a higher ambition level than most others, (score $=1$ ), (b) no (score $=0$ ), (c) do not know (score $=0$ ). We gave this item a score of 1 because it is just an addition to item 1 .

These three irems form a scale of adoption rate having a minimum scote of 0 and maximum score of 5 (Cronbach's alpha is 0.60 ). Housing associations with an adoption rate of $4-5$ belong to the early market - they adopt an innovation quickly. Housing associations with an adoption rate of less than 4 belong to the mainstream market. Those with an adoption rate of 3 , however, adopt more quickly than the mainstream average and form the early majority. The actors of the niche segment can be found within the early majority. Table 5.2 shows the adoption rate and the different adoption categories.

Table 5.2: Adoption rate and adoption categories

\begin{tabular}{|c|c|c|c|c|}
\hline $\begin{array}{l}\text { Adoption } \\
\text { rate }\end{array}$ & $\begin{array}{l}\text { Adoptlon category according } \\
\text { Rogers }\end{array}$ & $n=205$ & $\begin{array}{l}\text { Adoption category } \\
\text { according Noore }\end{array}$ & $n=205$ \\
\hline Score $4-5$ & $\begin{array}{l}\text { adoption speed fast: innovator } \\
\text { or early adopter, a trend-setter }\end{array}$ & $\begin{array}{l}22.9 \% \\
n=47\end{array}$ & early market & $\begin{array}{l}22.9 \% \\
17=47\end{array}$ \\
\hline Score 3 & $\begin{array}{l}\text { adoption speed higher than average: } \\
\text { early majority (trend-follower), containing } \\
\text { the niche actors }\end{array}$ & $\begin{array}{l}28.3 \% \\
n=58\end{array}$ & \multirow[t]{3}{*}{$\begin{array}{l}\text { mainstream } \\
\text { market }\end{array}$} & \multirow[t]{3}{*}{$\begin{array}{l}77.1 \% \\
n=158\end{array}$} \\
\hline Score 2 & $\begin{array}{l}\text { adoption speed average } \\
\text { late majority (trend-follower) }\end{array}$ & $\begin{array}{l}33.7 \% \\
n=69\end{array}$ & & \\
\hline Score $0-1$ & adoption speed slow or laggard & $\begin{array}{l}15.1 \% \\
n=31\end{array}$ & & \\
\hline
\end{tabular}




\section{The pragmatism variable}

From theory, we know that the actors of the niche segment of the early majority are the most pragmatic actors within the early majority. Once the early majority actors have been identified, based on adoption rate, the niche actors can be identified by their relarively high level of pragmatism.

To assess the level of pragmatism, we constructed the variable pragmatism from the following 13 questionnaire items. We selected these items by screening all the items of the questionnaite on the characteristics of pragmatism as given in table 5.1. We have grouped the items according to their answer-structure. The scores of the items 1-3, and 8-13 have more weight, because these items connect energy conservation to the core business of housing associations, and the items 4.7 score less because they have a more conditional character.

1. Is there a yearly maintenance plan including energy conservation (EC) measures? Answers: a. yes, (score $=2$ ) b. a plan without EC measures (score $=1$ ), c. no (score $=0$ ), d. do not know (score $=0$ ).

2. Does taking of $\mathrm{EC}$ measures contribute to the quality of the housing property? Answers: a. to a latge degree (score $=3)$, b. fairly ( $($ core $=2)$, c. little, $($ score $=1)$ d. hardly (score $=0$ ).

3. Do you estimate the allocated budget to invest in energy conservation to be: Answers a big? ( $($ core $=3)$, b. fair? ( $($ core $=2)$, c. small? (score $=1)$, d. don't know? (score $=0)$.

4. Is the taking of EC measures set down in an implementation plan?

5. Are there plans to conclude a covenant or performance agreement?

6. Is energy conservation part of the quality policy of your association?

7. Does your association ever join a covenant or performance agreement with energy conservation targets?

Answers: (a) yes (score $=1$ ), (b) no (score $=0$ ), (c) do not know (score $=0$ ) (8-13):

8. Has the life span of an EC measure effect on the investment decision?

9. Has the outcome of an EC measure effect on the investment decision?

10. Has the instrument "good assistance at engineeting technical measures" a stimulating effect?

11. Has the instrument "information about the performance of other associations" a stimulating effect?

12. Has the instrument "covenant or performance agreement" a stimulating effect?

13. Has the instrument "intersectoral cooperation" a stimulating effect?

Answers: (a) big (score $=2$ ), (b) average (score $=1$ ) (c) no effect (score $=0$ ). 
These 13 items form a scale of pragmatism having a minimum score of 4 and maximum score of 23 (Cronbach's alpha $=0.60$ ). There is a significant difference between the mean scores of pragmatism for the early majority and the rest of the mainstream (Table 5.3).

Table 5.3: Difference in pragmatism

\begin{tabular}{|l|l|l|l|l|}
\hline Segments & $n$ & mean & min & max \\
\hline Early majorty & 58 & 15.34 & 9 & 23 \\
\hline Late majority & 69 & 13.71 & 6 & 22 \\
\hline Laggards & 31 & 12.74 & 7 & 17 \\
\hline Total & 158 & 14.12 & 6 & 23 \\
\hline Test: ANOVA F=8.9, df=2, ps.001 &
\end{tabular}

\section{The actors of the niche segment}

The actors of the niche segment are the highly pragmatic actors within the early majority, the adopter category of the mainstream most near to the early market. With the variable pragmatism we identified those actors in the mainstream, which are most pragmatic. So the niche segment consists of actors from the early majority with a high score on pragmatism. We assume that all actors in the early majority that have an above average score on pragmatism, more than 15 , belong to the niche. We identified 29 housing associations belonging to this niche segment. Marketers have to target these actors when marketing energy conservation innovations because they are most likely to buy the innovative products.

\subsection{Implications for practice: a protocol to cross the chasm}

To translate the findings of our research into the practice of policy development and implementation, and to speed up the diffusion of innovative products into the mainstream, we developed a protocol to cross the chasm. The protocol consists of four steps: (1) identifying the policy-desirable innovative products, (2) identifying the niche in the mainstream of the target group, (3) completing the product to satisfy the needs of the niche, and (4) setting up marketing activities. We discuss the steps mote in detail.

\section{Step 1. Identify the policy-desired innovative products}

Policy makers must identify innovative products in a specific policy field, for example solar boilers and heat pumps, which can contribute to achieving policy goals if they are implemented on a large-scale. Sales figutes over the last two ot three years indicate if a product is "stuck in the chasm". If sales are stable the product has fallen into the chasm, and only buyers in the early market are buying it. In this phase it is necessary to establish 
contact with manufacturers and vendors of the innovative product to make a first assessment of the market. In this assessment the following questions require answers:

(1) How easily will the whole product solution travel from segment to segment within the entire matker? (2) How likely and readily will one segment reference another segment? (3) Are the actors in the niche segment currently served by other actual or potential competitors? (4) How rapidly can a whole-product solution, tailored to the specific needs of the niche-segment in question, be deployed? Based on the answers of these four questions policy makers can decide which innovation has the best chance of crossing the chastio.

\section{The result of step 1 is a portfolio of innovative products.}

\section{Step 2. Finding the niche in the target group}

The second step is to find the niche by examining the target group market chosen by the policy maker. This is done by surveying the target group in order to identify the early majority in the mainstream. The niche is part of this segment. The survey must also identify the specific behaviour related to the innovative product, the main behavioural detriminants of these segments, the adoption rate and lewel of pragmatism.

\section{Survey design}

We followed the planning and evaluation model of Green and Kreuter (1999) and the survey must gather information from the actors of the target group on the following items.

\section{Assessment of the specific behaviour}

Energy and environment related behaviour: have they taken measures and invested in innovative products in the past? This makes clear how active the actors ate in the field of energy conservation and environment related issues.

\section{Assessment of the determinants}

\section{2a Predisposing factors}

Are they aware of and do they have knowledge about energy conservation and renewable energy? Do they have plans and a policy on the issue, and give attention to energy conservation?" Also derermine the relative priority of energy conservation: Do they have staff and management support for the issue? Take inventory of problems or needs which might be solved by taking energy conservation measures and innovations.

\section{$2 b$ Enabling factors}

The need for resources: Are there financial resources available? Is there need for technical and or organizational resources, to support the policy-desired behaviour? Only when we know what resources the target group needs, we can offer the correct resources. 


\section{2c Reinforcing factors}

Impact and support of peer organizations, and other intermediary organizations (market leaders), and of the authotities.

\section{Assessment of policy instruments}

Make an inventory of chosen and preferred instruments by the tatget group, including the support of significant external parties, and their infuence on the decision-making process. The four types of instruments and their relevance should be taken into consideration: (1) judicial instruments with regulation and covenants, (2) economic instruments with subsidies and levies, (3) communicative instruments with knowledge transfer, benchmarks and personal advice, and (4) physical provisions with infrastructural prowisions and steering of behaviour through technical means.

\section{Adoption rate}

Determine the rate of adoption, necessary to assess the early market actors, the mainstream actors and the niche segment.

\section{Background (marketing) variables}

We also want some background information on the respondents in order to verify that their opinions reflect the opinions of the organization. Furthermore, for segmentation purposes, we want to know background variables of the organization: size, financial position, number of staff-members, working area (urban or rural).

The result of step 2 is the assessment of the early adopters and the actors in the niche segment, and their characteristics.

\section{Step 3. Determine how to make the innovative product "complete" to meet the needs of the niche}

In the third step, interview the actors in the early adopter segment to determine which problems they solved by buying the specific innovative product. "Then, discuss the results of these interviews with actors from the niche segment to determine if these problems also exist in their segment. And if so, under what conditions would they purchase the innovative product to solve the problems. During this step, start a dialogue between vendors and manufacturers of the innovation and the actots in the wiche group. From these discussions, vendors and manufacturers learn how to complete the product better to meet the needs of the niche market.

The result of step 3 is a list of possible changes of the innovative product to make it complete.

\section{Step 4. Set up marketing activities}

The initiative to produce, market and sell a "complete" innovative product that is atractive to the entite mainstream is up to the vendors and manufacturers. "The 
government plays no further role, and the actual crossing depends on the market forces. If, however, from a policy point of view, faster diffusion of an innovative product is desired, the government can facilitate this by removing institutional barriers and providing specific subsidies.

The result of step 4 is a marketing plan of vendors and manufacturers.

\subsection{Discussion and Conclusion}

We have developed a method to cross the chasm and influence the mainstream of housing associations to adopt energy conservation innowations. Through "selfdesignation", it is possible to identify the early majority actors within the mainstream. Furthermore, with the constructed variable pragmatism it is possible to identify the most pragmatic actors within the early majority and, thus, zoom in and identify a niche. To cross the chasm, these niche actors are the first ones to target in marketing an innovative product. In our study, we have realized step 1 and step 2 of the protocol. And we know that identifying the niche does not, by itself, stimulate diffusion of energy related innovations into the mainstream; therefore steps 3 and 4 are necessary. Governmental agencies must stimulate producers and vendors of innovative products to "complete" their products in the sense that they meet the problems and needs of the pragmatic niche segment of housing associations. This means that the vendors and manufacturers of innovative products must understand the needs of the niche market. Here, government, its agencies, such as SenterNovem, and the branch organizations must initiate dialogue between vendors/manufacturers and the niche segment. From here on, market forces will power diffusion into the entire mainstream.

We think that this protocol can be effective to stimulate diffusion of energy related innovations into the mainstream of various markets. Commissioned by the Ministry of Traffic and Transportation, we are now resting all four steps of this protocol in the automobile market. The goal is to speed up diffusion of environment-friendlly innovations such as silent tyres, ethanol-driven cars, and natural-gas driven cars. In due course we will report the results. 


\section{References}

Egmond C., Jonkers R., Kok G., 2005a.

A strategy to encourage housing associations to invest in energy conservation,

Energy Policy, 33, pp. 2374-2384.

Egmond C., Jonkers R., Kok G., 2005b.

Target group segmentation makes sense: If one sheep leaps over the ditch, all the rest will follow, Energy Policy, accepted for publication.

Egmond C., Jonkers R., Kok G., 2005c.

One size fits all? Policy instruments should fit to segments of target groups, Energy Policy, accepted for publication.

Green L.W., Kreuter M.W., 1999.

Health promotion planning, $3^{\text {rd }}$ edition, Mountain View, California.

Moore G., 2002.

Crossing the chasm, Harper Collins, New York.

Rogers E., 1995.

Diffusion of innovations, $4^{\text {th }}$ edition, The Free Press, New York.

Rogers E., 2003.

Diffusion of innovations, $5^{\text {th }}$ edition, The Free Press, New York.

Silvester S., 1996.

Demonstration projects and energy-efficient housing building, Erasmus

Studiecentrum voor Milieukunde, Rotterdam.

Wieffels P., 2002.

The chasm companion, Harper Collins, New York. 


\section{Chapter 6 \\ Discussion and Conclusion}

This dissertation focuses on the development of a strategy to select appropriate policy instruments to influence the behaviour of housing associations in such a way that they invest in and use energy conservation mensures. We concentrated on analyzing their behaviour and the choice of appropriate instruments to influence their behavious. We did not study the implementation and ewaluation of the instruments.

We show that within the group of housing associations the behaviour of the actors differs, as does their willingness to change. These differences are especially apparent in the speed at which they adopt innovative energy conservation technology. From this observation we derived three clusters of specific tesearch questions.

1. How can we develop a well-reasoned intervention strategy to influence the behaviour of housing associations? Using the PRECEDE-part of the planning and evaluation model of Green and Kreuter we formulated specific sub questions:

1.1 Which factors influence the energy-relevant behaviour of housing associations?

1.2 Which policy instruments are best suited to forming an intervention strategy?

2. Because target groups are not homogeneous in their behavioural change, and because changes in target group behaviour follow a gradual pattern, we addressed the following sub-questions about the specific characteristics of segments within the target group, following Rogers' diffusion theory:

2.1 Is it possible to identify different adopter segments within the target group of housing associations?

2.2 What are the characteristics of these adopter segments?

2.3 What are the differences in the determinants of behaviour of the adopter segments?

Knowing the different segments and their chatacteristics, we then wanted to know if policy instruments influence the segments differently. We explored the differences between these segments from a theoretical point of view. Specifically we asked:

2.4 In what way do existing policy instruments differ in influencing the behaviour of the early market and the mainstream market actors?

3. In order to intensify adoption of innovations in the field of energy conservation and renewable energy, we adapted Moore's marketing method to bring policy supporting innovations into the mainstream and, thereby, to cross the chasm between the early market and the mainstream. The first step of this marketing method is to win a niche 
market in the mainstream as a starting point for wining the rest of the mainstream. Therefore, we addressed the following research questions:

3.1 Is it possible to identify members of this niche market?

3.2 What are the characteristics of the niche market members who form the first segment in the mainstream to market?

3.3. How to develop an approach to stimulate the niche segment to adopt energy conservation innovations?

We answered these research questions in the chapters above. In this chapter we summarize the answers, discuss their implications to increase diffusion of energy-related innovations, and we point the way towatd further research. Specifically, we discuss the approach based on the model of Green and Kreuter (1999), and its contribution to policy sience. Furthermore, we discuss the strategy of segmenting target groups to more effectively implement policy instruments. And finally, we discuss two necessary conditions to increase diffusion of innovations: minimize the behavioural change of the mainstreatm actors and adapt the innovative products to meet their needs.

\section{Research questions}

The first cluster of tesearch questions explored the possibility to (1) determine the factors which influence the behaviour of housing associations, (2) develop an intervention strategy, based on an analysis of the factors, and (3) subsequently choose the best policy instruments. In two studies, we showed that these three items are possible. In a first study, we established the most important determinants, the influencing factors, of the enetgy-related behaviour of housing associations. In a second study, we analyzed how specific policy instruments influence the determinants through their so-called "active ingredients". By combining the results of these two studies, we matched the active ingredients of the instruments to the determinants of the behaviour of housing associations. In this way, we developed a theoretically founded intervention strategy to choose instruments that best encourage housing associations to invest in energy conservation.

To paraphrase our second cluster of research questions, we asked: Why do some housing associations adopt innovations early and others much later? There is always a small group of "first adopters" and the rest follows step-by-step. Rogers (1995) explains this gradual process, and Moore (2002) describes obstacles in the diffusion process between the "early marker" and the "mainstream market". Indeed, we identified different adopter segments in the target group of housing associations. We then categorized the adopters, as described by Moore, and found the early market to be more "visionary" than the "pragmatic" mainstream. 
Furthermore, we found that policy instruments influence the early market and mainstream market differently. The early matket is intrinsically highly motivated, and does not need specific encouragement. Although a general subsidy regulation may be effective to reward the early market actors, it causes the "free-rider" effect (Jeeninga, 2002). To encourage the mainstream market, however, policymakers have to reckon with the pragmatic attitude of the mainstream actor: they will only adopt an innovation if it solves a problem or meets a need.

The above-mentioned differences between the early market and mainstream stem from different attitudes towards change and innovation. And these differences in attitude result in the mainstream being tather inactive in the innovative field of energy conservation, while the early market is active. Moore has described these differences as a "chasm" between the early and mainstream markets that prevents innovations from diffusing into the mainstream. We conclude that to choose and implement policy instruments effectively, policy makers must make a choice to specifically address the early market or the mainstream market.

The last cluster of research questions asks: How to cross this chasm and increase the rate of diffusion of innovations into the mainstream? Following Moore's (2002) marketing approach of niche marketing and "total-product" development, we found, in the mainstream of housing associations, a niche segment having characteristics close to those of the early market. This niche segment is the best market segment in the mainstream to approach first - we cross the chasm where it is narrow. To achieve policy goals, we adapted Moore's marketing method for targeting the mainstream and, thereby, crossing the chasm. To cross the chasm, an innovation must be modified to meet the pragmatic needs of the mainstream.

\section{The change oriented approach: the Green and Kreuter Framework}

We followed the change oriented approach, the PRECEDE part of the PRECEDEPROCEED framework of Green and Kreuter (1999). This approach to designing policy instruments focuses on the desired change to be achieved. In essence, it begins at the end (the goal) and works backward to derive a logical strategy to achieve the desired change. Its steps are: (1) assess the desired result (effect) of the change, (2) assess which change should be made by whom in order to get this result and, (3) determine how to accomplish this change.

The Green and Kreuter approach has proven its efficacy in various fields: health care, traffic safety and promotion of water conservation. Our research also demonstrates its applicability to develop an intervention strategy to influence the target group of housing associations, and we conclude that this approach can be applied to develop intervention strategies to influence the behaviour of other target groups as well. 
At SenterNovem, we have already used this method to chat the energy-related behaviout and determinants of other target groups: owners and tenants of office buildings, and local authorities. Through a survey with questionnaire, and statistical analysis of its data we established the determinants of the energy relevant behaviour of these different target groups and their relative importance (Egmond et al., 2005a).. In doing so, we operationalized the determinants of behaviour of these groups and made them measurable. And, we have developed intervention strategies.

From this, we conclude that the method provides a sound basis to develop an intervention strategy to influence the behaviour of target groups. An intervention strategy can be designed in a very specific way - the proposed instruments directly target the assessed determinants of behaviour. Therefore, we get an effective intervention strategy because the instruments match the determinants. Also, this intervention strategy is efficient because only potentially effective instruments are implemented.

\section{Contribution to policy theory}

The strength of the method lies in choosing instruments that influence the target-groupspecific behavioural determinants. This involves research within the target group to establish the behavioural determinants, as well as extracting the active ingredients from the policy instruments. Analysis of the determinants and active ingredients leads to an intervention strategy where the instruments fit the specific determinants of behaviour. This, in turn, leads to a potentially most effective set of instruments that will efficiently influence the target group.

The determinants form, so to speak, the bridge between instruments and behaviour. "This approach, which is derived from behavioural science, contributes to a more scientific development of policy to influence the behaviour of the target groups (Bartholomew et al., 2001). This is in contrast to the traditional instrument-oriented approach that focuses on impact and efficiency of policy instruments, but does not focus on the behavioural change necessary for innovations to be adopted. The instrumentoriented approach chooses instruments independent of their influence on behaviour and, indeed, the relationship between instruments and behavioural change is largely ignored. The instrument-oriented approach, therefore, cannot specifically explain how policies cause gains in energy conservation.

With our change-oriented approach, we can explain the causes of achieved energy conservation, and we can assess which instruments contribute the most. In this way our method also contributes to operationalizing the Fram Policy Formulating To Polliy Results 
(FPFTPR $)^{1}$ method, it provides a foundation for policy development. It also allows for monitoring and evaluating the efficacy of an intervention strategy. To this end, the "PROCEED" part of the PRECEDE-PROCEED framework focuses on process evaluation, impact evaluation and outcome evaluation. Through this, an intervention strategy towards target groups can be scientifically designed and evaluated.

The PRECEDE-PROCEED framework groups three sets of factors that make up behavioural determinants: the predisposing, enabling and reinforcing factors. We operationalized these in our survey and with them could explain $28 \%$ of the variance of energy-related behaviour of the target group of housing associations. In our survey, we considered and measured all factors. Our research was targeted at encouraging housing associations and, therefore, many items were about attitude and motivation.

From our analysis of the behavioural determinants of housing associations, we found five external-related factors that influence their behaviour. These include: one predisposing factor - subjective norm; two reinforcing factors - feedback from peers and feedback from local authorities; and two enabling factors - intersectoral cooperation and the influence of the branch-organization. This leads us to conclude that individual housing associations are sensitive to external parties.

We think we can imptove our explanation of the variance of the behaviour of our target group, which now stands at $28 \%$, by taking the externally related factors more into consideration. This improvement can be achieved by adding specific items to the questionnaire. These items should address the relationship with peers, the pros and cons of cooperation and planning with peers, coordination of activities, and the perception of barriers. Also, the actors' relationships with the local authorities should be further investigated and identified. The different toles of the local authorities, such as local policy maker, local spatial planner, permit provider and enforcer all influence the energy-related behaviour of housing associations.

The relationship and behaviour of external parties, such as peers, experts, tenants and local authorities, strongly influence the behaviour of the target group of housing associations. And, by assuming that housing associations are active within networks of organizations, we conclude that future applications of this method should also target this influence of the network on individual actors. Surveys should cover all relevant groups in the network, including their relationships and their relative importance to the actor. Based on analysis of the data of these surveys, an intervention strategy can be developed for

\footnotetext{
See Chapter 1, p. 13: Policy, in turn, began to focus on well-beilt implementation programmes with specific results. This change of focus is called: FPFTPR (From Policy Formulating To Policy Results), and is applied to all ministries.
} 
other target groups, analogous to our strategy for the target group of housing associations. If an intervention strategy is developed from a network perspective, implementarton can be coordinated to target the relevant network partners.

For policy developers who want to use our method, a litte warning is in its proper place. We reduced the complexity of reality by following an assumption in policy science that an organization can be considered as one-actor. And that in fact the determinants and behaviour of the decision-makers determine the determinants and behaviour of the organization. Therefore, as we did in our survey, the interviewees must be members of the decision-making unit of the organization. And this calls for careful preparation of the interviews and strict criteria for selection of the interviewees.

To futther increase the influence of an intervention strategy consisting of a number of instruments that target behavioural determinants, we tecommend further rescarch. We have established the so-called active ingredients of instruments by reviewing literature and consulting experts. The method can be improved, however, if the active ingredients of the instruments are empirically established. To do this, we suggest that the PROCEED part of the Green and Kreuter framework, which considers implementation and evaluation, be followed during implementation of intervention strategies. Such reseatch will help us to know more precisely the influence of the instmments on the determinants. It will allso give insight into the main and side effects of the individual instruments and, especially, how combinations of instruments influence behavioural determinants. Knowing whether combinations of instruments amplify each other's effects or hinder each other's effects will lead to a more effective mix of instruments.

\section{Segmentation of target groups}

We applied the segmentation method of Rogers (2003) with help of the constructed variable "acloption rate". The adopter categories of Rogers were identified in our target group of housing associations, and the relative sizes of our segments strongly resembled Rogers' theoretical sizes. We found $22.9 \%$ of the total market to be "innovators and early adopters" (Moore's early market) while theory predicts $16 \%$. We found $28.3 \%$ of our total market form the "early majority" while theory predicts $34 \%$. The "late majority" makes up $33.7 \%$ or our total market while theory predicts $34 \%$. And $15.1 \%$ are "laggards" while theory predicts $16 \%$. For Moore's mainstream, we found in total $77.1 \%$ (in theory $84 \%$ ) (Egmond et al., 2005b). Considering the distribution that we found closely matches the theoretical distribution, we assume that the energy-related behaviour of housing associations has a relatively behavioural-change-requiring character, and is perceived as innovative.

Furthemore, our case study demonstrates that the self-designating method effectively establishes the segment into which each actor belongs. This, in turn, establishes the early 
market and mainstream market segments. The relative segment sizes will not always agrea with the theoretical sizes. 'This depends on the innovative character of the behaviour studied.

We recommend that, while developing interventions, policy developers consider two issues. Firstly, target groups can be segmented into an early market and mainstream market. Secondly, policy instruments have a different influence on the early market and the mainstream market segments. To stimulate the early market, often no extra instruments are needed; with their vision and enthusiasm for technology, the actors of the early market are internally motivated. Because the early market is active and dynamic, it often encounters institutional barriers. Sometimes the best way to stimulate the early market is simply to remove the institutional barriers. To stimulate the mainstream market, however, policy instruments should be simple and act early in the decision-making process. If, for example, economic instruments are appropriate, they should not entail complicated subsidy schemes, but implement easily accessible and simple financial arrangements - "cash on the barrel head". Furthermore, they should present the experiences of peer organizations, and offer a choice of standard options. Policy developers should also take into account that mainstream actors avoid risk and want to solve problems (Egmond et al., 2005c).

\section{Comments on existing policy instruments}

Complicated and time-consuming subsidies are often used in attempts to stimulate adoption of innovative energy conservation measures. Many evaluations of subsidy regulations report, however, that 50-60\% of the adopters are "free riders" - actors who would buy the innovative product without subsidy, and then collect the subsidy afterwards. Our study explains this phenomenon. The early market is not stimulated by subsidies; they inherently choose for an innovative technology and then look to see if it is covered by a subsidy. Furthermore, when an innovation subsidy is announced, nany companies look into their existing projects to find something that fits the new subsidy regulation. Many firms have employees, or even special departments, dedicated to watching for and analyzing new subsidy regulations.

Current policy rests on the assumption that "high price is the mainstream's greatest obstacle to adopting innovative ptoducts". Many current policies only focus on reducing the costs of energy conservation measures by compensating the higher costs of the innovarive products with subsidies or grants. This strategy follows from the abovementioned false assumption. But we know, from our research of the target group of housing associations, that financial resources do little to stimulate investment in energy conservation. For the pragmatic mainstream actors, changing their own behaviour forms 
the largest obstacle. This mplies that the focus of policy should be on removing the olstacles to behavioural change that are ofter associated wh adopting an innovation.

To this end, policies can, for example, stimulate the manufacturets and suppliers of innovative products to adapt them to meet the needs and solve the problems of the pragmatic mainstream. Another possibility is to create a new problem for the mainstream by law and legislation that cam be solved through adoption of an innowative product. As investments in energy conservation become a part of economic traffic, for example, by emission trading, policies stimulating this will meet the pragnatic atcitude of the mainstream market.

\section{Behavioural change related to the diffusion of innovation}

We found that the early market and the mainstream differ in their attitude towards change and innovation. This creates a "chasm" between these two market segments. Innovations which require a change of behaviour, the so-called discontinuous innovations, do not: easily cross this chasm - mainstream actors do not readily change their behaviour. This finding is in agreement with Moore's marketing point of view (Moore, 2002). We operationalized Moore"s concept of crossing the chasm, a form of niche marketing. And we conclude that to speed up the adoption of policy desired innovations into the mainstream, it is the best to cross the chasm where it is narrowest. In other words" target a niche group in the mainstream that is most similar to the early market. (Egmond et al., 2005d).

From our findings about the chasm between the early market and mainstream, we also conclude that Rogers' assumption regarding the continuity of innovativeness does not always hold. In our case certainly, the concept of the chasm provides a more effective approach to systematically increasing diffusion into the mainstream. Discontinuous innovations, those reguiring the mainstream actors to change their behaviour, will be most quickly adopted by the mainstream when the innovative product is made "more complete". Make the product fit the mainstream actors, adapt it to minimize the required change in behaviour, and solve a problem of the mainstream.

As mentioned above, current policy rests on the assumption that "high price is the mainstream's greatest obstacle to adopting innovative products". Running the risk of repeating ourselves too much, we emphasize that this assumption is wrong. We conclude that innovative products require too much behavioural change, and they do not meet the needs of the mainstream. Even if you drop the price of an innovation to zero, a need for the innowation will nor arise.

Adapting innovative products to meet the needs of the mainstream of a target group presumes a behavioural analysis of the mainstream actors. To achieve policy goals, relevant innowative products must be adapted to meet the needs of the mainstream. The 
diffusion of innovations is, in other words, a matter of behavioural analys leading to behavioural change.

We mentioned in Chapter 1 that in NEPP-4 the solution of obstimate environmental problems was found in a more fundamental approach and that a systemic change was needed. To that end, a policy of transition towatd large-scale changes and innovative approaches was developed. In this systemic change, innovations must be adopted on a large-scale and by many parties.

Our behavioural and marketing approach to stimulate the mainstream to adopt innovations, helping innovations cross the chasm, contributes operationally to the system innovation (transition) approach of NEPP-4.

\section{Final conclusions and recommendations}

Summarizing, we conclude that the method explored in this dissertation contributes to policy science in two general ways. Firstly, adding behavioural analysis to policy development provides a rational foundation for choosing effective and efficient policy instruments. Secondly, segmentation of the target group into an early market and mainstream market and then analysing their decision-making behaviour reveals that policy instruments influence these two segments differently.

Furthermore, our method offers immediate practical application in policy development. Firstly, it provides a foundation for applying the FPFTPR-method (From Policy Formulating To Policy Results) ${ }^{1}$ to target groups. Secondly, it provides a rational basis fot operationalizing the system innovation (transition) approach of NEPP-4.

We recommend further research on the behavioural determinants of target groups in a network context. Specifically we would ask:

- What relationships does a target group have with external parties?

- How do external parties influence the behavioural determinants of the target group in question?

- How can these relationships be influenced?

We also recommend research to determine more precisely the influence of instruments on behavioural determinants. Specifically, we would ask:

- What are the main and the side effects of individual instruments?

\footnotetext{
1 See Chapter 1, p. 13: Policy, in turn, began to focus on well-built implementation programmes wikh specific results. This change of focus is called: FPFTPR (From Policy Formulating "To Policy Results), and is applied to all ministries.
} 
- How do combinations of instruments influence behavioural determinants?

- Do alteady implemented instruments amplify each other's effects or, on the contrary, do they hinder each other's effects?

Finally, future applications of our method should address the influence of networks. within target groups on the individual actors' adoption of energy-relevant innovations. We also tecommend sharpening the variables "visionarity" and "pragmatism" as key characteristics of the early market and mainstream market. We constructed these variables from the existing questionnaire which, for our explorative purposes, was appropriate. To speed up the diffusion of innovations, a mote scientific foundation for these characteristics would sharpen their power to distinguish between the early market and mainstream market segments. 


\section{References}

Bartholomew L.K., Parcel G.S., Kok G., Gottlieb N. H., 2001.

Intervention mapping, Mayfield, Mountain View, California.

Egmond C., Jonkers R., Kok G., 2005a.

A strategy to encourage housing associations to invest in energy conservation,

Energy Policy, 33, pp. 2374-2384.

Egmond C., Jonkers R., Kok G., 2005b.

Target group segmentation makes sense: if one sheep leaps over the ditch, all the

rest will follow, Energy Policy, accepted for publication.

Egmond C., Jonkers R., Kok G., $2005 \mathrm{c}$.

One size fits all? Policy instruments should fit to segments of target groups,

Energy Policy, accepted for publication.

Egmond C., Jonkers R., Kok G., 2005d.

Finding a niche segment in the mainstream of housing associations: the first step

for innovations to reach the mainstream, Energy Policy, accepted for publication.

Green L.W., Kreuter M.W., 1999.

Health promotion planning, $3^{\text {rd }}$ edition, Mountain View, California.

Jeeninga H., Honig E., Dril A., Harmsen R., 2002.

Effect van energie- en milieubeleid op broeikasgas emissies in de periode 1990-2000

(Results of energy and environmental policy on greenhouse gas emissions in the

period 1990-2000), ECN, Petten.

Moore G., 2002.

Crossing the chasm, Harper Collins, New York.

Rogers E., 1995.

Diffusion of innovations, $4^{\text {th }}$ edition, The Free Press, New York.

Rogers E., 2003.

Diffusion of innovations, $5^{\text {th }}$ edition, The Free Press, New York. 
AgriHolland, 2001.

Broeikasgasemissie door veehouderij blijft afnemen (Emission of greenhouse gases decreases steadily), Article in electronic Newsletter of AgriHolland, (15022001).

Beus J.W. de, Doorn J.A.A.van, 1984.

De interventie staat (The intervening state), Boom, Meppel.

Belastingdienst, 2002.

Rapportage van onderzoeksbevindingen in het kader van de evaluatie van de

Energiepremieregeling (Research results of the evaluation of the Energy Premiun

Regulation), Belastingdienst, Centrum voor proces- en productontwikkeling, Utrecht.

Bartholomew L.K., Parcel G.S., Kok G., Gottlieb N.H., 2001.

Intervention mapping, Mayfield, Mountain View, California.

Bandura A., 1986.

Social foundations of thought and action, Prentice Hall, Englewood.

Bressers J.Th.A., Klok P-J., 1988.

Fundamentals for a theory of policy instruments, International Journal of Social

Economics, Vol.15, no3/4, pp. 22-41.

Bressers J.Th.A., Lulofs K.R.D., 2002.

Charges and other policy strategies in Dutch water quality management, University

Twente Enschede.

Bressers J.Th.A., de Bruijn T.J.M.M., Lulofs K.R.D., 2004.

Evaluatie van de Nederlandse milieu convenanten (Evaluation of the Dutch environmental covenants), Beleidswetenschap, (18), no 3, pp. 242-260, Kluwer, Alphen aan de Rijn.

Bressers J.Th.A., Lulofs K.R.D., 2004.

Industrial water pollution in the Netherlands: a fee-based approach, Harrington W., Morgenstern R.D. and Sterner T. (eds.), Choosing environmental policy, comparing instruments and outcomes in the United States and Europe, pp. 91-110, Resources For the Future, Washington DC.

Bruijn T.J.M.M., Bressers J.Th.A., Lulofs K.R.D., Veer A. van de, 2003.

The use of covenants in target group policy. CSTM, Enschede.

Caluwe L., Vermaak H., 2002.

Leren veranderen (Learn to change), Kluwer, Deventer.

Cyert R.M., March J.G., 1992.

A behavioural theory of the firm (2ed), Blackwell, Oxford, UK.

Daft R., 2001.

Organizations theory and design, $7^{\text {th }}$ Edition, South west college Publishing. 
Doelen F.C.T. 1989.

Beleidsinstrumenten en energiebesparing (Policy instruments and energy conservation), University of Twente, Enschede.

Egmond C., Jonkers R., Kok G., 2005a.

A strategy to encourage housing associations to invest in energy conservation.

Ėnergy Policy, 33, pp. 2374-2384

Egmond C., Jonkers R., Kok G., 2005 b.

Target group segmentation makes sense: if one sheep leaps over the ditch, all the rest will follow, Energy Policy, accepted for publication.

Egmond C., Jonkers R., Kok G., 2005c.

One size fits all? Policy instruments should fit to segments of target groups,

Energy Policy, accepted for publication.

Egmond C., Jonkers R., Kok G., 2005d.

Finding a niche segment in the mainstream of housing associations: the first step

for innovations to reach the mainstream, Einergy Policy, accepted for publication.

Essers I., Mooij M., 2001.

Secundaire effecten van de EPN (Secundary effects of the EPS), Ecofys, Utrecht. Green L.W., Kreuter M.W., 1999.

Health promotion planning, $3^{\text {rd }}$ edition, Mountain View, California

Greet H., Jonkers R., Smits A., Görts C., Papadopolou K., Begley S., 2000.

The guide to change, a SAVE study, Aeneas, Best.

Grin J., Graaf H. wan der, Vergragt P., 2003.

Een derde generatie milieubeleid: een sociologisch perspectief en een

beleidswetenschappelijk programma. (A third generation environmental policy: a

sociological perspective and a policy-scientific progtam) Beleidswetenschap,

17, no1, pp. 51-72. Kluwer, Alphen aan de Rijn.

IPCC, 2001.

Climate change 2001 synthesis report. An assessment of the intergovernmental panel

on Climate Change, approved by the IPCC plenary (XVIII), Wembley, 2001.

Jeeninga H., Beeldman M., Boonekamp P.G.M., 2001.

Nadere invulling van de EPA doelstelling voor woningen,

(Definition of the Energy Performance Aclvice targets), ECN, Petten.

Jeeninga H., Honig E., Dril A., Harmsen R., 2002.

Effect van energie- en milieubeleid op broeikasgasemissies in de periode 1990-2000

(Results of energy and environmental policy on greenhouse gas emissions in the period 1990-2000), ECN, Petten. 
Jong J.J. de, Weeda E.O., Westerwoudt Th, Cortelje A.F., 2005.

Dertig jaat Nederlands energie beleid (Thitty years Dutch energy policy), Clingendael, CIEP, Den haag.

Klok P-J., 1991.

Een Instrumenttheorie Voor Milieubeleid (Instrument theory of environmental policy), Universiteit Twente, Enschede.

Kool R., Egmond C., Rijn D. van., Jemiskens S., 2002.

Strategisch kader gebouwde omgeving (Strategic framework for the built environment), SenterNovem, Utrecht.

Kool R., Egmond C., 2004.

The energy performance of a location; successes, setbacks and new approach; proceedings ACEEE summer study on energy efficiency in buildings, ACEEE, Washington DC.

Kotler P., 2003.

Marketing management (1 $1^{\text {th }}$ ed) Prentice-Hall, Pearson Education, New Jersey. Latour B., 1997.

De Berlijnse sleutel (The Berlin key), Van Gennep, Amstetdam.

Leroy P.L.M., 1994.

De ontwikkeling van het milieubeleid en van de milieubeleidtheorie,

(Development of the environmental policy and environmental policy theory),

Glasbergen P. (ed.), Milieubeleid, een beleidswetenschappeliike inleiding

(Environmental Policy, a policy-scientific introduction), pp. 35-58, VUGA, Den Haag.

Levitt T., 1986.

The marketing imagination, The Free Press, New York.

Ligteringen J.J., 1999.

The feasibility of Dutch environmental policy instruments, Twente University

Press, Enschede.

Lulofs K.R.D., 2001.

Implementing command and control directives: the case of ditective $89 / 429 / \mathrm{EEC}$, in

Glachant, M., Implementing European environmental policy: the impacts of directives in the member states, pp.81-109, Cheltenham/Northampton.

Lulofs K.R.D., Lettinga B., 2003.

Instrumenten mainstream market (Instruments mainstream market): $\mathrm{CO}_{2}$ reductie in de Gebouwde Omgeving, CSTM - SR202, Universiteit Twente, Enschede.

Minnesma M., 2003.

Dutch climate policy: a victim of economic growth, Climate Policy 3, pp.45-56.

Ministry of Economic Affairs, 1998.

Energy conservation white paper, Ministry of Economic Affairs, Den Haag. 
Moote $G_{x}, 2002$.

Crossing the chasin, Harper Collins, New York.

NEPT-1, 1989.

Nationaal Milicubeleidsplan (NMP) (National Environmental Policy Plan),

Ministeric van Volkshuiswesting Rumtelike Ordening en Milieu, Den Haag.

NEPP-2, 1993.

Nationaal Milieubeleidsplan 2 (NMP-2) (National Envitonmental Policy Plan 2),

Ministeric van Volkshuisvesting Rumtelijke Ondening en Milieu, Den Haag. NEPP-3, 1998.

Nationaal Milieubeleidsplan 3 (NMP-3) (National Enwironmental Policy Plan 3),

Ministerie van Volkshuisvesting Ruimtelijke Ordening Milieu, Den Haag. NEPP - 4, 2001.

Nationaal Milieubeleidsplan 4 (NMP-4) (National Environmental Policy Plan 4),

Ministerie wan Volkshuiswesting Ruimtelijke Ordening en Milieu, Den Haag. RTVM, 2005.

Environmental balance 2005, Milieu- en Naturtplanbureau, Bilthoven.

Rogers F.M., 1995.

Diffusion of innovations, $4^{\text {th }}$ edition, The Free Press, New York.

Rogers E.M., 2003.

Diffusion of innovations, $5^{\text {th }}$ edition, 'The Free Press, New York.

Schuddeboom J., 1990.

Milieubeleid in de praktijk (Environmental policy in practice), Universiteit van

Twente, Enschede.

Silverman D., 1970.

The theoty of organizations, Basic Books, London.

Silvester S., 1996.

Demonstration projects and energy-efficient housing building, Erasmus

studiecentrum voor milieukunde, Rotterdam.

Steckler A, Goodman R.M., Kegler M.C., 2002.

Mobilizing organizations for health enhancement: theories of organizational change, in

Glanz K., Rimer B., Lewis F. (eds.), Health behavior and health education: theory research and practice, $3^{\text {th }}$ Edition, pp.335-366, Josey Bass, San Francisco.

Tatenhove R., 1993.

Milieubeleid onder dak (Enwironmental policy under shelter), Universiteit van

Wageningen, Wageningen.

Vellinga P., Verseveld J. W., 2000.

Climate change and extreme weather events, Institute for environmental studies, VU, Amsterdam, WWF:

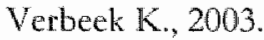

De toestand van het klimat in Nederland 2003 ("The situation of the climate in the 
Netherlands 2003), The fourth national climate report 2003, KNMI, De Bilt Vermeulen W., 1992.

De vervuiler betaald, Onderzoek naar de werking van milieusubsidies op wier deelterreinen van het milieubeleid (The polluter pays, research on the effect of subsidies in four fields of the environmental policy), Universiteit van Uitrecht, Utrecht.

VROM-raad, 2001.

Waar een wil is, is een weg (Where there is a will, there is a way), advice on the National Environmental Policy Plan - 4, Den Haag.

Wieffels P., 2002.

The chasm companion, Harper Collins, New York. WRR, 1992.

Rapport 41, Milieubeleid, strategie, instrumenten en handhaafbaarheid (Environmental policy, strategy, instruments and enforcement), SDU, Den Haag. 
Climate change confronts us all with enormous problems. Research into the influence of human action on climate change, via the enhanced green house effect, has led governments throughout the world to set policy goals to reverse the human causes of global warming. Reducing energy consumption and thereby reducing the emission of $\mathrm{CO}_{2}$ contributes to this reversing task and is, indeed, stimulated by governmental policy. This policy consists of stimulating energy conservation technology and renewable energy technology and investments in energy conservation and renewable energy.

Development of energy conservation technologies, by itself, does not conserve energy. Only if target groups use energy conservation and renewable energy technologies, energy will be conserved. The Dutch Government has specifically targeted the users and owners of buildings as being large energy consumers. By stimulating these target groups to bend their investment behaviour in the direction of energy conservation and renewable energy, the built environment will conserve energy, and contribute to climate change policy.

This dissertation answers the key question: In what way is it possible to develop a wellreasoned intervention strategy to influence the actors within the target group of housing associations to invest in energy conservation measures and renewable energy.

Answering this question we also meet the need of the Ministry of Housing for an intervention strategy with well-reasoned instruments to stimulate target groups to invest more in energy conservation. This key question is focused on realizing behavioural change. And therefore a change oriented approach was followed, provided by the planning and evaluation framework of Green and Kreuter (1999), the PRECEDEPROCEED model. To examine the change processes of the target group the diffusion of innovation theory of Rogers (1995) was used, and specifically related tot the adoption of innovations by the mainstream the high-tech marketing model of Moore (2002) was used. In the introductory chapter 1 the energy conservation policy was described in broad outline against the background of the environmental policy, to make the importance of the target group approach clear.

\section{The PRECEDE-PROCEED model van Green en Kreuter (1999)}

In chapter 2 the planning and evaluation framework of Green and Kreuter (1999), the PRECEDE-PROCEED model, was applied to design interventions to influence the behaviour of the target group of housing associations. The PRECEDE-model rests on the assumption that designing and planning an intervention strategy that stimulates behavioural change strongly depends on knowing the determinants of behaviour and knowing what methods effectively influence those determinants to stimulate such at 
change. We define a determinant to be: "a complex of factors that mediate or influence behavioural change of an actor in the target group".

In our application of the Green and Kreuter model we followed their assumprion that the determinants consist of three main groups of factors:

1. Predisposing factors, which are especially organization-internal antecedents to behaviour. They motivate the behaviour and include: awareness and knowledge, organizational norms, subjective norms, attude, self-efficacy, and intention.

2. Enabling factors, which are the external and situational antecedents to behaviour. They facilitate the realization of the new behaviout. These factors relate to external resources and new skills. Resources include external financial, technical and organizational, and judicial resources. Fxamples are subsidies, engineering advice, regulations.

3. Reinforcing factors are those consequences of an action which determine whether the organization receives feedback. These factors include: feedback of peer organizations, advice and feedback from powerful and significant organizations (e.g. authorities offering stimulating subsidies and enforcing obligations), and feedback from customers.

\section{Determinants of behaviour}

To establish the determinants that influence theit energy-related behaviour, we first surveyed the target group of housing associations, and we established their energy related behaviour - the degree to which they take energy conservation measures in their housing stock. Chapter 2 reports the design and the results of this survey. The results were that $28 \%$ of the total variance of enetgy related behaviour could be explained by the determinants studied in the survey. When taken separately, the determinants explained the wariance as follows:

- Giving priority to energy conservation in relation to "quality-of-life", "protection against burglary": 10\%;

- Having a "covenant with a local authority": $8.8 \%$ "

- Energy conservation as a means of "cost-saving": 6.7\%;

- "The presence of an "energy conservation champion" : $6.7 \%$;

- "The presence of "knowledge about energy conservation": 6.4\%;

- Energy conservation contributing to "housing confort": $5.3 \%$.

In order to establish from the determinants of the target group which factors of the model are most important, the relationship between the deteminants of the target group and the predisposing, enabling and reinforcing factors of the model was analyzed.

Of the predisposing factors, "attitude" is the strongest, followed by "subjective norm" and "self-efficacy". "Awareness" and knowledge" and do not play important roles. Of the enabling factors, "technical resources" is the strongest and "financial resources" 
plays only a weak role. "Feedback of peer organizations" and "feedback of the authority" are the strongest reinforcing factors.

\section{Policy instruments and determinants}

Furthermote in Chaptet 2 the active ingredients of the four main types of policy instruments - judicial, economic, communicative instruments, and physical provisions were established. To this end, we reviewed the literature in the field of policy instruments and interventions, and determined the instruments influences on the factors of the model that make up the determinants of behaviour. A number of experts in the fields of behavioural change and policy instruments judged these "active ingredients" of the policy instruments.

The policy instrument "covenant' has notably influence on the factors attitude and feedback of authorities. The instrument information and promotion' has influence on the factors awareness, attitude and new skills. The policy instrument 'personall advices has influence on knowledge, self-efficacy, organizational resources and new skills.

We then matched the active ingredients of the instruments with the strongest behavioural factors of energy-relevant behaviour of housing associations. This gave a list of the potentially most effective instruments. From this we conclude that effective judicial instruments axe covenants and agreements, combined with enfotcement. Economic instruments are hardly televant for housing associations. Effective communicative instruments give information and personal advice, and promote and demonstrate energyrelated technologies. Infrastructural provisions are also effective.

\section{Segmentation of the target group in: early market and mainstream market}

In Chapter 3 the fact that targer groups are not homogeneous in their behavioural change, was taken into consideration. Changes in target group behaviour always follow a gradual pattern. First, a relatively small group adopt an innovation (the earlier adopters) and other aclopters follow later. In a nutshell, the diffusion theory of Rogers (1995) states that some people or organizations are more willing to change and they adopt innovations relatively fast, while others "wait and see".

In the explorative study reported here was investigated how the target group of housing associations can be segmented into categories based on the rate of adoption (adopter categories), and how the behaviour of adopters belonging to those different categories can be effectively influenced. We then compared the differences in behaviourat determinants between the adoption categories. Specifically, we addressed fout questions: (1) how can the different segments of the adopter market be determined, (2) what are the characteristics of the adopters in the different categories, (3) how do the determinants of 
behaviour of the adopter categones differ, and (4) what instruments fit these segments best?

To address these questions, we further analysed the data from the survey of housing associations mentioned above, following the theory of Rogers and Moore. Rogers (1995) distinguishes five adopter categovies: the innovators, the early adopters, the early majority, the late majority and the laggards. From a marketing point of view, Moore (2002) has condensed this categorization of Rogers in two categories: the early market and the mainstream market. According to Rogers (1995) and Moore (2002) differences in adoption rates of the various markets originate from differences in the actors" artitudes towards change and imnowation.

We constructed the variable "adoption rate" and used it to distinguish between adopters on the basis of speed of adoption. In the table below we show the adoption categories with the variable "adoption rate".

Table: Adoption rate and adoption categories

\begin{tabular}{|c|c|c|c|c|}
\hline $\begin{array}{l}\text { Adoption } \\
\text { rate }\end{array}$ & $\begin{array}{l}\text { Adoptlon category according } \\
\text { Rogers }\end{array}$ & $n=205$ & $\begin{array}{l}\text { Adoption category } \\
\text { according Moore }\end{array}$ & $1=205$ \\
\hline Score 4-5 & $\begin{array}{l}\text { adoption speed fast: innovator } \\
\text { or early adopter, a trend-setter }\end{array}$ & $\begin{array}{l}22.9 \% \\
n=47\end{array}$ & early market & $\begin{array}{l}22.9 \% \\
n=47\end{array}$ \\
\hline Score 3 & $\begin{array}{l}\text { adoption speed higher than average: early } \\
\text { majority with the niche actors }\end{array}$ & $\begin{array}{l}28.3 \% \\
\mathrm{n}=58\end{array}$ & \multirow[t]{3}{*}{$\begin{array}{l}\text { mainstream } \\
\text { market }\end{array}$} & \multirow[t]{3}{*}{$\begin{array}{l}77.1 \% \\
n=158\end{array}$} \\
\hline Score 2 & $\begin{array}{l}\text { adoption speed average } \\
\text { late majority }\end{array}$ & $\begin{array}{l}33.7 \% \\
n=69\end{array}$ & & \\
\hline Score $0-1$ & adoption speed slow or laggard & $\begin{array}{l}15.1 \% \\
n=31\end{array}$ & & \\
\hline
\end{tabular}

Based on a housing association's score on the variable 'adoption rate" we know to which martwer segment the individual housing associations belongs. Housing associations with an adoption rate $4-5$ belong to the early market, housing associations with an adoption rate of $0-1,2$ and 3 belong to the mainstream market.

The early market and the mainstream market were further characterized based on Moore's comparison of the early market and the mainstream market. Moore characterizes these segments as follows:

The early market actors, as visionaries, are motivated by future opportunities and challenges, they seek revolutionary advances, and are somewhat contrarian and selfreferencing, they avoid the herd, take risks, have a long term decision hotizon and seek what is possible, and are oriented on the best technology.

The mainstream actors, as pragmatists, are motivated by current problems, seek evolutionary advances, they are conformists and reference others perceived as similar, they stay with the herd, are risk-averse, and pursue what is probable, they have a short 
term decision horizon, and will seek the best solutions provided by a matket leader. (Moore, 2002).

By means of the variable visionatity, constructed of 14 items of the questionnaire, it could be concluded that the early market segment of housing associations is significanty more visionary than the mainstream segment. From the analysis of behavioural determinants it appeared that the early market considers policy matters important. They often have an environmental policy plan including energy conserwation and renewable energy. But they percerve the influence from the branch organization and the infuence from the government as not so important. The mainstream, however, has a weakly developed policy or no policy at all. And the mainstream prefers intersectoral cooperation much more so than the early market. Renewable energy is not an important issue for the mainstream. Their decision making is more influenced by the branch organization, and they are more susceptible to governmental influence.

\section{Early market en mainstream policy instruments}

In Chapter 4 we studied which policy instruments will most effectively influence these two segments within the target group of housing associations. We first looked at the differences between the early and mainstream market actors from a behavioural-change point of view, and analyzed early market and mainstream decision-making behaviour. Secondly, we studied in what way existing policy instruments differ in influencing the behaviour of these actors, and how the active ingredients of policy instruments specifically target the behavioural characteristics of the early market actors and mainstream market actors.

We combined the results of these two studies in an overview of instruments suited for the early market and mainstream market.

Early market instruments. The early marker is best influenced through knowledge transfer about innovative technology and products, and stimulating communication. Demonstrations challenge these actors if they can play the role of demonstrator. There is no need for much instruments to stimulate the early market because they are highly intrinsically motivated.

Mainstream instruments. Instruments that best influence the mainstream market include: specific permits - they cause a problem that the target group has to solve; covenants have a deliberate character and orient the actors toward the group; subsidies can influence the cost-benefit reasoning of the mainstream, and here the most effective form is cash-on-the-barrelhead.

Furthermote, mainstream instruments should emphasize communication about advantages such as comfort and quality in addition to money and energy savings, and 
present energy conserwation as a sollution to an actual problem, i.e. quality improwement of the housing stock.

\section{Speeding up the adoption of innovations in the mainstream}

In Chapter 5 the question was addressed, that many innovations in the field of energy conservation reach - they diffuse only into - the early matket. The mainstream market is hardy reached, because the manistream has a much more pragmatic and cautious attitude towards change and innovation. This "chasm" betwreen the early market and the mainstream is caused by the different attitudes that the actors in these segments have toward change and innovation. In order to intensify the diffusion of energy ralated innowations into the built environment, this chasm between the early market and mainstrean market has to be crossed.

\section{Crossing the chasm}

According to Moore (2002) the first step of crossing this chasm is to first win a niche market in the mainstream as starting point for winning the rest of the mainstream. To cross the chasm, adaptation of the innovation to meet the more pragmatic needs of the mainstream market is indispensable. In order to perform this crossing task, the following three questions wete addressed: (1) how can members of this niche segment be identified, (2) what are the characteristics of the niche market, and (3) what approach should be used to reach this niche market? These questions wete answered by performing a secondary analysis of the data of the survey in the target group of housing associations. the early majority segment in the mainstream contains the members of this niche segment, and focus of marketing activities should be targeted at the most pragmatic members of the early majority segment.

The adaptation of Moore"s marketing method of "crossing the chasm" into the field of policy development led to a protocol to cross the chasm.

In Chapter 6 it was concluded that the method, explored in this dissertation, contributes to policy science in two ways. Firstly, by adding the behavioural analysis to policy development, the method provides a rational foundation to select effective and efficient policy instruments. Secondly, segmentation of the target group into an early market and mainstream market reveals that policy instruments influence these two segments differently. In choosing policy instruments this should be taken into account: every segment its proper instruments.

For future applications of our method it is recommended that it should address the influence of networks within target groups on the individual actors' adoption of energy relevant innowations, and should develop the method from a network perspective, by surveying all relevant target groups in the network. 
Further it was concluded that the method contributes to policy development in nwo ways. Firstly, it provides a foundation for applying the FPFTPR-method (From Policy Formulating To Policy Results) ${ }^{1}$ to target groups. Secondly, it provides a rational basis for operationalizing - crossing the chasm - the system innovation (transition) approach of National Environmental policy plan-4, by providing a method to speed up the adoption of innovations in the mainstream.

\footnotetext{
1See Chapter 1, p. 13: Policy, in turn, began to focus on well-built implementation programmes with specific tesults. This change of focus is called: FPFTPR (From Policy Formulating To Policy Results), and is applied to all ministries.
} 
De verandering van het klimaat is een van de grote milieuproblemen van onze tijd. Onderzoek naar de klimaatverandering heeft de invloed wan het menselijk handelen daarop, via het broeikaseffect, an het licht gebracht. Dit heeft veel regeringen ertoe gebracht beleid te maken dat erop gericht is om de menselipke ootzaken van de klimatverandering tegen te gaan. Het verminderen van het energiegebruik en darmee de vermindering van de $\mathrm{CO}_{2}$ uitstoot, dragt daar an bij en is onderdeel van het tegeringsbeleid. Dit beleid bestat uit het stimuleren van de ontwikkeling van energiebesparingtechnologie en duurzame energie en het stimuleren van investeringen in energiebespating en duurzame energie.

De ontwikkeling van energiebesparingtechnologie op zich bespart geen energie. Pas als doelgroepen energiebesparings- en duurzame energietechnologie gebruiken, wordt er energie bespaard. De Nederlandse regering heeft in het bijzonder gebruikers en eigenaars var gebouwen aangemerkt als grote energiegebruikers. Door deze doelgroepen te stimuleren hun investeringsgedrag om te buigen in de richting van energiebesparing en duurzatne energie, zal de gebouwde omgeving energie besparen en een bijdrage leveren aan het klimaatbeleid.

De hoofdvraag van deze dissertatie is: Op welke wijze is het mogelijk een goed onderbouwde interventiestrategie te ontwikkelen die het gedrag van de doelgroep woningcorporaties beïndoedt en hen stimuleert te investeren in energiebesparing en duurzame energie. Met het antwoord op deze vraag komen we tegemoet aan de vraag van het ministerie van Volkshuisvesting, Ruimtelijke Ordening en Milieu (VROM) naar een interventiestrategie die met beargumenteerd instrumentarium doelgroepen stimuleert om meer aan energiebesparing te doen.

De hoofdvraag heeft betrekking op verandering van gedrag. En om deze vraag te kunnen beantwoorden is er voor gekozen een verandering-georiënteerde aanpak te volgeri. Het model van Green en Kreuter (1999) het planning- en evaluatiemodel PRECEDEPROCEED, hanteert een verandering-georiënteerde aanpak. Daarom is het PRECEDEPROCEED model gebruikt. Om de veranderingsprocessen in de doelgroep nader te onderzoeken is de theorie over de diffusie van innowaties van Rogers (1995) gebruikt. En specifiek voor het onderzoek naar de adoptie van innovaties door de mainstream is gebruik gemaakt van het hightech marketing model van Moore (2002).

In het inleidende hoofdstuk 1 wordt het energiebesparingsbeleid geschetst tegen de achtergrond van het milieubeleid, waarbij het belang van een doclgroepaanpak duidelijk wordt. 


\section{Het PRECEDE-PROCEED model van Green en Kreuter (1999)}

In hoofdstuk 2 wordt allereerst het planning- en evaluatiemodel van Green en Kreuter (1999), het PRECEDE-PROCEED model, toegelicht dat gebruikt is om interventies te ontwerpen die het energiegerelateerde gedrag wan de doelgroep woningcorporaties beinvloeden. Dit model hanteert het volgende uitgangspunt: het ontwerpen en plannen van een interventiestrategie die gedragsverandering stimuleert, hangt af van inzicht in de cleterminanten van dat gedrag en van de kennis over de methoden die effectief de determinanten beïnvloeden om zo'n gedragsverandering te stimuleren. Determinanten zijn hier gedefinieerd als factoren die gedragsverandering bij een actor beïnvloeden.

Bij de toepassing van het model van Green en Kreuter is hun aanname overgenomen dat determinanten uit drie hoofdgroepen factoren bestaan:

1. De predisposing, voorbestemmende, factoren. Dit zijn de organisatie-interne factoren die, voorafgaand aan het gedrag, aanwezig zijn. Ze motiveren het gedrag. Het gaat hierbij om: bewustzijn en kennis, organisatie-norm, subjectieve norm, houding, eigen-effectiviteit en intentie.

2. De enabling, in staat stellende, factoren. Dit zijn de situationeel-externe factoren die, vootafgaand aan het gedrag, anwezig zijn. Zij faciliteren het nieuwe gedrag. Deze factoren hebben betrekking op externe hulpmiddelen. Hierbij gaat het om financiële, technische, organisatorische en juridische hulpmiddelen. Bijvoorbeeld: subsidies, engineering advies en vergunningen.

3. De reinforcing, versterkende, factoren. Dit zijn die gevolgen van gedrag die bepalen of een organisatie feedback krijgt. Ze omvatten feedback van collega-organisaties, advies van experts en feedback van belangrijke organisaties, bijvoorbeeld overheden die subsidies aanbieden en vetplichtingen handhaven, en, tenslotte, feedback van klanten.

\section{Determinanten van het gedrag}

Om de determinanten vast te stellen die het energierelateerd gedrag, het nemen van energiebesparende matregelen in hun woningvoorraad, beinvloeden, is in het eerste onderzoek een survey uitgevoerd onder de doelgroep woningcorporaties.

In hoofdstuk 2 worden vervolgens de opzet en de resultaten van deze survey besproken. Het resultat was dat $28 \%$ van de variantie van het energiegerelateerde gedrag verklaard kon worden door de gezamenlijke determinanten. De individuele determinanten verklaarden de variantie als volgt:

- de atandacht voor energiebesparing vergeleken met leefloarheid, diefstalpreventie: 10\% van de variantie;

- het hebben van een convenant met een gemeente: $8,8 \%$;

- energiebesparing als een middel om woonlasten te verminderen: $6,7 \%$;

- de anwezigheid van een energiebesparingvoorvechter: 6,7\%; 
- de aanwezigheid wan specifek energiebesparingkennis: $6,4 \%$

- energiebesparing als bijdrage ara het wooncomfort: $3,3 \%$.

Om uit de gevonden determinanten wast te stellen wat de belangrijkste beinvloedende factoren van het model zijn is een analyse gemakt van de relate tussen de determinanten wit de survey en de predisposing, enabling en reinforcing factoren van het model. Van de predisposing factoren is de attitude het belangrijkst, gevolgd door de subjectieve norm en de eigen-effectiviteit. Bewustzijn en kennis spelen geen belangrijke rol. Van de enabling factoren spelen de technische hulpmiddelen de belangrijkste rol en spelen financiele hulpmiddelen geen rol wan betekenis. Feedback wan collega-organisaties en feedback van de overheid zijn de belangtijkste reinforcing factoren.

\section{Beleidsinstrumenten en determinanten}

Verder is in hoofdstuk 2 van de vier hoofdgroepen beleidsinstrumenten - juridische, economische en communicatieve instrumenten en fysieke voorzieningen - onderzocht wat hun werkzame bestanddelen zijn, dat wil zeggen hun invloed op determinanten. Dit is gebeurd door literatuur op het gebied van beleidsinstrumenten te bestudeten, en vervolgens te analyseren op welke factoren van het model, de predisposing, enabling en reinforcing factoren, de verschillende beleidsinstrumenten invloed uitoefenen. Deze theoretische vaststelling van de werkzame bestanddelen is vervolgens beootdeeld door een aantal experts op het gebied van gedragsverandering en beleidsinstrumenten. Zo is gevonden dat het instrument 'convenant' met name invloed heeft op de factoren atritude en feedback van de overheid. Het instrument 'voorlichting en kennisoverdtacht' heeft met name invloed op de factoren awareness, attitude en nieuwe waardigheden, het instrument 'persoonlijk advies' heeft invloed op de factoren kennis, eigen-effectiviteit, organisator"sche hulpmiddelen en nieuwe vaardigheden, en het instrument "demonstraties" heeft met name invloed op de factor eigen-effectiviteit. De koppeling van beleidsinstrumenten met hun werkzame bestanddelen - hun effect op de determinanten aan de belangrijkste in de survey gevonden determinanten, levert een lijst van instrumenten op, dic het best passen bij de determinanten. Van de juridische instrumenten zijn convenanten en naleving ervan, wan belang. Economische instrumenten zijn woor woningcorporaties nauwelijks effectief. Van de communicatieve instrumenten zijn woorlichting en kennisoverdracht, demonstraties en persoonlijke advies effectief. Infrastructurele voorzieningen kunnen een effectief beleidsinstrument vormen.

\section{Segmentatie van de doelgroep in early market en mainstream market}

In hoofdstuk 3 is het niet-homogene verandetingsproces van doelgroepen onderzocht. Veranderingsprocessen bij doelgtoepen geleidelijk verlopen. Fir is eerst een kleine groep eetste adopters, die gevolgd wordt door latere adopters. In het kort komt de 
adoptietheorie van Rogers (1995) erop neet dat sommige organisaties, evenals mensen, gevoeliger zijn voor verandering en daarom veranderingen relatief snel accepteren, terwijl anderen 'de kat uit de boom kijken'.

Datrom wordt in het in hoofdstuk 3 besproken exploratieve onderzoek onderzocht hoe de doelgroep woningcorporaties gesegmenteerd kan worden in verschillende adoptiecategoricen en wordt tevens onderzocht hoe het gedrag van de adopters uit deze verschillende categorieen het meest effectief beinvloed kan worden. De volgende vier onderzoeksvagen zijn aan de orde gekomen: (1) hoe kunnen de verschillende adopter segmenten in de doelgroep worden vastgesteld, (2) wat zujin de karakteristieken wan deze adopter segmenten, (3) waarin vetschillen de determinanten van deze segmenten en (4) welke instrumenten passen het best bij deze segmenten.

Om deze wagen te beantwoorden is de theorie van Rogers (1995) en Moore (2002) gevolgd en is een nadete analyse uitgewoerd van de gegevens uit de survey die onder de doelgroep woningcorporaties is uitgevoend.

Rogers (1995) onderscheidt vijf adoptiecategorieën: de innovators, de early adopters, de early majority, the late majority and the laggards. Vanuit een marketing standpunt heeft Moote (2002) deze categorisatie van Rogers samengevat in twee categorieën: de early market and the mainstream market. Volgens Rogers (1995) en Moore (2002) komen de verschillen in adoptiesnelheid van de verschillende adoptiecategorieèn voort uit de verschillen in houding tegenover innovatie en verandering.

Met behulp van de variabele 'adoptiesnelheid' zijn de individuele woningcorporaties ingedeeld in de verschillende adoptiecategorieën. Zie hiervoor onderstaande tabel:

Tabel: Adoptic snelheid en adoptiecategorieën

\begin{tabular}{|c|c|c|c|c|}
\hline $\begin{array}{l}\text { Adoptle- } \\
\text { snelheld }\end{array}$ & \multicolumn{2}{|c|}{$\begin{array}{l}\text { Adoptlecategolleen volgens } \\
\text { Rogers }(n=205)\end{array}$} & \multicolumn{2}{|c|}{$\begin{array}{l}\text { Adoptlecategorieén volgens } \\
\text { Moore }(n=205) \text {. }\end{array}$} \\
\hline Score 4.5 & $\begin{array}{l}\text { adoptiesnelheid hoog: innovator } \\
\text { of early adopter }\end{array}$ & $\begin{array}{l}22.9 \% \\
n=47\end{array}$ & Early market & $\begin{array}{l}22.9 \% \\
n=47\end{array}$ \\
\hline Score 3 & $\begin{array}{l}\text { adoptiesnelheid lhoger dan } \\
\text { gemiddeld: early majority }\end{array}$ & $\begin{array}{l}28.3 \% \\
n=58\end{array}$ & \multirow[t]{3}{*}{ Mainstream market } & \multirow[t]{3}{*}{$\begin{array}{l}77.1 \% \\
n=158\end{array}$} \\
\hline Score 2 & $\begin{array}{l}\text { adoptiesnelheid gemiddeld: late } \\
\text { majority }\end{array}$ & $\begin{array}{l}33.7 \% \\
n=69\end{array}$ & & \\
\hline Scone 0.1 & adoptiesnelheid laag: laggard & $\begin{array}{l}15.1 \% \\
n=31\end{array}$ & & \\
\hline
\end{tabular}

De early market actoren, de visionairen, worden gemotiveerd door toekomstige kansen, en zijn op zoek natrevolutionaire oplossingen. De early market actoren zijn tegendraads en refereren vooral an zichzelf. Ze nemen risico's en kijken naar mogelijkheden. Hun 
beslishorizon ligt verder weg, ze zijn op zoek nat de beste technologid, het besto innovarieve product.

De mainstream market actoren, de pragmatici, zijn gemotiveert door de huidige problemen en zoeken naar evolutionaire vooidelen. Ze kijken uit naar de beste applicatie, aangeboden door een marktleider. Ze zijn conformistisch, refereren aan collega's en wolgen de groep. Ze mijden risico's en ze beslissen op de korte termijn.

Met behulp van veertien items uit de vragenlijst is de variabele "visionariteit' geconstrueerd. Hiermee is mate van wisionariteit bepaald wan de arly market en de mainstream market. Er kan geconcludeerd worden dat de early market van woningcorporaties significant visionairder is dan de mainstrem. Verder leverde een analyse van de verschillen in determinanten tussen de early market en de mainstream de volgende conclusies op: beleidskwesties zijn belangrijk voor de early market van woningcorporaties: zij hebben vaker een milieubeleidsplan watrin energiebesparing en duurzame energie zijn opgenomen. De early market actoren erwaren de invloed van de koepelorganisatie en de overheid als niet zo belangrijk.

De mainstream heeft weinig of nauwelijks beleid en heeft meer voorkeur voor samenwerking in de sector dan de early market. De mainstream heeft niet zoveel belangstelling voor duurzame energie en hun besluitworming wordt duidelijk beinvloed door de koepelorganisatie en ze zijn gevoeliger woor overheidsinvloed.

\section{Early market en mainstream instrumenten}

In hoofdstuk 4 wordt antwoord gegeven op de raag welke beleidsinstrumenten het meest effectief deze twee segmenten in de doelgroep woningcorporaties beinvloeden. Datrtoe zijn eerst de verschillen tussen de twee segmenten bekeken vanuit het oogpunt van gedragswerandering en is het beslutwormingsproces van beide segmenten geanalyseerd. Vervolgens is geanalyseerd op welke wijze de bestaande beleidsinstrumenten hier invloed op uitoefenen. Dit leverde een overzicht op van welke beleidsinstrumenten het best passen bij het early market segment en het mainstream segment.

Early market instrumenten. De early matket wordt het meest beinvloed door kennisoverdracht over innovatieve technologie en producten en door stimuletende communicatie: demonstraties, bijvootbeeld, dagen deze actoren uit voor de rol van demonstreerder. Overigens zijn er niet veel instrumenten nodig om de early market in beweging te brengen: ze zijn al actief vanuit zichzelf.

Mainstream instrumenten. Instrumenten die goed bij de mainstream passen zijn: 'specifieke vergunningen'. Deze veroorzaken namelijk een probleem dat de actor moet 
oplossen Het instrument "convenanten" werkt doot het groepskarakter en door het feit dat er weloverwogen voor gekozen moet worden. Subsidies kumnen de kosten-baten afweging bij twainsteam actoren beinwloeden, waabij subsidies volgens het principe 'boter bij de vis' het best werken.

Richting de mainstrean wan woningconporaties moet vooral gecommuniceerd worden over de vootdelen van energiebesparing in termen van kwaliteitsverbetering en comfortverhoging, gevoegd bij kostenverlaging en energiebesparing. Energiebesparende maatregelen moeten zoveel mogelijk gepresenteerd worden als cen oplossing voor een bestand probleem, bijvoorbeeld als kwaliteitsverbetering van de woning voorraad.

\section{Innovaties versneld in de mainstream brengen}

In hoofdstuk 5 wordt geanalyseerd en besproken hoe het komt dat veel innovaties op het gebied van energiebesparing alleen de early market bereken. Actoren wit het mainstream segment hebben door hun pragmatisme een veel voorzichtiger houding tegenover verandering en innovatie dan actoren wit het early market segment, die door hun visionaire instelling positief staan tegenover innovatie en verandering. Tussen deze twee segmenten ligt daarom een kloof die voot veel innovaties moeilijk te overbruggen is. Om de diffusie van energie gerelateerde innovaties te intensiveren, zal deze kloof tussen de early market en mainstream market overgestoken moeten worden.

\section{Kloofoversteek}

Volgens Moore (2002) bestaat de eerste stap van deze kloofoversteek uit het veroveren van een nichesegment in de mainstream. Vanuit deze niche wordt de rest van de mainstream benaderd. Om dit nichesegment in de mainstream te veroveren is het absoluut noodzakelijk dat het innowatieve product wordt aangepast of compleet gemaakt, zodat het product regemoet komt aan de pragmatische behoeften van de mainstream masket.

Om deze kloof zo goed mogelijk over te steken hebben we de volgende drie vragen onderzocht: (1) hoe kunnen leden wan dit nichesegment worden gë̈dentificeerd, (2) wat zijn de kenmerken van dit nichesegment, en (3) wat voor benadering zou gebruikt moeten worden om deze niche te bereiken? Deze vragen zijn beantwoord met behulp van een secundaire analyse van de data uit de survey onder woningcorporaties. De leden van het nichesegment behoren tot de early majority wan de mainstream. En marketing activiteiten zouden zich moeten richten op de meest pragmatische onder hen.

Moore's marketing methode is aangepast naar het terrein van beleidsontwikkeling en dit heeft geresulteerd in een protocol, wat het te volgen proces van deze kloofoversteek beschrijte. 
In hoofdstuk 6 is tot de conclusie gekomen dat de in deze dissertatie verkende verandering-georiënteerde methode, gebaseerd op een analyse van gedrag en determinanten, op twee manieren cen bijdrage levert aan de beleidswetenschap.

In de eerste plaats is de analyse van gedrag toegevoegd aan de ontwikkeling van belleid. Dit verschaft een rationele onderbouwing voor effectief en efficiènt beleidsinstrumentarium ter beïnloeding van het gedrag van doelgroepen. In de tweede plaats heeft de segmentatieanalyse van de doelgroep opgeleverd dat beleidsinstrumenten de segmenten verschillend beïnvloeden. Bij de keuze van het beleidsinstrumentarium zou hier rekening mee gehouden moeten worden: ieder segment zijn type instrument.

Verder wordt bij toekomstige toepassing van deze verandering-georiënteerde methode aanbevolen on rekening te houden met de invloed van netwerken rond doelgroepen op de individuele actoren. Ze moet toegepast worden vanuit een netwerk perspectief, waarbij alle relevante doelgroepen in het netwerk met surveys in kaart gebracht moeten worden. Verder draagt onze verandering-georiënteerde methode op twee manieren bij aan de ontwikkeling van beleid. Allereerst schept het de voorwaarde om de VBTB Methode toe te passen bij doelgroepen. Op de tweede plaats schept het de voorwaarde om - via de kloofoversteek - de transitie anpak van NMP-4 operationeel te maken door innovaties daadwerkelijk in de mainstream te brengen. 
Veel mensen hebben bijgedragen aan de tot stand koming van dit proefschrift. Ik wil hen allen hiervoor bedanken. Ik wil enkelen in het bijzonder bedanken.

Op de eerste plaats wil ik mijn copromotor Ruud Jonkers bedanken. Ruud is feitelijk de aanstichter van mijn promotie geweest. Nadat ik een samenvatuing van Rogers" Diffusion of Innovations had gemaakt had gemaakt en Green en Kreuter via een kleine brochure toegankelijk had gemaakt voor SenterNovem, daagde Ruud the uit met de vraag: schrijf nu eens zelf eens cen boekje? En by the way mak je studie nu eens eindelijk af, doctorandus: hij die moet promoveren.

Tijdens mijn promotie heb ik veel van Ruud geleerd. Ik heb zeer veel waardering voor je kritische feedback, Ruud, en de manier waarop je me hebt gemotiveerd bij het schrijven van de artikelen en het proefschrift. Ik denk met veel genoegen aan de hele periode terug.

Verder wil ik mijn promotor Gerjo Kok bedanken voor het vertrouwen dat hij in me stelde om er wat van te maken, ik had dat vertrouwen af en toe wel nodig om door te gaan, en door de nodige zure appels heen te bijten.

Het mooie Engels is te clanken aan Ed Hull, waarvoor ik hem hier wil bedanken.

En ik wil Esther Kool bedanken voor de mooie omslag.

Verder wil ik Diana Uitdenbogerd bedanken, die concepten van hoofdstukken heeft gelezen en becommentarieerd, en me wanneer nodig weer een zetje gaf om de conclusies een stap verder te trekken. Diana, ook bedankt voor je bijdrage in de proefpromotie.

In vele inspiretende gesprekken met Marleen Kwak zijn de actieve ingrediënten van de instrumenten, de zogenaamde grijze blokjes bepaald. Dank voor je geduld en je positieve feedback.

Als instrument- en gedragexperts wil ik: Kris Lulofs van het CSTM van "T"wente Universiteit en Linda Steg van de Rijksuniversiteit Groningen bedanken voor hun advies en tijd.

Verder wil ik mijn directe collega's bedanken, waar voor ik zeker in de laatste wat stressvolle periode niet de gemakkelijkste was: Rence Bruel, William Visser en Charlie Kock, jullie hebben mede aan de wieg gestaan van deze promotie, en me de ruimte en steun gegeven om mijn ideeën verder te ontwikkelen. 
Verder wil ik van mijn collega's speciaal ook Rob Kool bedanken die me op het moeilijk grenswlak van promotie (eigen tijd) en werk (baas-tijd) de goed keuzes heeft doen maken. Speciaal wil ik mijn collega's Frank Witte, Joost Koch, Geert Thijssen, Renee Bruel, William Visser, Albert Kerssies en Rob Kool bedanken die me in een proefpromotie op een leerzame manier het intellectuele vuur aan de schenen hebben gelegd, dank voor jullie grondige voorbereiding en kritische bevraging.

Om in de laatste fase de promorietekst netjes te kopiëren en in te binden wil ik hier mijn collega's Edwin Kamphuis en Hein Hendriks bedanken voor hun hulp daarbij.

Familie heeft er ook altijd mee te maken als er gepromoveerd wordt.

Op de eerste plaats waren Gea Verhagen en Rhea Pots Verhagen daar vrijwel dagelijks getuige van. Een promovendus vraagt nogal wat van zijn directe omgeving, en ik dus ook. Gea en Rhea bedankt voor jullie geduld, jullie goede zorgen en begrip. In de aanloop naar de promotie hebben mijn broer Dick Egmond en ik vele inspirerende wandelingen gelopen en gesprekken gevoerd, Dick bedankt.

Verder wil ik alle vertegenwoordigers van woningcorporaties bedanken voor hun tijd en inzet bij de interviews en workshops.

En last but not least wil ik VROM/DGW bedanken, omdat zij geloof hadden in de doelgroep aanpak, waardoor ik mijn promotie heb kunnen vormgeven. 
Cees Egmond was born on March 11, 1950 in Eindhoven. In 1968 he received his Gymnasium B certificate at the Augustinianum Gymnasium in Eindhoven.

In 1968 he began to study business management at the University of Eindhoven. He completed his masters in 1975. In 1985, after a ten year career as a high school teacher in mathematics, he started a business career in the field of energy conservation and environmental policy at SenterNovem, the Dutch agency for innovation and sustainable development. He managed several projects in the field of the promotion of energy conservation in schools and local authorities, and built and managed a network of tive regional offices promoting energy conservation in schools and other local organizations. He became program leader of the behavioural program.

In 2001, under commission of the Ministry of Housing, Spatial Planning, and the Environment he dexeloped the "target group approach" for a large program implementing energy conservation in the built environment. He then started on his $\mathrm{PhD}$ topic: the behaviour of target groups and how to influence this. He still works at SenterNovem. 